Portland State University

PDXScholar

7-30-1976

\title{
International Variation in Metropolitanism: National Integration into an International System of Countries as an Important Consideration
}

Michael Lee Lindsay

Portland State University

Follow this and additional works at: https://pdxscholar.library.pdx.edu/open_access_etds

Part of the Sociology Commons

Let us know how access to this document benefits you.

\section{Recommended Citation}

Lindsay, Michael Lee, "International Variation in Metropolitanism: National Integration into an International System of Countries as an Important Consideration" (1976). Dissertations and Theses. Paper 2559. https://doi.org/10.15760/etd.2556

This Thesis is brought to you for free and open access. It has been accepted for inclusion in Dissertations and Theses by an authorized administrator of PDXScholar. Please contact us if we can make this document more accessible: pdxscholar@pdx.edu. 
AN ABSTRACT OF THE THESIS OF Michael Lee Lindsey for the Master of Science in Sociology presented Ju1y 30, 1976.

Title: International Variation in Metropolitanism: National Integration into an International System of Countries as an Important Consideration.

APPROVED BY MEMBERS OF THE THESIS COMMITTEE:

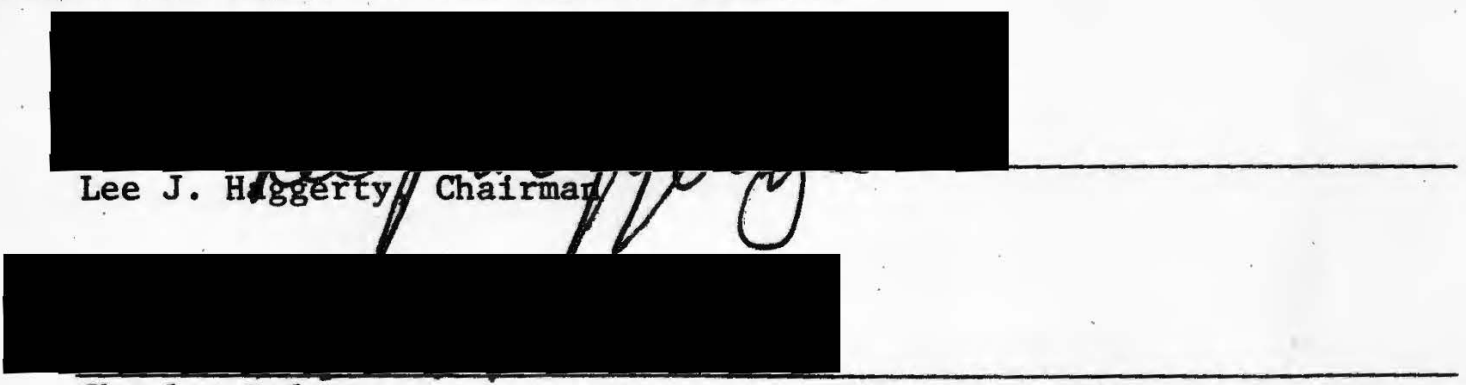

Charles Bolton
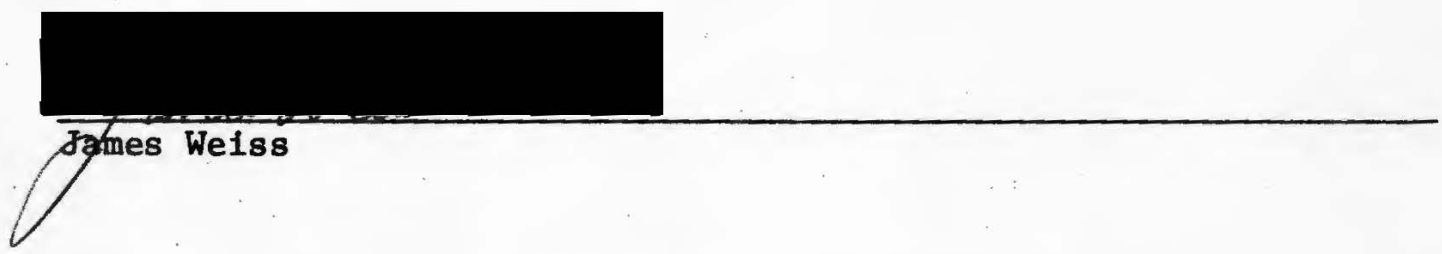

The research reported here is directed toward the determination of whether or not the proportion of a country's population living in cities of 100,000 or more is significantly affected by that country's involvement in trade relations with other countries. The proportion of a country's population living in cities of 100,000 or more was termed its level of metropolitanism. It is proposed that international variation in metropolitanism is a function of, among other things, the country's position relative to other countries in a world system of intersocietal functional 1inkages. It is argued that one of the best indicators of the 
functional linkages between countries is the volume of economic exchange made between the various nations.

The ecological approach to the study of urbanization is reviewed. The ecological approach, along with other theories of the emergence and growth of cities, postulates that urbanization in any society may be explained by the structural characteristics of the society itself. The four characteristics of any soclety suggested by the ecological approach--population, organization, technology, and environment--are discussed in terms of their relationship with and influence on large citles. These four characteristics of societies are termed "Internal factors".

While these "internal factors" are certainly of critical importance to the existence of large cities in any country, it is argued that the pressures of population growth make it necessary for the cities in the various countries to extend their boundaries and to "link-up" with other cities in other countries in order to support their populations. A primary way in which this is accomplished is seen to be the trading relations with other countries in which each country becomes involved. The cities in any country are seen to play a critical role in these trading relations. It is proposed that these trading relations will influence the extent of metropolitanism in any country.

It was only possible to obtain relevant data for the empirical test of this proposition for 70 of the world's countries. These 70 countries were divided Into two sub-groups according to their per capita gross national products. Such a division made it possible to discuss international variation in metropolitanism in a group of underdeveloped countries and in a group of developed countries. The data utilized in 
this study were obtained from the various publications of the United Nations and from the Rand-McNalley World Atlas. All data are for the year 1971, since this was the most recent year for which the broadest range of data was available.

Multiple regression analysis was the primary statistical technique used in this study. It was found that in the underdeveloped, developed, and combined group of countries more variation in metropolitanism could be explained when international trade was included in the regression equations. It was also found that in the developed countries the largest Independent contribution to the total variance in metropolitanism was made by international trade; however, in the underdeveloped countries the largest independent contribution to total variance in metropolitanism was made by the population indicators, whereas in the combined group of 70 countries the largest independent contribution was made by the organization indicators. Finally, the independent effects of the indicators of the components of the ecological complex on metropolitanism were inspected. These effects were first observed when the indicators of international trade were not included in the regression equations, and then when international trade was statistically controlled. It was found that the Independent effects of the Indicators of the components of the ecological complex always changed when international trade was statistically controlled. In many cases the change was substantial. The evidence indicates, therefore, that international trade is an important factor which must be considered in order to understand metropolitanism on a world-wide scale. 
INTERNATIONAL VARIATION IN METROPOLITANISM: NATIONAL INTEGRATION INTO AN INTERNATIONAL SYSTEM OF COUNTRIES

AS AN IMPORTANT CONSIDERATION

by

MICHAEL LEE LINDSEY

A thesis submitted in partial fulfillment of the requirements for the degree of

\author{
MASTER OF SCIENCE \\ in \\ SOCIOLOGY
}


TO THE OFFICE OF GRADUATE STUDIES AND RESEARCH:

The members of the Committee approve the thesis of

Michael Lee Lindsey presented July 30, 1976.

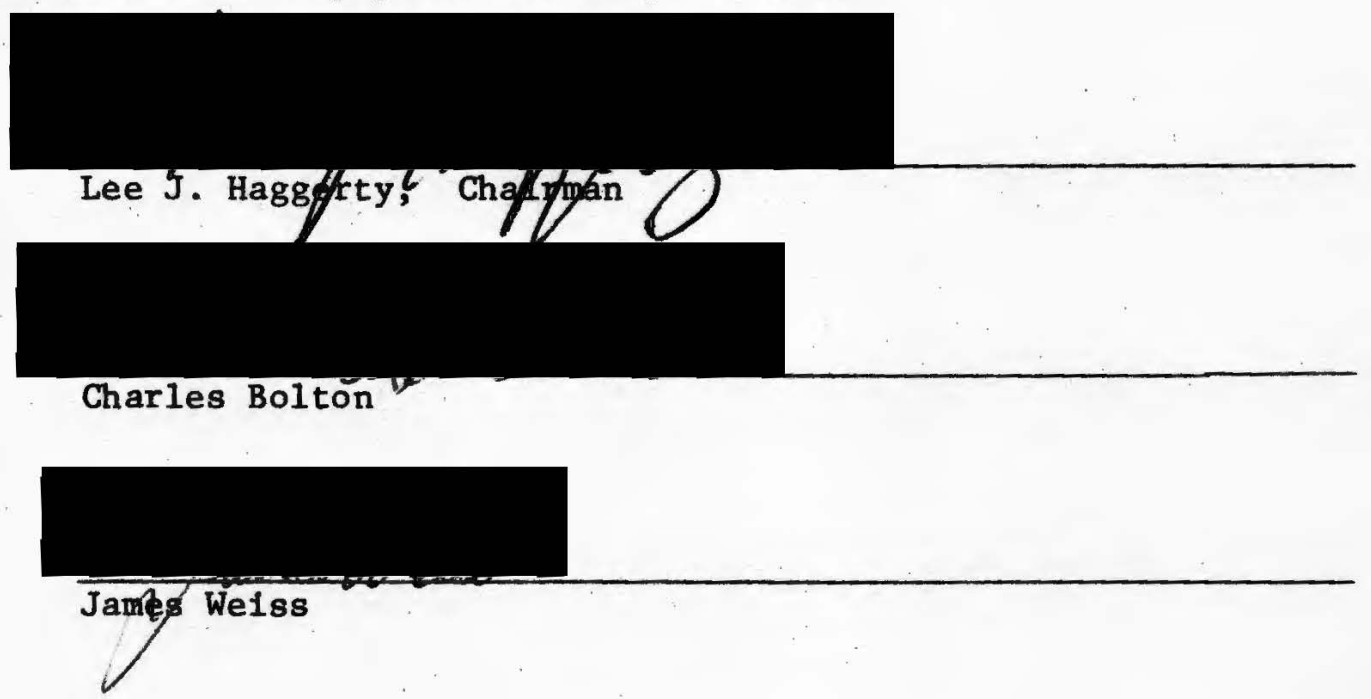

APPROVED:

Robert Shotola, Head, Department of Soclology

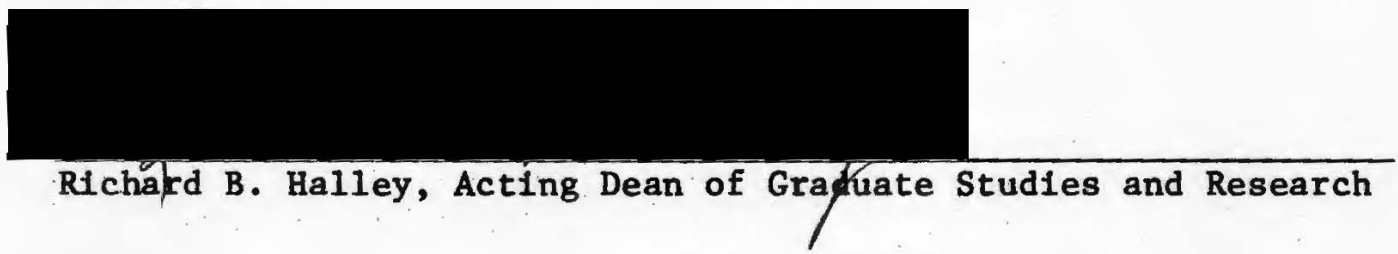




\section{ACKNOWLEDGEMENTS}

A thesis, since it is a scholarly work, is a learning experience. The author must assimilate, synthesize, and coherently state a great number of 1deas in such a way that the reader can learn what the author has learned. The writing of a thesis is also an ordeal: a seemingly endless number of encounters with the typewriter on a seemingly endless number of days. While the thesis is being written, then, the author 1s often in need of both intellectual and emotional support from those around him. I would like to take this opportunity to extend my gratitude to the members of my committee for contributing to the writing of this thesis in both of the above mentioned senses.

I must first thank Lee Haggerty. In the most strict 11teral sense, this thesis would not have been done without Lee. The data ut111zed in this study was gathered, by myself and others, under Lee's direction. The statistical manipulation of this data was performed at the computer center here at Portland State University. Before this thesis was begun, I was totally unfamillar with computers and the1r use. Only with Lee Haggerty's help was I able to perform this essential part of the research; with 1ncredible patience Lee withstood my numerous vis1ts to his office and taught me to learn from my mistakes and also not to make them again (through no fault of his own he was at least partially unsuccessful in this last respect). When it came time to analyze the results of this work, Lee encouraged me to "get to the heart" of the matter and to present a concise discussion of what I had found. 
Once again, his patience and understanding encouraged me to proceed and finally complete the many drafts which are synthesized in the following pages. For all of these reasons, and many more, I would like to extend my profound thanks to Lee J. Haggerty.

There can be no doubt that this thesis owes much of its final form to the insightful comments of Charles Bolton. Dr. Bolton, time and again, attempted to discourage the "mindless empiricism" which presented itself in earlier drafts of this thesis. By virtue of his constant insistence on tracing the theoretical implications of my empirical findings, Dr. Bolton provided me with the prodding I needed to more adequately conceptualize the large-scale social processes I empirically discovered. While he sometimes had to be very firm with a somewhat hesitant author, his cheerfulness and receptiveness, and above all his patience, greatly aided the completion of this project. I thank him for his efforts.

James Weiss, although he was absent during much of the writing of this thesis, deserves a great deal of thanks. His receptiveness to the type of analysis I was undertaking, and his understanding of the problems involved in the writing of a thesis made the completion of this study, within the time limits imposed, possible. All in a11, he was very easy to work with and provided me with much encouragement.

Fina11y, my wife, Margaret, deserves a great deal of thanks. It is not altogether appropriate that she should be thanked last; for it was she who had to contend with an author who inevitably brought all the ups and downs of this project home with him. While my committee members only had to contend with me during the school day, Margaret was not afforded that Iuxury. For her constant good humor, emotional support, and for just being there, I cannot thank her enough. 
TABLE OF CONTENTS

PAGE

ACKNOWLEDGEMENTS . . . . . . . . . . . . . . . . . 111

LIST OF TABLES . . . . . . . . . . . . . . . . . . . vi1

LIST OF FIGURES . . . . . . . . . . . . . . . . . . . . vi11

CHAPTER

I INTRODUCTION . . . . . . . . . . . . . . . . 1

Perspective of the study ............ 5

Outline of the Study ............. 6

II INTERNAL FACTORS AND METROPOLITANISM . . . . . . . . 9

The Ecological Complex . . . . . . . . . . . 11

$$
\begin{aligned}
& \text { Population } \\
& \text { Environment } \\
& \text { Technology } \\
& \text { Organization }
\end{aligned}
$$

III THE PROPOSED RELATIONSHIP BETWEEN CONTEXTUAL FACTORS

AND METROPOLITANISM . . . . . . . . . . . . . 49

Population and Resources . . . . . . . . . . 51

The Urban Metropolitan Revolution . . . . . . 56

Conclusion ................ 66

IV THE DATA ..................... 67

$\checkmark$ THE DELINEATION OF EMPIRICAL INDICATORS TO BE USED IN

THE ANALYSIS . . . . . . . . . . . . . 75

The Three Groups of Countries . . . . . . . . 78

70 Countries

The Underdeveloped Countries

The Developed Countries 
Categorles of Per Capita Imports Plus Exports . . . 89

VI AN EMPIRICAL TEST OF THE PROPOSED RELATIONSHIP BETWEEN

CONTEXTUAL FACTORS AND METROPOLITANISM : • • • . . . 95

Introduction . . . . . . . . . . . 95

International Varlation in Metropolitanism . . . 99

Independent Effects of Internal Indicators on Metropolitan1sm . . . . . . . . . 123

The Combined Group of 70 Countries

The Underdeveloped Countries

The Developed Countries

Independent Effects of Contextual Indicators on Metropolitanism . . . . . . . . . 159

ConcludIng Remarks . . . . . . . . . . . 163

REFERENCES CITED . . . . . . . . . . . . . . . . . 168

APPENDIX A . . . . . . . . . . . . . . . . . 172

APPENDIX B . . . . . . . . . . . . . . . . . . 173

APPENDIX C ........................ . . 174

APPENDIX D . . . . . . . . . . . . . . . . 175

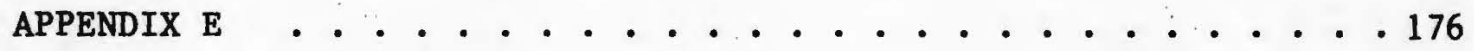

APPENDIX F . . . . . . . . . . . . . . . . 178

APPENDIX G . . . . . . . . . . . . . . . . 179

APPENDIX H . . . . . . . . . . . . . . . . . 180

APPENDIX I .......................... 181

APPENDIX J . . . . . . . . . . . . . . . . . 184

APPENDIX K . . . . . . . . . . . . . . . . . 187

APPENDIX L . . . . . . . . . . . . . . . . . 190

APPENDIX M . . . . . . . . . . . . . . . . . 193

APPENDIX N . . . . . . . . . . . . . . . . . 195 
LIST OF TABLES

TABLE

I Variables to be Utillzed In the Study and Thelr Sources - 69

II 70 Countries With Which This Study W111 Be Concerned . . 79

III Two Groups of Countries And Their Average Per Capita Gross National Products . . . . . . . . . . 81

IV Nine Regression Equations in Three Groups of Countries, The Variables Composing the Equations, and the Amount of Varlance in Metropolitanism Explained by the Variables .................. 100

V Corrected $R^{2}$ Values for Nine Regression Equations in Three Groups of Countries . . . . . . . . . . . 108

VI Independent Contributions of Four Components of the Ecological Complex, and the Contextual Variable and Categories of Contextual Variables, to Total Varlance in Metropolitanism, in Three Groups of Countries . . . 115

VII Independent Effects of Indicators of the Components of the Ecological Complex on Metropolitanism when the Indicators of the Components are Considered Alone, and when Contextual Variables are Added, in Three Groups of Countries ... . . . . . . . . . 128

VIII Independent Effects of Categories of Per Capita Imports Plus Exports, with the Components of the Ecological Complex and the Remaining Categorles Controlled, in Three Groups of Countries . . . . . . . . . . . 161 


\section{LIST OF FIGURES}

I Data from Table I in Terms of the Four Components of the Ecological Complex 


\section{INTRODUCTION}

For the first 99 percent of his time on earth man lived without cities. In the last ten thousand years, however, man has made up for his long lack of cities. The separation between town and country is thus of relatively recent origin. Yet, referring to this separation Karl Marx (1970: 352) noted that, "...the whole economic history of society is summed up in the movement of this antitheses". Although Marx wrote off a great part of human experience with this remark, when it comes to that part of history we call "civilized", his statement is not inaccurate. City life has come to describe the lot of more and more of the world's population.

One need only glance at the not too distant past to gain an idea of how quickly urbanization has progressed. According to Kingsley Davis (1968: 8), in the year 1600 the combined population of all the cities of 100,000 or more inhabitants in Europe constituted only 1.6 percent of the estimated population of all of Europe; in 1700 the percentage was 1.9 , and in 1800 it was 2.2. Davis also notes that,

In general, the later each country became industrialized, the faster was its urbanization. The change from a population with 10 percent of 1 ts members in cities of 100,000 or larger to one in which 30 percent lived in such cities took about 79 years in England and Wales, 66 in the United States, 48 in Germany, 36 in Japan, and 26 in Australia.

The growth of large cities is thus quickening. It has been noted (Davis, 1972: 9) that of the world's 3.6 billion people in 1970, 
approximately 864 million, or 23.8 percent of the world's people, lived In urban places having 100,000 or more inhabitants. In other words, by 1970 nearly one in four of the world's people lived in the 1777 cities of 100,000 or more. Davis (1972: 121) also suggests that if present trends continue, between 34 and 42 percent of the world's population will live in cities of this size.

Statements which apply to the population of the world as a whole are often decelving, however. While it is true that nearly one in four of the world's people lived in cities of 100,000 or more in 1970 , a significant amount of variation exists between the various regions of the world in terms of the extent to which their populations are urbanized. In particular, important differences exist between the so-called underdeveloped countries and the developed ones in terms of the scale of urbanization and the times at which it began. This fact has led one author (Berry, 1973: chapter 3) to argue that urbanization occurs in third world countries for very different reasons than the ones which accounted for urbanization in the countries of the developed regions. A great deal of attention will be given to Berry's claim as this study progresses. Suffice it to say here, however, that any statements about "world" urbanization must be assessed with Berry's argument in mind.

Whatever the sources of regional variation in urbanization, it is clear that a good deal of importance should be attached to the study of the Increasing proportion of the world's people living in cities of 100,000 and over. For conventence, let us call the percentage of a country's population living in cities of 100,000 and over the country's level of metropolitanism, or, simply, metropolitanism. This study will be primarily concerned with international variation in metropolitanism. 
A perfectly legitimate question is, why was the proportion of a country's population living in cities of 100,000 or more chosen as the criterion for the definition of metropolitanism?

The answer to this question is two-fold. First of all, choosing the proportion of a country's population in cities of 100,000 and over avoids the thorny problem of definition. The countries of the world vary immensely in the manner in which they define an urban area. Thus, if one focused on the urban areas of each country as each country defined them, there would be excellent grounds for asserting that one is not studying comparable units. While one country may define an urban area as any concentration of 2500 or more people, another country may choose 5000 , or even 500 , as its criterion for delineating an urban area. However, if one chooses the proportion of the population in citles of 100,000 or more as the focus of study, the problem of what is or is not an urban area is less critical; in all countries, population agglomerations of 100,000 or more are considered to be urban places. The second reason for focusing on the proportion of a country's population in cities of 100,000 or more is that it increases one's ability to make comparisons between countries. Most of the world's countries collect information regarding the populations of their large urban centers. That is, nearly all countries have a very good idea of the sizes of their largest cities. This being the case, focusing on the proportion of a country's total population residing in these cities makes it possible to obtain information on as many countries as possible; as a result, one gets a fairly good idea of the manner in which the majority of the world's countries vary with respect to this characteristic. Indeed, 
Kingsley Davis (1969: 5), In a recent study, reserved the term "city" to only those places having 100,000 or more inhabitants; anything less was termed a "town". Davis (1969: 3) notes,

....in the effort of our research office to gain world coverage, we have confined ourselves to certain types of urban data for which such coverage is feasible--that is, for which estimates could be found or made with some chance of being near the truth.

International variability in population concentration may best be studled, it is suggested, when large concentrations are the focus.

For the purposes of this study the term metropolitanism is intended to denote only that a specific proportion of a country's population is concentrated in cities with a minimum size of 100,000 . In this sense, the strict definition of metropolitanism is made on demographic grounds. It is made in the same sense as Tisdale's (1942: 311) classic definition of urbanization as a process which "...proceeds in two ways; the multiplication of points of concentration and the increase in size of individual concentrations.". Such a conception postulates simply that what I have called metropolitanism is a particular level of population concentration. It has been suggested that the simplicity of such a conception enhances its utility for exploratory research. Lampard (1965: 520), for Instance, notes that this conception "...discriminates among processes which, although associated with population concentration, may in fact have counter effects upon $1 t$; thus the structural concomitants of urbanization at any time are not to be ignored, they are simply to be distinguished from it.". This study, then, will attempt to account only for the existence and persistence of population concentrations of a particular size. 
PERSPECTIVE OF THE STUDY

Each of the countries of the world may be concelved as a functioning unit. No matter how small or large a particular country might be, It forms an integrated unit which is, in a number of ways, distinguishable from other countries. Each country may be seen to be typified by any number of characteristics or properties; for instance, all countries are characterized by population growth rates, the number and sizes of c1ties within their borders, their gross national products, and so on. These varfous characteristics tend to vary from country to country. Thus, for any characteristic one could state that the countries of the world exhibit significant varlation. How might one study the variation In any particular characteristic?

One perspective from which to study this variation might be to ask: "Is any particular characteristic of the countrles of the world more effected by the other characteristics of the country itself than it is by the characteristics of the group of countries of which it is a member?" For example, one might ask: "Are the growth rates of the countrles of the world more effected by their resource bases and the characteristics of their labor forces than by their economic and political relations with other countries?" Asking questions of this type will enable one to determine whether or not, and to what extent, the internal unft characteristics of countries are more important in explaining vartation In any particular characteristic than the contextual characteristics of a system of countries.

The purpose of this study will be to empirically determine if international variation in metropolitanism, a very important structural aspect 
of any country's population, is significantly affected by the contextual characteristics of a system of countries. It will be proposed that international variation in the manner in which population's distribute themselves over the area of their country is a function of, among other things, the country's position relative to other countries in a world system of intersocietal functional 1inkages. It is argued that one of the best indicators of the functional linkages between countries is the volume of economic exchanges made between the varlous nations. Thus, it is hypothesized that international variation in metropolitanIsm is affected by the volume of each country's economic exchanges with other countries. It follows, then, that a country with a comparatively high volume of economic exchange would also have a comparatively high level of metropolitanism, and that a country with a low volume of economic exchange would have a low level of metropolitanism (internal characteristics being equal). A good part of this study will be concerned with the examination of this proposed relationship. The findings may also be expected to shed 11ght on the importance of the internal characteristics of each country as opposed to the effects of their contextual environment on one structural characteristic of the countries of the world.

\section{OUTLINE OF THE STUDY}

The following two chapters of this study will discuss metropolitanism in theoretical terms. Chapter II will attempt to partially summarize the ecological approach to the study of urbanization. It will first discuss the ecological framework for conceptualizing the structure of socleties, and will then look at the manner in which this 
perspective is applied to the emergence, persistence, and growth of c1ties. In essence, Chapter II w111 be concerned with how the structure of the society itself influences the process of urbanization.

Chapter III, on the other hand, will forward the proposition that population concentrations in any society are interdependent with population concentrations in other societies. It will be argued that the pressures of population growth make it necessary for the cities in the varlous socleties to extend their boundaries and to "Iink-up" with other cities in other societies in order to support their populations. Chapter III, then, w111 provide the theoretical rationale for suggestIng that the "context" of any country effects the extent of its population concentration.

After this theoretical "groundwork" has been lald, attention will shift to the empirical investigation of the proposed relationship. Chapter IV will be devoted to an explanation of what sorts of data are necessary in order to test the relationship. The sources of these data and the many methodological problems associated with this sort of comparative research will be discussed.

Chapters V and VI will center on the methods used in this study and w111 present the results of the analysis. Chapter V will be concerned with the technique of factor analysis and 1ts application to the data in this study. It will be seen that factor analysis is utilized first as an exploratory technique to determine which of the many variables are most "relevant", and then to provide a criterion for more closely considering some varlables and not others in the investigation of international variation in metropolitanism. 
Utilizing the information which the factor analyses have provided Chapter VI will focus on correlation and regression analysis. The type of analysis presented in this chapter will provide an empirical test of the proposed relationship by giving us an idea of the extent to which metropolitanism in the varlous countries can be predicted by the volume of economic exchange of those countries. We will then know to what extent the theoretical notions of what is related to metropolitanism are either confirmed or disconfirmed by the empirical information obtained. 


\section{INTERNAL FACTORS AND METROPOLITANISM}

The existence of cities has long interested and puzzled social thinkers. One need only note that a truly voluminous literature has arisen concerning cities to perceive that the "how" and "why" of population concentration has been, and is, a preoccupation of economists, political scientists, sociologists, and, indeed, nearly all social scientists. Naturally, different groups of social scientists attempt to account for cities from the viewpoint of their own particular discipline; one gets a different picture of what promotes and maintains population concentration from an economist than one would get from a political scientist or sociologist. It is inevitable, then, that more than a few disagreements will arise in scientific circles as to just what those entities we call cities "really" are.

At a very general level, however, there is a certain amount of consensus concerning the origin and growth of cities. It would be fair to say that the many factors which are suggested to influence and determine the existence and growth of cities have one thing in common: they are organizational, environmental, technological, or demographic characteristics of the country in which metropolitanism is to be explained. In other words, social scientists Inevitably attempt to account for the existence and growth of population concentrations by focusing on the structural characteristics of the society itself. 
In a sense, this view may be the result of a perspective often identified with sociology--in socleties, as in nature, everything is effected by everything else. While sociological perspectives of the interdependence between groups and Individuals are certainly far more sophisticated than the above statement suggests, the view that societies are coherent wholes often leads one to focus on the complex relationships between the various parts of a society. Having adopted this viewpoint, it would only seem natural to argue that what may be expected to produce and maintain cities will be found in the other characteristics of the society 1tself. When this sort of explanation of population concentration is advanced, we might say that the "internal" characteristics of the country are emphasized.

It should be noted at the outset that these internal characteristics of countries are not spurious explanations of metropolitanism. There can be no doubt that the various organizational, environmental, technological, and demographic characteristics of each country are indeed highly related to their levels of metropolitanism; metropolitanIsm is not something which just happens. Yet, metropolitanism is a tremendously complex phenomenon. Perhaps as a result of its complexity, there have been any number of factors which have been forwarded to account for it. In order to gain some idea of the many characteristics of socleties which have been argued to account for metropolitanism, let us first look at one way of conceptualizing societies and the interrelationships between their various parts. We will then have a framework for a more detalled discussion of the various internal factors and their relationships to metropolitanism. 
THE ECOLOGICAL COMPLEX

To study society is, in the most general sense, to study the relationships between individuals and the relationships between the groups which they compose. One of the very important results of this study has been the realization that patterns of relationship can be observed to emerge from individual and group interaction. These patterns of relationship have been attributed to have a central place in the study of soclety; indeed, O.D. Duncan and L.F. Schnore (1959: 132) have argued that it is these patterns which form the focus of concern for the sociologist:

Although there are various understandings as to the scope and problems of sociology, many would grant that the study of society as a system or pattern of organization constitutes the core problem, whatever other preoccupations it may have. As a result, a rather amorphous area, usually called 'social organization', seems to provide sociology's central concern.

If this view of society is deemed legitimate, then one may inquire as to how these patterns of relationship emerge, how they are maintained, and how they are changed. An answer to these questions requires a sensitivity to the different types of relationships in which individuals engage and the functions these relationships serve for those performing them.

Human ecology provides a very conclse way of concelving the various types of relationships in which individuals engage. In a very important statement of the ecological perspective, 0.D. Duncan and L.F. Schnore (1959: 135) note, "In the most general terms the framework of human ecology embraces four main referential concepts: population, environment, technology, and organization which define what may be called the 'ecological complex'". In perhaps the classic statement of this viewpoint O.D. Duncan (1959: 681-5) elaborates: 
The unit of ecological analysis is a human population, more or less circumscribed territorlally. That at least some spatially delimited population aggregates have unit character is one of the key assumptions of human ecology, as is the premise that there are significant properties of such an aggregate which differ from the properties of its component elements...A concrete human population exists not in limbo but in an environment. Moreover, to continue to exist, it must cope with the problems posed by an environment which is indifferent to its survival but offering ( 1 varying degree) resources potentially useful for the maintenance of $11 \mathrm{fe} .$. . The concept of 'technology' in human ecology refers not merely to a complex of art and artifact whose patterns are invented, diffused, and accumulated...but to a set of techniques employed by a population to gain sustenance from its environment and to facilitate the organization of sustenance-producing activity...For the ecologist, the significant assumptions about organization are that it arises from sustenanceproducing activities, is a property of the population aggregate, is Indispensable to the maintenance of collective $11 \mathrm{fe}$, and must be adapted to the conditions confronting a population--including the character of the environment, the size and composition of the population itself, and the repertory of techniques at its command.

According to Duncan, then, all societies may be described in terms of the four components of the ecological complex. Note that when this perspective is adopted, the manner in which each population adapts to the objective conditions confronting it takes on critical importance. Since populations are territorially delimited--that 1s, they exist in a particular physical environment which is somehow restricted in its extent--they are compelled to inhabit and adapt themselves to the conditions in a finite physical environment. Indeed, Duncan (1959: 683) views the physical environment as one of the primary reasons for differences between societies:

Societles differ because, among other things, each territorially delimited aggregate confronts a special set of environmental circumstances and differs from other such aggregates in size and composition. Even more important: since most environmental and demographic situations permit alternative solutions to the problems of adaptation and since such solutions have a tendency to persist as they are embodied in organizational forms and technical apparatus, initial differences tend to produce continuing diversification.

A society, in order to continue to exist, must "make the most of" what it finds in the territorially delimited environment in which it finds 
itself. The physical environment must be viewed as a critical factor which limits the range of adaptations, both technological and organizational, which a population might make.

While the physical environment of a population makes certain sorts of activities feasible, while discouraging others, it is not the only factor which functions in this way. In fact, the characteristics and distribution of the population itself serve to influence the organizational characteristics of the society. Turning to Duncan (1959: 708) once more we find,

On the one hand, size and distribution of population are major limiting factors in the evolution of organization. Any elaborate form of organization is virtually precluded if population is small and dispersed. On the other hand, growth and concentration of population appear to be major forces behind the emergence of functional specialization, territorial and occupational, and the elaboration of the division of labor.

Thus, whether the population is large or small, concentrated or dispersed, or is someplace between these extremes, these characteristics will have important consequences for the ability of that population to engage in particular types of activity. It may be said that the characteristics of the population influence the manner in which that population may act to assure its survival.

It should be apparent that although the ecological complex provides a means for concelving of society as composed of four major parts, each of these parts is intimately related to the other three. We have seen that the environment of a population sets limits for its organization; we have also seen that the characteristics of the population itself influence the activities in which its members will engage. It must be argued, then, that although the ecological complex provides a relatively parsimonious orientation toward society, this stance should not be perceived as 
simplistic or shallow. Perhaps one of the strongest arguments for the adoption of an ecological orlentation toward soclety is the stress placed upon the reciprocity and functional integration of the various parts of soclety. Referring to this characteristic of the ecological perspective, Duncan and Schnore (1959: 136) tell us, "The notion of an 'ecosystem' may be used as a heuristic designation for the ecological complex in order to bring out this aspect of interrelatedness which some writers have identified as the most fundamental premise in ecological thinking".

Thus, although we may think of soclety as having four component parts, we must be careful to remember that they "...are functionally interrelated: a change in one leads to modifications in the others..." (Sjoberg, 1965: 165). This sort of analysis leads one to the realization that the fundamental bond which holds individuals together is the fact that they need each other to meet their common needs. Since the ecological complex describes the interaction between a population, its environment, the organization it creates, and the technology invented, it provides a means of investigating the ultimate problem any group must face: how must actions be orlented so that collective survival is achleved? Insofar as the survival of groups is dependent on the coordination of their members, ecological thinking is a means for the investigation of these functional relationships.

The ecological framework is thus a very important orientation toward the study of that which we call soclety. However, this framework may also be seen to be of considerable utility when the focus is not on the society as a whole but is on only a part or particular characteristic of the society. This is to say that the ecological viewpoint 
lends 1tself well to the Investigation of such things as the demographic characteristics of the population, the invention and diffusion of technology, or the population concentrations of the various societies. While this is certainly not a comprehensive 11st of those areas susceptible to ecological analysis it does 1llustrate some of the concerns of the human ecologist.

Very often human ecology is Identified with the study of the prevaling patterns of urbanization, the manner in which that pattern emerged, and what 1ts future shape might be. Sjoberg (1965: 165) Informs us that, "The ecological complex obviously encompasses more than fust the urban fleld, but 1ts chlef proponents have focused their attention mainly on the study of citles and urbanization". Given this emphasis, it is clear that the components of the ecological complex provide a means for the study of population concentration. For example, Lampard (1965: 527-8) uses this ecological framework to conceptualize the process of urbanization when he states, "...the 'problem' of urbanization can be restated in terms of human ecology... Restatement of the 'problem' In terms of the human ecosystem takes the following form. Further differentiation of functions within a population and its territory results In more speclalized components; in the Integration of such parts into a coherent 'system' of Interdependence, the level and form of urban organization is achleved". Lampard argues that the community structure may be concelved as a balance between a population aggregate and its environment; this balance is achieved as a result of the technology and social organization developed by the population. Technology and organization, therefore, may be concelved as attributes of the population. It is suggested that technology may be regarded as a cultural varlable, while organization 
Is a social variable. Organization is the characteristic which gives the population its "systemic" aspect, as a result of the regularities of behavior it demands. Thus, Lampard argues, organization is the crucial ecological variable since in its absence, regularities of interaction are reduced, technology is not applied, and the aggregate disintegrates. In this way, population concentration may be concelved to be an organizational characteristic of the society. Note, however, that this is only the case because of the interaction between the various components of the ecological complex; this interaction results in the particular form which organization takes.

If it is accurate to think of population concentration as an organizational characteristic of a society which is influenced by the remaining three components of the ecological complex, then one might wonder exactly how each of these components effects and promotes this concentration. As has been noted, human ecology is often associated with the study of cities and how they grow and persist. The utility of this type of analysis is reflected in Lampard's (1965: 522) statement that, "By means of this human ecological framework, the task of explaining the process of urbanization over time--of identifying its determinants--becomes more amenable to solution". It will be useful, then, to review each component of the ecological complex, paying particular attention to the manner in which it has been suggested to influence the process of population concentration in society.

\section{Population}

An obvious requirement for the existence of cities are groups of individuals. A city is, after all, a comparatively dense agglomeration 
of people in a particular location. As such, the number of people must be comparatively large for these agglomerations to exist. This necessity is elaborated by Hauser (1965: 1) when he states:

Population size is necessarily a factor in urban development because to permit any agglomeration of human beings there must be some minimum number to sustain group life; and to achieve large urban agglomerations relatively large total populations are required.

We have seen that cities are structures of organized activity which require the integration of the various groups composing them. The interdependence between these groups makes it necessary that each group have sufficient numbers to perform its tasks. Only if this is, in fact, the case may the activities which we identify with cities be performed.

Perhaps one of the most significant factors in the growth of cities is often thought to be the rate of natural increase of the population. Population growth caused by the excess of births over deaths has been suggested to be one of the primary forces encouraging the growth of population concentrations (Tisdale, 1942: 315). Indeed, Davis (1972: 59), writing specifically in reference to the period between 1950 and 1970 , has argued that, "... It appears that the excess of births over deaths was unusually large in towns and cities and that this was the principal factor in the acceleration in urban population growth". The importance of natural increase for the growth of cities can be observed when it is noted that Davis was speaking of the world as a whole in the above statement. At a later stage of his analysis, Davis (1972: 162) tells us that if cities far larger than New York and Tokyo are to be avoided in the future, it is absolutely necessary to lower the overall rate of population growth in the world. 
It is generally recognized that the excess of births over deaths affects urban growth in two ways (Davis, 1972: 308): "1) If the excess occurs in urban areas, it causes the existing urban population to more than replace itself; 2) If it occurs in rural areas, it causes places that were formerly rural in character to become urban by reclassification". The first way in which natural increase may cause the growth of population concentrations requires no clarification. The problem of reclassification, however, can be seen to proceed in two ways. First, a rural village or town may increase its population beyond a minimum figure stipulated in the definition of a town. In this way, the town becomes a city by redefinition. Secondly, a town or village may become an urban place by belng annexed to or included in an expanding urban agglomeration. For those places in close proximity to cities, this is a fairly common means by which they may make the transition from village or town to c1ty. Note that this occurrence does not presuppose that the village or town experience population growth itself; regardless of the rate of natural increase in these places, they become parts of cities solely by virtue of their relationship to an existing population agglomeration.

Regardless of the particular manner in which natural increase Influences citles, it can be observed that the excess of births over deaths has been, and 1s, a very important factor in the existence of cities. A study of Egyptian cities (Abu-Lughod, 1973: 72) has concluded that, "There are now excellent reasons to suspect that since the 1940 's natural increase has accounted for at least half the growth recorded for Egypt's major cities and for possibly as much as three- 
fifths in the $1950^{\prime} \mathrm{s}$ ". Although this is merely one example of the influence of natural increase on cities, it is clear that natural increase affects the process of urbanization on a world-wide scale. In terms of the level of metropolitanism of the various countries of the world, natural increase has been argued to be of major significance. Davis (1972: 310), for instance, explains that, "... In $197041.1 \%$ of the growth of cities of 100,000 or more in the developed countries was attributable to natural increase; in the less developed countries, $38.4 \%$ of the growth of cities of this size was attributable to natural increase".

There is yet another way in which the natural increase of a population promotes population concentration. A growing population is dependent on any number of natural resources. In order to sustain themselves, the members of this population must have at least a minimal resource base which is somehow exploitable. The higher the standard of living to which this population has become accustomed, the more extensive and diversified its resource base must be. Thus, the ratio of the population to its resources serves as an indicator of not only the standard of living the population can achieve, but also of the types of activities in which 1 ts members must engage. Further, this ratio has implications for the extent and level of population concentration in any society.

There can be no doubt that vast differences exist between the developed and underdeveloped regions of the world in the ratios of their populations to their resources. Hauser (1965: 37), for example, views this difference as having important consequences for the level of population concentration in the underdeveloped world. He argues, 
In most of the developing areas today the ratio of population to resources is much higher than that which prevailed at the beginning of the industrialization and urbanization of the West...Much of the urban growth in the developing areas today is in fact the result of the push of population from the already overpopulated rural countryside.

What Hauser seems to be arguing is that individuals in the underdeveloped countries are "pushed" from the countryside to the city, rather than "pulled" by the city from the countryside. That is, since the rural areas are over populated, there is little for the people who live there to do; as a result these individuals find it necessary to migrate, often unwlllingly, to the large urban areas. Unfortunately, these urban areas have a surplus of population and, as a result, none but the most menial jobs to offer the new migrant.

The above described situation is frequently attributed to be characteristic of the underdeveloped countries today. These countries are often termed "over-urbanized". Because their populations are growing in such a way that the ratio between these populations and the resources they may exploit is increasingly unfavorable, their cities are experiencing very high levels of growth. Although their cities are growing, there is little accompanying increase in industry and technological sophistication. When these areas are compared to the developed countries, It is seen that the latter enjoyed higher levels of industrialization at similar levels of urbanization. The differences between the developed and underdeveloped countries in this respect are well stated by Germani (1973: 37):

The velocity and magnitude of some of the processes causing urban growth are much greater in countries developing today than in those which industrialized earlier. For example, never in a European country did population growth reach the level of three percent annually 
which nowadays characterizes certain regions. With a growth which frequently did not surpass one-third of current rates, Europe was forced to send more than $60 \mathrm{million}$ people overseas. To a considerable degree the present rural exodus to the cities is the substitute, in developing countries, for the great European migration of the previous century... On the other hand, in many developing countries-particularly Latin America--urban natural demographic increase caused by high fertility is a component of urban total growth sometimes more important than internal migration.

When this sort of comparison is made between the developed and underdeveloped countries, it must be understood that groups of countries having dramatically different historfcal backgrounds are being evaluated. By no means is this sort of comparison encouraged, or taken as valld, by everyone. For example, N.V. Sovani (1964: 325) remarks of this sort of comparison that it is "...based on historical experience which elevates the course of urbanization and industrialization in some developed countrles, namely, the Unfted States, France, Germany, and Canada, into a norm...". Although Sovani is critical of the concept of over-urbanization, and the type of normative suppositions it makes, the point to be stressed here is that the overall high levels of natural increase in the underdeveloped countries may very well encourage c1ty growth. In addition, we have seen that regardless of whether the country is considered developed or not, the nature of Its population and the growth rates characteristic of it may very well influence the level and extent of population concentration.

\section{Environment}

All Iffe takes place in physical space. Because this fact is a "given" and something we must accept as such, the relationship between humans and thefr environments has been a subject which has always been 
of the greatest interest to man. Hawley (1950: 80) states,

The significance of place for both the identification and the study of population has long been apparent to social scientists. This has resulted in strenuous efforts to arrive at a most appropriate characterization of the human habitat. The attempt, in other words, has been to define the habituation area so as to contain all that is relevant for an understanding of collective $11 \mathrm{fe}$.

Needless to say, the "habituation area" has most often been assumed to be that area coinciding with the political boundaries of the country. Thus, the activities and characteristics of a population have most often been identified with the immediate physical environment in which that population finds itself.

It has also been recognized that the physical environment of a population is important as a factor which influences the site at which a city is located. It is no surprise, then, that the earliest cities were located in river valleys and alluvial plains; these environments provided the best conditions for the development of agriculture and thus permitted a surplus of produce to exist. As Hauser (1965: 2) explains,"...the environment must be amenable to control in the sense that it meets at least the minimal requirements for aggregative living". The earliest cities grew up in these areas, then, as a result of the fact that they provided the optimum conditions for the exertion of human control over the physical environment.

The relationship between the physical environment and the extent of population concentration can be seen as relevant once population concentrations have been established. In other words, the environment is an important influence on cities as they persist over time. Its importance may be seen in the fact that the members of any population concentration are not, in the vast majority of cases, in a position to 
produce the food and other goods which are needed on a day to day basis. The city-dweller is critically dependent on those members of the population who engage in agricultural, and related, activities. Another way of stating this same fact is that all citles are dependent on their hinterlands.

This relationship between the physical environment and the city Is conceptualized by Gibbs and Martin (1958: 309) in the following way. They argue that "...a high degree of urbanization depends on widely scattered materials and represents the type of spatial organization necessary for acquiring them". Any population, they suggest, depends on various "objects of consumption" for 1ts existence. These objects of consumption consist of anything the people can consume which is necessary for their survival. Since these objects of consumption are produced outside the borders of the city, they must be transported to the city in any way possible. It is argued that the distance that these objects of consumption must be transported has important implications for the level of population concentration in the particular soclety. The distance between the point of production and the point of consumption they call the degree of "dispersion". It is suggested that the greater the degree of dispersion, the greater the level of urbanization. In other words, Gibbs and Martin seem to be postulating that the degree of urbanization 18 contingent upon the avallability and distribution of resources. As a result, it should be clear that the characteristics of the physical environment--the type and quality of resources offered, and their distribution-- will greatly influence the extent of population concentration. 
Considering the world as a whole, incredible diversity exists in terms of the types of physical environments exhibited. While some regions of the world have hot and humid climates, others are typified by constant ice and snow. The populations of these diverse regions must, as a result, adapt themselves to the conditions they encounter. One way in which this sort of adaptation takes place is specialization of activity. When the physical environment lends itself to certain sorts of productive activities, and not others, the population w111 inevitably engage in those courses of action open to them. The result is a falrly clear geographic speclalization of activity. It has been suggested that cities arise and malntain themselves as a result of these sorts of limitations which are Imposed by the physical environment. As Isard (1974: 286) notes,

It makes sense for a region with excellent agricultural soll for growing wheat to trade with another area having excellent fish resources, or easily worked deposits of copper, iron ore, coal, and other mineral resources. Accordingly, trade in commodities takes place, and clusters of population oriented to different resources and allied economic activities emerge.

According to this view, population concentrations are determined, in part, by the fact that the physical environment very seldom, if ever, provides everything a population needs or desires; cities emerge, much as Gibbs and Martin suggested, as structures of activity oriented toward the acquisition of resources not immediately avallable to the population.

The city, as a form of social organization, is thus intimately dependent on its environment. This perspective can be closely identified with human ecology. For example, In a study of the relationships between clties and the areas surrounding them (Duncan, et. al.; 1960: 3), the following statement is made:

...as far as we are concerned the sallent characteristic-if not a unique one-of an ecological approach is its proclivity for 
analyzing human communities and economic systems in terms of their place in a total ecosystem, the major facets of which are populations adjusting to their environments by means of their technological equipment and patterns of social organization.

It is clear that this statement conveys the idea that an intimate interdependence exists between the varfous parts of a soclety; insofar as population concentrations are forms of social organization they may be seen to be critically influenced by the objective physical conditions confronting them.

The extent and complexity of this relationship may be seen in the fact that while the city depends on the region the region also depends on the city. That is, reclprocity between the city and its environment is manifested in the functions each performs for the other. Describing this sort of relationship, Duncan, et. al. (1960: 40) suggests, "...we concelve of region and city as being differentiated one from the other in terms of their complementarity and reciprocally related activities. The relationship is, therefore, a symbiotic one rather than one established by a simflarity or identity of the city's attributes to those of the region." This statement illustrates a very important point: while It is certainly true that the physical environment influences the extent of population concentration in any society, it is also true that the city influences the manner in which the physical environment is modified and regarded. As was suggested above, the relationship is one of reciproc1ty, not clear-cut causality.

It is important to remember that we are ultmately speaking of the manner in which the various parts of a society are integrated; in essence, we are looking at the manner in which the components of the ecological complex influence and affect one another. This being the 
case, it should be clear that these components are intimately integrated. Thus, the argument we have been advancing should be conceived in the following way: one type of social organization--population concentration-is critically influenced by the physical environment in which it is located; while this is so, there can be no doubt that this particular type of social organization has very important consequences for its surrounding physical environment. In other words, it is fully recognized that the relationship between the city and the environment goes both ways; however, the focus of attention has been placed on the city as the phenomena to be explained, and not the modifications of the physical environment. If this is recognized, the argument that the physical environment influences the level and extent of population concentration in any soclety, while certainly not describing the relationship completely, is not, on the other hand, Incorrect.

\section{Technology}

The role of technology in promoting population concentration has long been recognized to be of extreme importance. At a conceptual level, technology may denote any number of phenomena; in other words, technology often refers to techniques for getting things done which are many and diverse. Even though technology may refer to a great variety of particular things, it has often been suggested as a prime factor in the origin and development of cities. Sjoberg (1965: 214) provides a conventional view of the importance of technology to the process of urbanization:

Ours takes technology as the key variable for explaining the nature of the industrial city. As we define technology, it involves the tools, the sources of energy, and the know-how connected with the use of both tools and energy that a social system employs. Industrialization is that kind of technology that relies on inanimate energy sources, highly complex tools, and the speclalized 
know-how required to tap these power sources and utilize these advanced tools.

Sjoberg is here, of course, referring to a particular type of city which originated at a certain time and under certain conditions. He is basically concerned with cities as they arose in the nineteenth century and have persisted up to the present. Yet, there can be no doubt that technology has consistently been seen to have had significant implications for the origin and development of all cities. Recently, however, some social scientists have argued that the relationship between technology and the extent and scope of population concentration is not the same in the underdeveloped countries as it was in the developed ones. Let us first review the conventional arguments concerning the relation between technology and population concentration; we may then examine the emerging objections to this perspective.

In order to grasp the central importance attributed to technology In the development of cities, it should be noted that the type of technology which emerges is partially determined by the environment and resources avallable. Again we find that it is nearly impossible to discuss one component of the ecological complex without considering its relationship to at least one of the other components. Th1s indicates, I suggest, not only that societies are extremely complex entities but also that the cities contained within them share this complexity. Even so, technology is often given a paramount place in the existence of cities. Indeed, Lampard (1965: 521) argues,

What a population does in and with its environment depends in large part on the material means at 1 ts disposal and the form of social organization it adopts, that is, upon adaptation. Hence, the actual number and sizes of population concentrations at any time are largely determined by the technological capacity of the population. The existence of natural resources is a further 
condition, but the utilization or 'avallability' of such resources is again a function of the technological and organizational capacities of the population...Technology is the sine qua non of urbanization, as of every other form of community organization...

Note, first of all, that even though it is realized that any population is dependent on the resources it can find, technology is asserted to be one way of modifying this environmental "given" so that a surplus may be used to support concentrated populations; it should also be noted that the technology created by any population will inevitably make necessary modifications in the manner in which the population may organize its activities. Thus, the technology necessary for the creation and maintenance of cities will also influence the particular types of activity appropriate to the population. If technology makes possible the concentration of population, it also makes necessary the reorganization of activities (from traditionally rural ones to those necessary for dealIng with the new technology and the city it creates). Changes in technology will go hand in hand with changes in organization, with the creation and maintenance of cities resulting from the interaction.

The Intimacy of the connection between technology and organization for the development and proliferation of cities may be 1llustrated by the following statement (Sjoberg, 1968: 32): "The course of urban evolution can be correctly interpreted only in relation to the parallel evolution of technology and social organization...these are not just prerequisites to urban life but the basis for its development". This same author, as we have seen, has argued in another place that technology is the sine qua non of urbanization. One can only conclude that although a very complex reciprocal relationship exists between the technology a particular population possesses and the manner in which their activities 
are organized, the technology with which any population approaches its environment is seen to be the critical factor influencing the level of population concentration.

In one of the most frequently quoted essays ever written about the process of urbanization, Hope Tisdale (1942: 315) suggests a perspective from which the development and growth of cities may be inspected:

Two conditions appear to be necessary for urbanization. One is people and the other is technology. Population 1ncrease and surplus feed the process; technology gives it form and focus... The whole thing is a spiral arrangement whereby technology produces population surplus and encourages population increase, population surplus and increase encourage further technology, and the upshot is urbanization... Urbanization is so closely bound up with technology that we can say without qualification that technology is the sine qua non of urbanization.

Here Tisdale reconglzes the importance of the relationship between technology and population growth for the development of cities. Unlike Sjoberg and Lampard, who stressed the relationship between organization and technology, Tisdale views urbanization as possible only when a population surplus is created by an advancing technology. However one might choose to resolve this dispute, I suggest that it is instructive to observe that although technology is frequently felt to be the most critical factor for the existence of cities, it is nearly always discussed in the context of its relationship with the other components of the ecological complex.

It was commented earlier that not all social scientists agree that technology is a necessary condition for the development of cities. These individuals point to the nations of the underdeveloped world as examples of how citles exist in the absence of comparatively sophisticated technology. In our discussion of the characteristics of the 
population as factors which influence urbanization, 1t was noted that relatively high levels of urbanization are achieved in many parts of the world without the levels of Industrialization which accompanied similar levels of population concentration in the developed areas. It was further noted that this situation was of ten referred to as "overurbanization". Insofar as the level of industrialization in a country Is a valid Indication of the level of technology it possesses, these analyses pointing to "over-urbanization" seem to point to the view that in countries of this type, the level of urbanization has surpassed the level of technology.

In a recent book primarily concerned with the characteristics of those countries we would call underdeveloped, P1zzorno (1973: 128) asserts that,

The general characteristics of urbanization in today's underdeveloped areas is the intensity of its pace, faster than that of any other process of urbanization in history. In fact, it is referred to as 'over-urbanization'. This judgment is based on the following observations. a) The level of urbanization in underdeveloped countries is higher than it was in Western countries at an equal level of industrialization. b) The increase in urbanization during recent years has been faster than in economically more advanced countries, although the opposite has occurred with respect to increase in per capita income. c) Immigration to the cities exceeds the creation of new sources of work.

It would seem, then that a certain degree of independence exists in these countries between the level of technology and the level of population concentration. Observations such as Pizzorno's are not 1dle conjecture; they have been empirically verified by investigators concerned with the Implications of disparity between technology and urbanization. One such Investigation is reported by Germani (1973: 312), who created an index which related urban growth and Industrial growth: 
Among other things, the index showed that whereas in the more developed countries urbanization and Industrialization are both high, in the less-developed ones urbanization is higher than the degree of Industrialization. Thus the correlation between the urbanization-industrialization index and the GNP per capita, is negative $(-.74)$. It is also interesting to observe that this inverse correlation tends to be higher at the lower levels of urbanization (and of economic development).

Germani goes on to note that when countries are separated into two groups, one group composed of those countries which have been industrialized for relatively long periods of time, and the other group composed of those countries which have only recently begun to industrialize, the former group has an urbanization-industrialization index lower by fifty percent than the second. Germani concludes that higher urbanization in relation to the level of industrialization occurs in countries which have only recently become industrialized; this indicates, it is suggested, that a certain degree of independence exists in these countries between their levels of urbanization and their levels of industrialization.

Germani also reports, however, that in the advanced stages of economic development the urbanization-industrialization index appears to be independent of the level of economic development. In other words, in those countries which industrialized relatively long ago, the relation between urbanization and technology is not closely dependent on the degree and extent to which the country is economically developed. A study done much earlier than the one Germani reports was performed by N.V. Sovani (1964: 324). Sovani centered his attention on 41 countries for which data were avallable in the period from 1946 to 1951. The correlation between urbanization and industrialization was worked out for these 41 countries. It was found that 17 of these countries could be considered 
to be highly developed, while the remaining 24 could be grouped together and considered less-developed. For the group of 17 highly developed countries, it was found that a correlation coefficient of .395 existed between urbanization and industrialization. For the remaining 24 lessdeveloped countries, the correlation coefficient was .85. Sovani states:

These results indicate that the association between the two variables is much more close in the under-developed countries than in the highly industrialized countries or, by implication, that the pace of urbanization in the underdeveloped countries is much more closely dependent on the pace of industrialization than in the highly industrialized areas. This flies in the face of the entire over-urbanization thesis, at least in the way it has been formulated up to now.

On the basis of the studies reported above there would appear to be at least some disagreement over the independence of industrialization and urbanization in the various countries of the world. Whether urbanization is more independent of technological development in the underdeveloped countries than it is in the developed ones is not altogether clear. Whatever position one takes in this controversy, it would appear to be clear that population concentrations can and do occur in the absence of high levels of technology. It certainly cannot be denied that in many third world countries huge urban agglomerations exist without the technological equipment and expertise which one finds in the developed countries. Not everyone agrees, however, that these cities offer little to their inhabitants because of the "abnormal" nature of their origins and growth. Sjoberg (1965: 223), for example, suggests, "...these fundamentally ant1-urban views are deserving of searching criticism, for city dwellers in most modernizing countries enjoy many economic, educational, and other social advantages over ruralites". This may well be so. Yet, the conventional 
wisdom tells us that technology is the sine qua non of urbanization. Let us more closely examine the various ways technology has been attributed to promote urbanization; while this is being done, however, it should be remembered that these relationships between technology and urbanization probably are valid for those countries which began their economic development in the eighteenth and ntneteenth century. As we have seen, their validity for contemporary third world countries is subject to more than a little doubt.

Probably the most widely acknowledged step necessary for the existence of population concentrations is the emergence of agricultural technology. It was in the Neolithic period that the first concentrations of population emerged and persisted over any length of time. Between 6000 and 4000 B.C. a number of inventions made possible a more intensive use of the physical environment. Most important of these inventions were the ox-drawn plow and wheeled cart, metallurgy, irrigation, and the domestication of new plants. In an analysis of the origin of urbanization, Davis (1955: 430) argues that,

When this enriched technology was utilized in certain unusual regions where climate, soil, water, and topography were most favorable...the result was a sufficiently productive economy to make possible the sine qua non of urban existence, the concentration in one place of people who do not grow their own food.

The critical contribution which agricultural technology makes to the existence of cities is the creation of a surplus of sustenance materials. It is obviously true that individuals living in cities cannot produce themselves all of the food they need in order to exist. As a result, they must rely on others to produce enough food so that there will be enough not only for the food producers themselves but for the urban population. Until the introduction of technological innovations, 
such as the ones listed above, it was generally imposstble for individuals to produce enough food to support anyone but themselves, and perhaps some members of their famtlies. Agricultural technology made it posstble for more food to be produced by fewer people. Thus, at least a segment of the population found themselves freed from the necessity of producing what they consumed; it was then possible for this segment to, in effect, be supported by the productive labor of others.

If one can imagine himself living in Neolithic times one can no doubt appreciate the importance of improvements in agricultural technology for the increased freedom from agricultural labor it could provide. We often tend to forget, however, that we are intimately dependent on agricultural technology today; in fact, we are no doubt more dependent on technological sophistication in agriculture today than was Neolfthic man. This is so because the ratio between the agriculturalist and the consumers he supports has increased tremendously. As a result, fewer agriculturalists support more and more consumers. And, In our contemporary situation, the vast majority of these consumers live in cities. Thus, just as cities could first emerge when agricultural technology increased productivity and created a surplus, cities can only persist when those inhabiting them are supported by surpluses engendered by the same means.

The role of agricultural technology in promoting population concentration is far less clear in the underdeveloped countries than it is in the developed ones. Earlier, it was noted that in the underdeveloped countries a relatively unfavorable ratio between the population and its resource base existed. We saw that the high levels of 
population growth in these countries put greater and greater strains on their environments. It should not surprise us, then, that in most underdeveloped countries an agricultural surplus is very rare. It has been observed (Fisher and Potter, 1969: 116) that, "Per capita food output in Latin America, Asia, and Africa is no greater than it was thiry years ago--progress has occurred principally in North America, Western Europe, Japan, and the Soviet Union. The areas which have lagged contain two-thirds of the world's population, and have notoriously poor diets". This indicates, I suggest, that the advances in agricultural technology which have occurred have not been able to keep pace with the increasing demands of growing populations. At the same time, as we have noted, the underdeveloped countries are characterized by high levels of urban growth. It would seem that simply on the basis of the agricultural productivity, these population concentrations could not exist; in other words, since advances in agricultural technology have apparently been unable to keep up with population growth, the urbanization these countries have experienced should not have occurred. The fact that they have occurred indicates that the population concentrations in these countries are supported by alternative means.

The history of the industrial city can be seen to be closely identified with advances in the technology of transportation. More than a few modern cities owe their present size and past growth to the fact that they are located at or near a heavily used transportation route. Whether this transportation route is a river, harbor, railroad, or highway, the fact remains that cities have always been very responsive to the needs for mobility of material goods and humans themselves. Until industrial cities emerged in Europe, it has been suggested 
(Pizzorno, 1973: 126) that the primary cause of urbanization in these areas was the need for defense. However, we are told that as industrial cities emerged "...the trend...seems to obey stimuli of a technological nature and of organization of the production system". The primary technological stimuli which are here being referred to are coal and steam power. The centripetal tendencies reflected in population concentrations are encourged, in other words, by the introduction of coal and steam power. This introduction encourages population concentration in two ways. First of al1, coal and steam power revolutionized the productive system. The transition from the cottage system to the factory system was intimately dependent on the discovery and use of nonhuman sources of energy. This new form of energy utilization necessitated the close physical proximity of the productive units; that is, the emergence of the factory system, which was only made possible by the utilization of coal and steam power, encouraged each individual factory to locate near its suppliers and consumers so that various economies of scale could be realized. Secondly, the introduction of coal and steam power certainly made it possible for each productive unit, or factory, to transport its products to markets which would have been otherwise inaccessible. This meant that labor was needed to cope with this increased demand. Since the factories were located in the growing cities, they encouraged population concentration by drawing their labor to the city.

We are told by Berry (1965: 405) that, "All specialized economic activities are influenced in their choice of location by, and many have their locational patterns prescribed by, transport costs and the nature of transport networks". The introduction of coal and steam power made 
the specialized economic activities we call factories possible. Insofar as these economic activities are specialized, they were forced to locate near their suppliers and a direct source of customers so as to minimize the costs of acquiring their raw materials and transporting their products. On the other hand, the availability and proliferation of improved transportation technology enabled the productive units to expand their markets and increase the demand for their products. U1timately, the productive unit grew and diversified in order to keep pace with this demand. It thus required increased manpower and continued use of the transportation technology and the facilities available. Both of these requirements could best be satisfied when these productive units were located in the cities.

The importance of transportation technology for the emergence of cities can certainly be seen in the United States. Our country is a comparatively large one and is typified by a certain degree of regional diversity. As such, transportation played an important role in the movement of people from one region to another, and in the movement of products and raw materials from region to region. Perhaps for these reasons, it was possible for Cook (1960: 116) to argue that, "After 1840, the railroads became the most important single factor in the formation of new cities and their growth". It must be remembered that cities are places which must be supported; they require a vast variety of consumer goods to be imported from their points of production. The emergence of cities, then, in a country like the United States was clearly dependent on the existence of transportation technology.

It would seem that the importance of transportation technology to the development of cities is not restricted to the United States. 
Rather, this relationshlp may very well be typlcal of cities in all socleties. Indeed, Glbbs and Martin (1962: 309) assert the generality of the relationship when they note that,

... If large-scale urbanization requires that materials be brought from great distances, and if a high degree of division of labor and technological development are necessary for this, then the level of urbanization is contingent, at least in part, on the division of labor and technology.

To these authors, the ability of population concentrations to persist over time is contingent on the capacity of the population to obtain what it needs for survival; Insofar as the population is able to bring the needed resources from the point of their production to the city, the city as a physical and social entity will be able to persist. If the population is not able to do this, according to these authors, these population concentrations cannot persist.

The role attributed to transportation technology for the emergence and growth of cities once again points to the extreme interdependence between the components of the ecological complex. As Gibbs and Martin noted above, not only do cities depend on the technology associated with bringing objects of consumption from their origins, but they also depend on the rather elaborate division of labor which makes this possible. Cities thus depend on the specialization of economic activity without which the creation, maintenance, and improvement of transportation technology would not be possible. Cities, once again, are thus illustrated to be very complex entities which depend for their existence on a variety of factors. However, if Gibbs and Martin are correct, transportation technology would seem to be at the very heart of city existence. In another paper the same authors (1958: 269), once again, attempt to link the existence of cities with the organized effort to obtain the 
products needed for survival. A great deal of time is spent in the analysis of the effects of different degrees of dispersion of the needed objects of consumption on the ability of cities to emerge and grow. It is argued that the degree of the dispersion of objects of consumption will influence the manner in which the population will attempt to "link" the sources of the needed objects and the population. One of the most expedient ways to link the resources to the population is suggested to be the development of a city which is in the middle of the many transportation routes; through this city will pass the majority of the materials from the outlying areas (in order to better visualize what is being discussed, imagine a "star" shaped figure; the legs, or points, of the star are the place at which the objects of consumption originate, while the middle of the figure represents the city). Of this type of city the authors note, "Transport and control centers...arise as part of an organized effort to convert widely dispersed natural resources into objects of consumption for the country as a whole". While It is certainly true that these cities are the result of an organized attempt to modify the original raw materials, it must not be forgotten that these types of cities would not exist where they do in the absence of at least a minimal level of transportation technology; in other words, the "transport and control centers" of which Gibbs and Martin speak are Intimately dependent upon the technology of transportation in the particular society. Indeed, if it were not for transportation technology there would be 11ttle for these "transport and control centers" to control.

The effects of transportation technology on the development of cities in the underdeveloped countries would be expected to be similar 
to those mentioned above if Gibbs and Martin are correct. In truth, I could find 1ittle in the 1iterature explicitly concerned with the relationship between transportation technology and population concentrations. One notable exception was the following statement by Germani (1973: 36):

... the Introduction of modern means of transportation, largely shaped by the needs of the primary export economy, contributed strongly to break the isolation of many areas of the nation territory, thus favoring contact with urban centers and prompting migration to 'primate' cities which had expanded because of their economic and political role in the export economy.

What is of greatest interest here, I would suggest, is that the role of transportation technology in promoting urban growth is relegated to a position of lesser importance than that attributed to the demands of economic activity focused at points located beyond the borders of the particular country. While it is suggested that "modern" transportation may prompt migration to the largest cities, thus causing some urban growth, the primary reason for urban growth seems to be the city's relation to other countries via the exportation of goods.

The point to be stressed is that this view of city development and growth is one which is very often associated with cities in the underdeveloped countries. If correct, it would point to yet another example of the difference between developed and underdeveloped countries in the manner in which technology may influence the emergence and persistence of population concentrations.

Improvements in the technology of communications are often observed to have important implications for the existence and growth of cities. There can be 1fttle doubt that a close relationship exists between communication technology and transportation technology. Insofar as an elaborate transportation network emerges in a society, an equally 
elaborate communication system must also arise; that is, in order for the transportation of goods and individuals to proceed smoothly, it is necessary that a fairly high degree of coordination of these activities takes place. This is the role of communication technology: to supply the facilities which enable goods and individuals to be efficiently transported from one place to the next.

It has been argued that communication technology, in confunction with transportation technology, served to promote population concentration in the industrial city. Lampard (1955: 82-3) explains, "The great urban explosion of the second half of the 19 th century was seen to stem directly from improvements in communications which served to concentrate economic opportunities in locations which offered the greatest cost advantages in the procurement, processing, and the distribution of goods". In confunction with transportation technology, c1ties developed at nodal points in an evolving network of local and regional specialization. Whereas before these advances occurred, a relatively uniform mode of rudimentary activities existed, after their introduction a highly differentiated but closely integrated system of local specialization resulted. It was the integrative role of communication technology which enabled these specialized cities to effectively utilize the rapidly evolving transportation networks.

The possible role of communication technology in the development of cities in the underdeveloped countries is not widely discussed in the literature. Indeed, I could find no reference to it at all. It is worth noting that when communications are discussed as characteristics promoting population concentrations, the early industrial city is invariably the object of attention. It might be concluded then, that while 
the role of communciation technology is considered to be important in the evolution of cities in the west, it has not been argued that this sort of technology is necessary for the existence of cities in the underdeveloped countries.

The role of technology in the development of metropolitan places has thus been argued to be of the greatest importance. As we have seen, however, population concentrations can and do exist in the absence of comparatively high levels of technology. It might be, then, that population concentrations exist for very different reasons in the third world than in the developed countries. Indeed, Berry (1973: 80) suggests that this is the case when he notes, "The conclusion we reach is that Third World urbanization is a fundamentally different process than that described by Adna Weber, with human consequences that do not conform to the conventional wisdom codified by Louis Wirth". Adna Weber was a late nineteenth century author who felt that urbanization in England and the United States was promoted by the various technologies introduced in the industrial revolution and by the railroads. Berry seems to be arguing, in essence, that urbanization in the third world is more independent of the level of technology than was the case in the developed countries. If this is so, there would certainly be solid ground for arguing that the process of urbanization in the underdeveloped countries is very different than it was in the developed ones.

\section{Organization}

As a structure of activity, the city can only arise and persist when reciprocal and complementary relations exist between the individuals composing 1t. This is to say that population concentrations depend on 
the speclalized activitles which their members perform. The city may then be conceived as being composed of a variety of activities which, taken together, form the economic basis for the city's existence.

It is clear that the organized activities of city populations are very closely dependent on the type and extent of technology available. Yet, it is also clear that without a fairly high degree of spectalized knowledge, the numerous improvements in technology could not have occurred. Thus, we have still another instance of the reciprocity between the various components of the ecological complex. This reciprocity between, in this case, technology and organized activity has been argued by Lampard (1955: 88 ) to be a major factor in the evolution of the Industrial clty:

It was this ongoing specialization among men and machines which gradually transformed the techno-organizational base of society and, with it, the spatial order of economic activities. Specialization provides an essential link between the technical and spatial conditions of economic progress. It holds an important clue to the nature and creative significance of urban-industrial growth.

The close association between technology and organization in their effects on urbanization is reflected in the fact that a great many cities specialize in the production and distribution of some particular good or service. It has long been realized that some cities are centers for activities of certain types. Pittsburgh, for instance, has long been Identified as a clty which spectalizes in the production of steel, while Miami is a mecca for tourists. While many other examples of cities specializing in certain activities could be given, the point is that because of the spatial distribution of resources and the technology available for processing and distributing those resources, employment opportunities in these activities emerged which attracted members of 
the population seeking work. Population concentrations emerged which had a high proportion of their labor force engaged in certain sorts of activities.

The process being described here is one in which an increasing differentiation of economic functions between the various cities in a soclety emerged. Naturally, the existence of cities in which certain activities predominated acted much like a magnet to draw populations with the appropriate skills or interests; an inevitable result was city growth. However, city growth was encouraged by speclalization in yet another way.

The existence of speclalists in a certain fleld requires that speclalists in other fields exist. Since an individual employed in a speciflc occupation only performs a rather narrow range of activities, it is necessary that other occupations exist so that they complement his activities. In other words, factory workers do not usually transport the raw materials they work with to the factory; instead, it is the task of other Individuals to transport the materials to the factory. Although this example of the manner in which specialized activities may complement each other is rather rudimentary, I would suggest that it does 111 ustrate the process at work at a far higher level of complexity. Now, in order for highly complex economic tasks to be accomplished in a city, it is necessary that groups of specialists are able to interact with each other. In this 1ight, it can easily be seen that even the most highly specialized city is composed of any number of specialized groups. It is suggested, then, that the existence of specialized groups In a city attracts (and makes necessary) other specialized groups. One way, In which citles grow is the simple fact that specialized groups 
need other speclallzed groups; a large c1ty is 1tself a diverse group of speclallzed groups. As Hawley $(1950: 200)$ has observed, "Diversity is the stuff of which interdependence is made and is thus basic to the community".

It must be remembered that we are here discussing how cities emerge and grow in the developed countries. In these countries, a generally accepted model of urban growth has been summar1zed by German1 (1973: 33). A first stage in c1ty growth accompanies the increasing percentage of the total population employed in Industry. As a result, the material standard of living in the country (or at least in the clty) tends to rise. The technological capacity of the population serves as an upper Iimit to the proportion of the total population which may be employed in industry. The 1mproving standard of living in the country stimulates an increase in the level of expectations of the population which, in turn, creates a demand for more services and amenities. As this occurs, more and more individuals are attracted to the city to fill the jobs opening In the service sector, with the result that the percentage of the total population engaged in the service sector increases. More demand for services is stimulated as expectations rise ana more individuals flock to the c1ty to f111 the demand, and so on.

What is being suggested here is a circular process in which the demand for more and more services increases as the avallability of these services increases. In effect, one stimulates the other; the logical conclusion of such a process would be the vast preponderance of the labor force engaged in service occupations. While this is unlikely, the point to be stressed is that processes of this type increase specialization in the city (and in the soclety as a whole, as well) and promote 
urban growth. As Berry (1973: 4) argues, "Increased division of labour and increased spectalisation, the necessary concomitants of increased productivity, Inevitably become forces promoting population concentration in cities". The specialized activities characteristic of cities, if Berry is correct, acts much like a magnet to attract individuals and groups to cities.

The situation in the cities of the third world is much different, however. The close links between the level and type of technology and the organized activities which go on in the cities of the developed world are absent in the cities of the underdeveloped world. Some idea of the differences which exist between the cities of these two groups of countries may be gained from an inspection of the economies of third world cities. Once again, Berry (1973: 91-2) provides a concise analysis:

The individual enterprise sector comprises the unemployed workers of the "street economy' of the city, including the offspring of urban residents, recent migrants to the city, those laid off from other jobs, street hawkers, casual construction workers, prostitutes and panderers, professional beggars and petty thieves. It accounts for between 25 and 40 percent of the urban labour force... The second sector of the Third World's urban economies is that devoted to family enterprise in the traditional bazaar-type economies... such family enterprise accounts for 35-45 per cent of the labour force in small trade and service establishments and industrial workshops... The third sector is the corporate, including capital-intensive businesses, the government, and the professions. Depending upon the particular city and country, this sector provides between 15 and 50 percent of the urban employment.

This picture of the economies of third world cities provides us with a completely different view of the opportunities avallable to the citydweller or recent migrant to the city, in these countries, and gives us an Idea of the sorts of activities engaged in.

For the average city-dweller in an underdeveloped country, the prospects of obtaining employment in a comparatively high-paying 
industrial job are anything but encouraging. A generally held view of the influx of population to these cities in the 1950's was that the industrial development which existed required more and more labor. The demand for labor in industry was regarded as a "cause" of urbanization. It is now recognized, however, that such was not the case. In reference to the influx of population to the cities of the underdeveloped countries, Myrdal (1974: 177) argues, "In reality it must be recognized as a flight from agriculture. The cities in all the underdeveloped countries now have a much bigger labor force than can possibly be employed in industry, however fast it is growing. They are simply displaced rural people". These individuals are not "pulled" to the city, they are "pushed" from the rural areas. In addition to the fact that not enough fobs in industry exist to employ these individuals, we should also note, as Berry has implied, that the cities of the third world are typified by much lower levels of occupational diversification than the cities of the developed world. Cities of very large size in the third world very often have occupational structures which are far less diversified than one might expect if one compared them to cities of similar size in the developed world.

There is little reason to expect improvement in this situation in the future. Third world countries simply have not been able to provide jobs for many residents of their cities, while the populations in these countries continue to grow. Turnham and Jaeger predict that, "Taking al1 less developed countries together, we can fairly confidently expect not less than 25 per cent growth in the numbers wanting work between 1970 and 1980, while the corresponding figure for developed countries is only about 10 per cent...". They go on to suggest that for an 
increasing number of countries, employment is emerging as a more serious population problem than the much more widely discussed question of the adequacy of the food supplies.

Since the cities in these countries do not provide enough employment for their populations, a fairly high proportion of the urban population is marginal from the point of view of its economic activities as well as in relation to the patterns of consumption and other aspects of modern culture. Perhaps this is one of the most important ways in which cities in the underdeveloped countries are different from cities in the developed ones. The elaborate division of labor in citles, so typical of developed countries, is generally absent in cities in the third world; the result is a truly displaced population, unable to participate in the many activities generally assoclated with iffe in the cities. 
THE PROPOSED RELATIONSHIP BETWEEN CONTEXTUAL

FACTORS AND METROPOLITANISM

In the previous chapter we observed the manner in which the varlous characteristics of the countries of the world influenced the levels of population concentration within their borders. The many phenomena which were discussed under the headings provided by the components of the ecological complex all had one thing in common: they were factors, or characteristics of each of the countries of the world; for this reason they were termed internal factors. One might summarize the relationship discussed in Chapter II with the following equation: Metropolitanism = organizational variables + technological variables + environmental variables + demographic variables. This is to say that metropolitanism has been conceived to be a function of the many characteristics of the country in which it occurs.

One of the most important conclusions which may be drawn from a review of the contemporary literature on cities is that critical differences exist between the developed and underdeveloped countries in terms of the forces which promote and maintain the process of urbanization. In other words, the various internal factors which apparently promote and maintain urbanization in the developed countries are not operating, or not operating in the same way, to promote and maintain urbanization in the underdeveloped countries.

Thus in order to understand metropolitanism in a world-wide perspective, I would suggest that something more is needed than the 
simple consideration of these internal factors. That "something", I would argue, is consideration of the fact that all the countries of the world are members of a world-wide system of countries. That is, the context in which each country finds itself is suggested to be an important force in the level of metropolitanism the countries of the world exhibit. Nothing could be more erroneous than to think that the physical boundaries of a country act as barriers which prohibit interaction with other countries. Any country may interact with any other country in any number of ways: the importation and exportation of technology and organizational expertise are common occurrences in the modern world.

But what may be conceived to be an indicator of a country's membership in an international system of countries? Perhaps one of the best empirical indicators of a country's interaction with other organized populations is its volume of economic exchange with other countries. In other words, it is now proposed that in order to investigate international variation in metropolitanism, an equation of the following form is needed: Metropolitanism = organizational variables + technological variables + environmental variables + demographic variables + volume of economic exchange with other countries. Thus, it is argued that it is necessary to add the contextual effects of economic interaction with other countries to the "internal" variables already discussed if international variation in metropolitanism is to be best understood.

The aim of this chapter is to provide a theoretical basis for the suggested relationship between metropolitanism and the volume of economic exchange with other countries. In order to do this, it will 
be necessary to look at the demographic characteristics of the countries of the world and to inspect the relationship between these characteristics and the resources avallable in these countries. Only by beginning with the conditions within the countries of the world may one gain an idea of the need for, and the importance of, a country's economic interaction with other countries.

\section{POPULATION AND RESOURCES}

It has long been recognized that Malthus was correct when he stressed the critical importance of the relationship between a population's size and its supply of sustenance materials. Although technological innovations may increase productivity so that more sustenance materials exist, it remains true that the size of the population cannot grow faster than Its supply of sustenance materials. Over a quarter of a century ago Hawley $(1950: 150)$ noted that the populations of most of the world were straining the resources within their boundaries:

However harsh and dismal may be the picture of man's estate on earth painted by Malthus, his statement is descriptive of the Iffe situations of most populations of the world in the past and in many at present. Man's dependence on the resources and conditions of the physical and blotic environment is a fundamental fact of his existence. And for the large majority of mankind the opportunities for life are closely restricted... Man's tendency to multiply up to the maximum carrying capacity of the land is superficially evident in many parts of the world.

The history of man's existence on this planet could accurately be described in terms of his constant struggle to provide himself with the finite materials necessary for the maintenance of $11 \mathrm{fe}$.

The fact that man has struggled for his entire existence to provide his numbers with adequate supplies of sustenance materials should not deter us from realization that the problem of population growth 
has not yet been solved. The fact 1s, that a world-wide problem of population growth still exists. The immensity of this problem is reflected in the following statement (Spengler, 1974: 8):

In the 1850 's about 68 million were added to the world's population; in 1900-1910, 90 million; and in 1950-1960, $482 \mathrm{mil-}$ 1 ion - seven times as many as in 1850-1960... In short, people are belng added to a finite world at a rate about seven times that of a century ago, and this rate could soon be double that of the 1950's.

Now, the only possible way for a rate of population growth seven times higher than a century ago to be sustained, is through the intense utilization of advanced technology. Agricultural technology and industrial technology are probably the two major means by which the supply of sustenance materials could be increased enough to support this tremendous proliferation of the human race. Yet, 1t cannot be disputed that the resources of the world are finite and, ultimately, exhaustible. It would seem, then, that technological advances will not be able to increase the avaflability of sustenance materials forever; at some point the raw materials they have to work with will run out. Naturally, just when this might occur is a subject of more than a 11ttle dispute. The point is, however, that given the finite and exhaustible nature of resources, the growth of the world's population must cease at some point.

While it is true that the population of the world is growing, it is of the greatest importance to note that the level and intensity of this growth varies by region. As we might expect, underdeveloped countries generally have far higher rates of population growth than developed ones. Referring to a United Nations report on the world's population published in 1966, Hauser (1969: 19-20) explains: 
The United Nations 'hIgh' projections indicate that the lessdeveloped areas would have an aggregate population of about 5.4 blllion persons by 2000 , whereas the more developed areas would total about 1.6 blllion...Moreover, the less developed areas, according to this projection--a quite plausible one--would increase in the last four decades of this century by a number of persons as great as the population of the entire globe in 1960.

In terms of their demographic characteristics, then, the populations of underdeveloped countries are very different from the populations of developed countries. Indeed, an underdeveloped area may be distinguished from a developed one by at least four demographic characteristics: high fertility, falling or low mortality, accelerating or higher population growth, and a very young age distribution, (Coale, 1969: 61-2). There can be no doubt that the populations of these areas are placing a very high degree of strain upon the resources found in their particular country.

The strains on the resources of underdeveloped countries may be seen to be the result, in particular, of two of the demographic characteristics of their populations mentioned above: high fertility and the very young age distribution of the population. The high fertility in underdeveloped areas is coupled, in general, with inadequate amounts of arable land. Whether it is because of relatively low levels of agricultural technology which makes part of the land of little utility for farming, or simply because there are too many people in relation to the arable land, serious agricultural shortages are commonplace in the underdeveloped countries. The young age distribution of the populations of the third world means that in these countries there is a relatively high number of Individuals who are economically unproductive. These individuals must be supported by the adult population if they are to survive. Since they form a falrly high proportion of the 
total population, a correspondingly great amount of the economic effort of the adult population must be devoted to their support. This means, in effect, that Income which otherwise could have been devoted to capital accumulation must instead be devoted to the support of a large number of dependents.

When one considers these demographic characteristics of the underdeveloped countries and the problems they create between the populations and their environments, it is somewhat surprising to note that the growth of cities in these countries is much higher than in the rest of the world. As Turnham and Jaeger (1971: 11) put 1t, "If the rate of increase in population in many less developed countries merits the description 'explosion', superlatives are lacking to describe the urban growth rate." The long-term growth of the cities in the deve1oped countries is cogently contrasted with the awesome long-term growth In cities in the underdeveloped countries by Berry (1973: 74):

As part of the quadrupling of the world's urban population during the last 50 years, the developed regions increased their urban population by a factor of 2.75 (that is, from 198 to 546 million), while the Third World countries increased their urban population by a factor of 6.75 (from 69 to 464 million)... Clearly it is the Third World that is experiencing the major thrust of urban growth today.

It should be remembered that Berry is here referring to urban places of all sizes; regardless of the manner in which the particular country defines "urban", these places are experfencing high levels of growth. It may be perhaps more significant to note that between 1950 and 1960 the proportion of the population in cities of 100,000 or more rose about a third faster in the underdeveloped regions than in the developed ones (Davis, 1968: 16). Clearly, then, not only are all cities, in general, growing faster in the underdeveloped countries than in the developed 
ones, but the big cities in the former group of countries appear to be growing much faster as well. This means that large urban agglomerations are rapidly growing in those countries typified by the worst levels of economic development, nutrition, energy consumption, iffe expectancy, and education.

Besides the fact that the regions of the world vary in terms of their rates of total population growth and the growth of their cities, it is also true that they vary in the type and extent of resources they offer. This variation can readily be seen if one inspects the countries of the world and the material resources available within their boundaries. Since resources are very unevenly distributed over the surfaces of the earth, the national environment in which a populatIon finds itself greatly influences the activities in which that population will engage. Now, when one recalls that the population of the world is growing, it becomes clear that any population of any country must adapt to its immediate environment in such a way that its growing numbers may best be supported. That is, population growth, in conjunction with the constraints reflected in the distribution of resources, forces any population to modify its activities. As Matras (1973: 65) notes, "It is under the pressures of population growth that changes in the settlement, soclal organizational, and economic and technological arrangements of a population are effected...".

We might surmise that populations faced with different rates of growth and different environmental constraints might adapt themselves to these conditions in any number of ways. We might speak of these different possible modes of adaptation, as Matras does, as "societal strategies of survival and adaptation". Concelving of the relationship 
between a population and its environment in this way, according to Matras (1973: 66),

... assumes that populations must organize to effect their collective survival--and that in so doing they define other collective 'Interests' in addition to survival itself--and that populations disperse and settle themselves over the available territory and organize themselves socially and economically so as to assure their collective survival and promote what they view or accept as their key interests.

The spatial and social organization of any soclety can, if Matras is correct, be viewed as reflecting the soclety's need to cope with the strain its growing numbers place on its finite environment. Lest there be any misunderstanding, it is certainly not argued that a society's organization is solely determined by its efforts to obtain the various sustenance materials necessary for its survival; societies are extremely complex entities and their particular "form" is not determined by any one factor. Rather, what is being suggested is that a complete understanding of the spatial and social organization of any society cannot be achieved without awareness of the necessity for any population to orient its activities toward the provision of sustenance for its members.

\section{THE URBAN METROPOLITAN REVOLUTION}

How might a population adapt itself to its environment? It was noted above that the populations of the world may adopt varlous strategies of adaptation. Although it is concelvable that a growing population may adapt to its environment in a variety of ways, in reality it appears that there have been four major alternative adaptations to the pressures of population growth on the environment (Matras, 1973: 72-85).

The first of these is areal expansion. In this case a society simply expands its area of settlement. This may occur in two related 
ways: the soclety may diversify itself so that its various groups command more territory than was formerly the case, and/or a second group within the soclety simply migrates, leaves the original society, and forms its own settlement in another place.

The second alternative adaptation a society may make is the adoption of technological and social innovations. These adoptions are aimed toward Intensifying the exploftation of the territories already under the population's command. This intensification may be effected in two ways. First, the soclety may adopt improvements in technology which raise the sustenance yield of the occupied territory; this permits the population to support increases of their number. Secondly, the population may modify its mode of social organization. It may increase its speclalization and division of labor in order to increase the productivity of its labor and the diversity of products available.

The third type of adaptation a society may make is increasing control of its numbers. The population may, more or less self-consclously, develop modes of controlling its population growth. For example, it may either promote mortality or dampen fertility. Although the former means is seldom chosen by "modern" populations, the latter has achleved a tremendous degree of importance for a great many of the countries of the world.

The fourth alternative adaptation a society may make to the pressures of its population growth on its resources Matras calls the "Urban Metropolitan Revolution". There can be no doubt, according to Matras, that the principal population trends found throughout the world today are increasing population size, increasing density, increasing concentration and agglomeration, and the political organization and integration 
of large geographic areas. This leads Matras (1973: 84) to suggest that, "The societal strategy of adaptation is changing in the direction of Increasing differentiation, but at the same time there is a greatly increasing interdependence among individuals, groups, and socletles located at great distances from one another". The "Urban Metropolitan Revolution" then, may be concelved as the increasing Interdependence between urban agglomerations located at great distances from one another and perhaps even in different societies.

I would suggest that although the first three modes of societal adaptation have occurred, and may still be occurring, in any given country at any given time, the "urban metropolitan revolution" has become an increasingly Important strategy for the population of the varlous countries to cope with their growth. It has long been observed that many cities began as trading centers; thus, it has long been rea1ized that cities engage in economic relationships with organized populations which exist outside of its boundaries. In a very basic sense, a city's ability to engage in economic relationships with entities outside its boundarles depends on the level of transportation and communication technology which exists at the time. As a result, when animals, of various kinds, were the primary means for the transport of materials from one place to another, the geographical area which any city could profitably and reliably exploit was fairly small. As inanimate sources of power were developed and communication technology became a means for the coordination of distant transport activities, the area accessible to the city increased dramatically. Cities became increasingly sensitive to a larger and larger environment. Realization of this basic fact has led Lampard (1955: 128) to state that, "Every clty, no matter 
how large or smal1, functions in relation to, and as an integral part of, the wider economic order around it. In some cases this mutuality corresponds to a whole region or country". It is fust this sensitivity to a larger and larger "environment" that is the key component of what Matras calls the "urban metropolitan revolution".

The extent to which the support of the modern city depends on a large environment outside its boundaries cannot be overestimated. Keyfitz (1965: 292-3), for example, argues that, "The fully developed industriai city depends on no particular countryside to buy its products and furnish it with food; if there is a crop failure in the place of its usual supply, it can draw food from elsewhere. The fields of the world are its ecological base...". It is not at all surprising, given the generally high levels of population growth in the world and the very uneven distribution of natural resources between its countries, that the modern city, in whatever country, must seek support from an ever-wider area.

It must not be thought, however, that the modern city depends only on the agricultural produce and raw materials that a predominantly rural hinterland can provide. In reality, the relevant environment for any city now is also composed of many other citles; and, these other cities need not be located in the same country. In fact, the greater the differences in the economic functions of two cities the more 11kely it is that they will engage in vigorous economic relations with one another. That is, two cities located in different countries having dissimilar resources are attracted to each other if they both have a need for the materials produced by the other. Matras (1973: 106) seems to imply just this sort of relationship in the following statement: 
The most 1mportant characterlstic of the megalopolitan network is the kind of specialization and interdependence that obtains among cities. Whereas the key interdependence in a regional economy is between the city and its rural hinterland, or between the metropolitan center and its smaller urban satellites and rural hinterland, the interdependence characterfzing the megalopolitan network is between cities of different types, different functional spectalization, and different economic bases.

Interdependence can thus be seen to occur between larger, more formal, and more distant units. Interdependence, based on the speclalization of activities, has customarily been observed to appear between cities and their immediate hinterlands, and within a network of cities in the same soclety. What Matras is suggesting is simllar in principle but very different in areal extent.

If this is an adequate representation of the current state of affalrs, the growing urban agglomerations in the various countries may be viewed as nodes in a network of interdependence which extends far beyond any country's political boundaries. To the extent that what the population of any country needs or desires in order to subsist is not accessible within the political boundarles of the country, the most convenient and acceptable manner of obtaining it is to acquire it from a country wlling to trade for it. The cities which exist in the various countries are suggested to be the structures of organized activity representing the most expedient manner to transact such exchanges.

Al1 of the world's countries can readily be seen to engage in the sort of economic exchange described above. The developed countries must engage in such relationships if they are to maintain the high standards of living they now enjoy. It does not take a great deal of $1 \mathrm{~m}-$ agination to conceive of what life would be like in the United States in the absence of trading relations with other countries. There is little 
chance that the Untted States could maintain its standard of living without the many and varied economic exchanges we make with other countries everyday. The Untted States, however, is luckier than most In that it enjoys vast and diverse natural resources and thus could support a large population (at a comparatively low standard of living) without economic interaction with other countries. The situation in a country Itke Japan is far different. The population of Japan depends on trade relations with other countries not only for its high standard of living but for its very existence. Even developed countries, therefore, are critically dependent on economic exchange with other countries. It can readily be seen that these exchanges are of the greatest Importance to the underdeveloped countries. As we have observed, these countries are typifled, in general, by low levels of industrial development, and the industrial and economic enterprise which does exist is most often of comparatively low productivity. Thus, for the populations of these countries the importation of many types of goods is an absolute necessity. The sad fact is that even with the importation of food and other products, the populations of these countries are faced with a truly abysmal standard of living.

I have noted time and again that the underdeveloped countries generally have far higher rates of urbanization than the developed countries. As yet, however, perhaps the most important question of all has not been asked: how are these rapidly growing urban agglomerations supported in even a minimal manner? A first step toward an answer to this question is taken when it is realized that for many citles in the third world one of the few avenues open for the acquisition of needed consumer goods is intense trade with other countries. According to Keyfitz 
(1965: 266). "...when the clty elite is determined to develop at all costs, being possessed at the outset of no efficient manufacturing industry, its strategy is to sell abroad the products of the countryside in order to secure its first modern producers" goods". Thus, a certain type of reciprocity develops between the city in the underdeveloped country and any number of extra-societal populations. In order to support their populations, these cities must seek to obtain an ever firmer hold on a larger and diverse territory; the resources of the national hinterland of these cities serve as the source for what the city may efther trade directly, or process in some way for trade.

This situation may be considered typlcal of the underdeveloped countries taken as a whole. If this is so, there can be little doubt that the structure of these cities is profoundly effected. That is, the organized activities and the alternatives avallable to the populations of these cittes are influenced to a significant extent by their relationships to organized populations outside thelr boundaries. Referring to this structure, Germant (1973: 34) comments:

In present developing nations, however, that structure was in large part formed in a situation of economic and political 'dependence' with respect to the metropolis, or the industrialized nations. Both the politico-administrative needs during the colonial perlod (when there was one) and the economic needs derived from the export of raw materials and the import of finished products (the most common form of incorporation of a 'new' country into the world market and modern economy) profoundly affected the urban structure. Thus, already at the point of departure there is a difference in comparison with the countries in which the step from pre-industrial urbanization occurred more as a function of indigeneous than because of exogeneous factors.

Although the cities of the third world are growing, then, it is critical to realize that the activities which go on in these cities are influenced by the demands of an International system. Economic specia1- 
ization within the city conforms to the characteristics of the functions which link the city to other cities in a world-wide system. What the city has to offer on the international market, and what it needs to support itself, are the dominant criteria by which the activities in that city are organized. It would be accurate to say, as a result, that the growth of these cities is influenced by the manner in which it relates itself to other organized populations. Pizzorno (1973: 129) observes that, "Obviously administrative functions also develop as well as a whole series of other functions whose main objects are the internal problems and situations pertinent to the clty; but the generating functions are for the most part turned to the outside world, at least insofar as their origins are concerned". Restricted in what they can offer on the world market by low levels of industrial development, these citIes are placed, very often, in the role of supplier of raw materials to the other countries. Since they must play this role, the activities carried on within them are greatly influenced by the relationships this role necessitates.

Growing urban agglomerations in both the developed and underdeveloped countries thus depend for their support on the acquisition of the needed goods and services provided by participation in the intersocletal network of interdependence. At its base, this system of interdependence is necessitated by the diverse distribution of the world's resources. The fact that one country is endowed with materials which another country desperately needs, gives rise to a certain degree of dominance of one country over another. Relations of this type have created a sort of "world hierarchy", or "international stratification", In which countries may be ranked in terms of their relationships with 
others. In describing an intersocletal network of interdependence, we must not lose sight of the fact that "not all countries were created equal". Conceived in this way, it is clear that a country's relationships with other countries, as reflected in its economic exchange with them, are very important influences on the structure and characteristics of 1ts cities. Isard (1974: 286), for example, concludes:

The world hierarchy, of course is the basic structure within which key behavior takes place, whether in the realm of economics, politics, culture, or social life. One cannot hope to conduct basic research on the welfare of different regions and cities and other areas of the world without taking into account their positions and roles within this hierarchy.

If Isard is correct, the close interdependence of the various regions and countries of the world has resulted in the creation of a truly planetary system; it is in the context of this system that the world's growing cities must be considered.

The existence of, and the participation in, this network of interdependence has two primary effects on the population of any country. First of all, it liberates the population from the inadequacies of its immediate environment (that is, from the territory within its national boundarles). It functions to increase the diversity of resources and products available to the population. Secondly, this network of interdependence, to the extent any country becomes involved in $1 t$, forces the population to become dependent on the system of countries. The relevant environment of the populations of the various countries increases in areal extent in such a way that it becomes the system of countries.

The network of international interdependence of which we are speaking is clearly based on the trading relations between the various countries involved. The volume of economic exchange of a country with other 
countries may very well reflect its interdependence with other countries. Thus, a country having a comparatively high volume of economic exchange with other countries might be argued to be highly integrated with other countries. As Katzenstein (1975: 1021) has observed, "A1though international interdependence and international transactions are not conceptually identical...transaction data provide...one basis for inferring changes in international interdependence". Since the economic interaction between countries is mutually profitable, in some sense, it is clear that this sort of interaction "may generate mutual profits and the accompanying positive feedback which encourages future exchanges" (Clark and Welch, 19.75: 356). Indeed, this appears to be fust what is occurring; world trade has outpaced world output, world income, and world manufacturing production since 1945 . Katzenstein (1975: 1031) claims that, "The average export/GNP ratio for all states has increased from 15.3 percent in 1950 to 18.9 percent in 1965 , and the average trade/GNP ratio rose from 42 percent in 1955 to 47 percent In 1965". Other researchers (Fisher and Potter, 1969: 121) have found that there has been a 70 percent increase in total world imports of food and foodstuffs since the 1930 's; further, the trade in fuel products has increased nearly 10 times between 1938 and 1966, and was 52 percent higher in 1966 than in 1960. Clearly, these increases in the volume of economic exchange between countries would seem to indicate not only an increasing dependence on sources or markets in other countries, but also the emergence of a system of countries based on the functional interdependence of its members. 


\section{CONCLUSION}

The purpose of this chapter has been to provlde a basis for the perspective that the contextual characteristics of a system of countries will influence the extent of metropolitanism in the countries of the world. The "Urban Metropolitan Revolution" has provided a description of the adaptation to population growth now occurring in the countries of the world by pointing out that, "...the nature of the city makes possible the acquisition of globally dispersed materials" (Martin, 1962: 97). The international interdependence which arises from this type of adaptation may be measured, it is suggested, by the volume of economic exchange a country has with other countries. If the relationships described in this chapter are not invalid, I would argue that the volume of a country's economic exchanges with other countries will influence the extent of a country's metropolitanism. Although metropolitanism will most surely vary with the internal characteristics of the country itself, I suggest that international variation in metropolitanism cannot be fully understood without consideration of a country's economic interdependence with other countries. Thus, it is a primary goal of this study to determine how much of the international variation In metropolitanism can be accounted for by international variation in the volume of economic exchange between countries. It is toward the achievement of this goal that the remainder of this study is directed. 
CHAPTER IV

\section{THE DATA}

The empirical exploration of a hypothesis demands that an adequate amount of data be available. In order to test a relationship of the kind proposed in Chapter III, a great variety of information must be available for the various countries of the world. The most convenient sources of such information are the numerous publications of the United Nations and the various World Almanacs.

While it may initially appear that the task of obtaining information of this type from these sources is relatively simple, this is not at all the case. The nations of the world vary considerably in terms of the amount and types of information collected and subsequently made available for publication. An obvious consequence of this state of affairs is that data applying to all the countries of the world is seldom, if ever, obtainable. Solely in terms of the data available, it is nearly impossible to make any empirically based statements concerning the world as a whole. Recognition of this short-coming led Davis (1969: chapter II) to employ very sophisticated techniques for the estimation of city sizes in many of the countries of the world. Without such techniques, Davis was of the opinion that no statements concerning world urbanization were possible.

Besides the problem of missing data, any attempt to study cities on a world-wide basis must be sensitive to the lack of international agreement on the basic definition of urban places. As pointed out in 
Chapter I, the countries of the world vary Immensely in the size criterla employed for the definition of urban (Gibbs and Davis, 1958, and Davis, 1969 devote a great deal of time to this problem). It was for this reason that metropolitanism was defined in this study as the proportion of a country's total population living in cities of 100,000 or more. This definition, it was argued, avolds many of the problems of definftion.

In order to investigate the degree to which a country's volume of economic exchange with other countries influences 1 ts level of metropolitanism, it is necessary to obtain data of five types. That is, in order to test the proposed relationship empirical indicators of the components of the following equation must be available: Metropolitantsm= organization + technology + environment + population + volume of economic exchange with other countrles. What is more, measures of this type must be available for the largest number of countries possible.

Table I is a 11st of the data which will be ut111zed in this study and the data's source. These data are suggested to be adequate empirical measures of the more abstract components in the equation presented above. Which of the varlables in Table I represent the various components in the equation will be discussed below. For now, let us focus our attention on Table $I$.

The data in Table I are self-explanatory, except for the per capita imports plus exports. With the exception of this Item, all the data are "prime" data in the sense that they were directly obtainable from a publication and could be utilized in a straightforward manner. In contrast, the per capita imports plus exports might be described as "derived" data. It is "derived" in the sense that it was not obtainable 


\section{TABLE I}

VARIABLES TO BE UTILIZED IN THE STUDY AND THEIR SOURCES

Variable

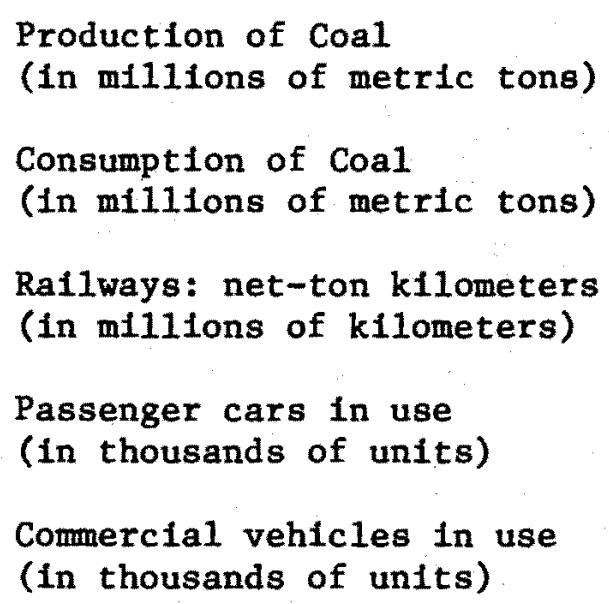

Production of coal

(in millions of metric tons)

Consumption of Coal

(in millions of metric tons)

Railways: net-ton kflometers

(in millions of kilometers)

Passenger cars in use

(in thousands of units)

Commercial vehicles in use

(in thousands of units)

number of cities with populations of

1 million and over

percent of the economically active in the total population

percent of the economically active in agriculture

percent of the economically active in manufacturing

percent of the economically active in construction

Yearbook of Labour Statistics, 1971.

percent of the economically active in commerce

percent of the economically active in electricity, gas, water, sanitary services

percent of the economically active in transport, storage, and communication
United NatIons Demographic Yearbook, 1971.
Rand-MeNalley World Atlas, 1971. 


\section{TABLE I (cont.)}

$\underline{\text { Varlable }}$

Source

percent of the economically active in services

annual rate of growth

(per thousand)

per capita Gross National Product

land area

(In thousands of square miles)

Population Division Working

Paper $\$ 34$, United Nations.

natural increase

(per 1000)

percent of total population in

cities of 1 million and over

percent of total population in

United Nations Demographic

citles of 100,000 and over

Yearbook, 1971.

per capita imports plus exports

"Derived Measure" (see text) 
from a publication, but had to be created by mathematical manipulation. This variable was obtained in the following manner. It was first necessary to find the total dollar value (In U.S. dollars) of imports for each country, the total dollar value (In U.S. dollars) of exports for each country, and the total population of the country (The total imports and exports for each country were obtained from the Yearbook of International Trade Statistics 1972-73). The total dollar value for imports and exports were summed and then divided by the total population of the country, thus yielding a per capita measure of each country's economic interaction with other countries. When the volume of economic exchange is referred to in this study, this is the measure under consideration.

All of the data in Table I are for the year 1971. The primary reason 1971 was chosen was because it was the most recent year for which the most data was available. Although many countries had more recent data available, a great many countries did not. Thus, one had to sacrifice more recent data in order to achieve the best coverage of the world's countries possible. It should also be noted that choosing a single year as a "base" for which all data will be collected greatly aids one in making comparisons between countries. It helps provide at least some security that conclusions made on the basis of the data will, in fact, summarize conditions existing between countries at a specific point in time.

The maximum number of countries which this study can address on the basis of the data in Table $I$ is 70. As suggested previously, many countries simply do not collect some of this data at all, or if they do they do it rather infrequently. The total of 70 countries can only be obtained, however, if the first five varibles in Table I are excluded. 
When all of the variables in Table I are utilized, only 30 countries remain in which the data is available. These 30 countries constitute only a small proportion of the total number of countries in the world but In this type of research one quickly finds that good data on al1 countries, or even a majority, are impossible to obtain.

Thus, we may look at 21 variables for 30 countries, but at only 16 variables for the total of 70 countries. Naturally, the measure of metropolitanism, and the measure of volume of economic exchange are available for all 70 countries. In order to see how the loss of the first five variables effects the statements this study can make about internation variation in metropolitanism, let us translate the data in Table I into variables representing the four components of the ecologica1 complex.

This has been done in Figure 1. The first five variables in Table I can be observed to compose all but one of the "technology" variables in Figure 1. Therefore, while we may discuss the effect of these technological variables on metropolitanism in 30 of the world's countries, we will not be able to assess its effect on the total of 70 countries. It is fully realized that this is a serious shortcoming, but there is little that can be done about it.

The remainder of the variables in Figure 1 are avallable for a11 70 countries. While it can be seen that all the variables in the various components of the ecological complex do not correspond exactly to the internal factors described in Chapter II, it is suggested that the grouping of the available data under the four components is a fairly good "operationalization" of the earlier discussed internal factors. For instance, the consumption of coal (Gibbs and Martin, 
ENVIRONMENT

LAND AREA

\section{POPULATION}

ANNUAL RATE OF GROWTH

NATURAL INCREASE

TOTAL POPULATION

\section{TECHNOLOGY}

PRODUCTION OF COAL

CONSUMPTION OF COAL

RAILWAY: NET-TON

KILOMETERS

PASSENGER CARS IN USE

COMMERCIAL VEHICLES

IN USE

PER CAPITA GNP

\section{ORGANIZATION \\ NUMBER OF CITIES WITH \\ POPULATION OF 1 MILLION \\ OR MORE \\ PERCENT OF THE POPULATION \\ IN CITIES OF 1 MILLION \\ AND OVER \\ PERCENT OF THE ECONOMICALLY \\ ACTIVE IN TOTAL POPULATION \\ PERCENT OF THE ECONOMICALLY \\ ACTIVE IN THE SEVEN CATE- \\ GORIES OF EMPLOYMENT}

F1gure 1. Data from Table I in terms of the four components of the ecological complex. 
1962: 316) and the Gross National Product (Ogburn and Allen, 1959: 128) of any country have been considered to be generally valid indexes of the level of technology in the country. The activities in which the members of the labor force in each country engages are certainly valid measures of the type of economic organization exemplified by each country.

I would suggest, then, that these 21 variables provide both a theoretical and empirical basis for the investigation of international varlability in metropolitanism. They provide an adequate amount of information for the statistical test of the hypothesis previously suggested. Concelving of the data in the manner Figure I suggests will provide firm theoretical direction for these statistical manipulations. 


\section{CHAPTER V}

\section{THE DELINEATION OF EMPIRICAL INDICATORS TO BE USED IN THE ANALYSIS}

All that has been sald to this point leads us to an obvious observation: metropolitanism is a tremendously complexphenomenon. As we have seen, a great diversity of factors have been suggested to account for the presence of, and changes in, thisphenomenon. The first step has been taken toward ordering these many factors by the ut1lization of the four components of the ecological complex. Yet, even If the data gathered for this study are ordered in terms of whether or not they are environmental, demographic, organizational, or technological characteristics of the particular countries, it is clear that two of these categories of data (the organizational, and the technological) are represented by a number of empirical indicators.

It is not at all undesirable to have a large number of empirical indicators for these two components of the ecological complex. However, if the varlables categorized under these two components are indeed valid empirical indicators of these components, it is clear that these variables are highly correlated with one another. That is, the technological variables, for example, are very likely to be very closely related to one another; we would expect that the per capita GNP in any country would be highly influenced by, and would itself Influence, the consumption of coal in that country. Likewise, the consumption of coal would likely influence, and be influenced by, the 
number of passenger cars in use. Although it would be possible to cite many more examples of the close relation between the variables classifled under these two components of the ecological complex, it should now be clear that these two groups of variables are highly intercorrelated.

I suggest that since this is the case, it would be conceptually more simple, and methodologically more sound, to attempt to choose from these two components of the ecological complex those variables which are most significant. One could, for instance, attempt to select from the ten organlzational variables two or three which might best represent the remalning seven or efght. This would enable us to think more concisely about the effects of these types of variables on metropolitanism. In terms of the regression analysis to be discussed in Chapter VI, the selection of the "best" indicators of the organizational and technological components would make any conclusions based on this analysis more significant. If one, for example, placed the ten organizational variables in a regression equation, we could expect that the obtained measures of the independent effects of each of these variables would be influenced by the fact that these variables are highly intercorrelated. As Blalock (1972: 450) te11s us, "...It should be obvious that if one adds variables to a regression equation, the partial correlations can be expected to change according to the nature of the intercorrelations among the independent variables. Exactly the same applies to the partial and standardized slopes...". If, on the other hand, one could select a much smaller number of organizational varlables, and if these organizational variables could be shown to define statistically independent dimensions of the organiza- 
tlonal component, then the effects of each of these varlables on metropolitanism could be argued to be relatively uneffected by each other.

But how might one go about selecting the "best" organizational and technological varlables? I would suggest that a factor analysis of these two components of the ecological complex would provide one with a criteria for this selection. In a very general sense, factor analysis is a set of methods for analyzing a table of intercorrelations (Baggaley, 1964: 91). According to Rummel (1967: 445), "What factor analysis does is this: It takes thousands and potentially millions of measurements and quantitative observations and resolves them Into distinct patterns of occurrence". Thus, one can take any number of varlables which are highly related to one another ( In our case, types of internal characteristics of countries) and manipulate them statistically so that groups, or patterns, of varlables w11l emerge; what is more, these groups or patterns of varlables w111 be Independent of one another. ${ }^{1}$ One can then inspect these patterns of variables and select one or more variables from this pattern which can be considered to be "representative" of the other variables in the pattern. The result would be that the selected varlables would be those most representative of distinct dimensions of the organizational and technological components of the ecological complex.

The organizational and technological varlables so selected could

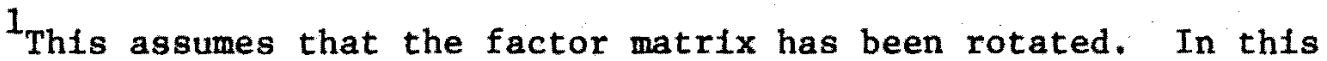
study, independence between patterns of variables has been ensured by the utilization of the technique of orthogonal rotation. For a discussion of factor rotation in general, and orthogonal rotation in particular, see Rumme1, pp. 471-476. 
then be placed in the regression equations, along with the environmental and demographic variables. Since the environmental component has only one varlable-land areardescribing 1t, it will enter the equations automatically. The population component has three variables which describe it: the annual rate of growth, and natural increase and the total population. Since these three variables are clearly very strongly correlated, the annual rate of growth and the total population size were selected as the empirical indicators of this component. The variables in these two components, then, were not included in the various factor analyses.

\section{THE THREE GROUPS OF COUNTRIES}

Before we look at the factor analyses of the organizational and technological components of the ecological complex, let us take a closer look at the countries for which all relevant data is available.

Table II provides a list of the total of 70 countries which will be the focus for the empirical investigation of the effect of international economic exchange on metropolitanism. A cursory inspection of these 70 countries will inform us that they are anything but a homogeneous group. This, I would argue, is a desirable state of affairs; since international variation in metropolitanism is what is to be explained, the greater the diversity in the group of countries under consideration, the more meaningful will be any conclusions reached.

As we observed in Chapter II, however, there is more than a 1ittle controversy concerning the existence and growth of cities in the third world. If international variation in metropolitanism is to be 
TABLE II

70 COUNTRIES WITH WHICH THIS STUDY WILL BE CONCERNED

Algerla

Libya

Morocco

Tunisia

Egypt

Ghana

Liberia

Slerra Leone

Mauritius

Angola

Gabon

South Africa

Cyprus

Israel

Jordon

Kuwa1t

Turkey

Ind 1a

Iran

Pakistan

Indonisia

Malaysia

Thailand

Hong Kong

Japan

Korea (Republic of)

Canada

Un1ted States

Costa Rica

E1 Salvador

Guatamala

Honduras

Mexico

Nicaragua

Panama

\author{
Barbados \\ Dominican Republic \\ Jama1ca \\ Tobago \\ Columbia \\ Ecuador \\ Guyana \\ Peru \\ Surinam \\ Venezuala \\ Argentina \\ ChIle \\ Paraguay \\ Denmark \\ Finland \\ Iceland \\ Ireland \\ Norway \\ Sweden \\ Un1ted Kingdom \\ Austria \\ Belgium \\ France \\ Germany (Federal Republic) \\ Bulgarla \\ Czechoslovakia \\ Hungary \\ Greece \\ Italy \\ Malta \\ Portugal \\ Spain \\ Yugoslavia \\ Australia \\ F1j1
}


examined in a world-wide context, and if the effects of international economic exchange on metropolitanism are to be completely examined, 1t would be necessary to look at both developed and underdeveloped countries.

Toward that end, the countries in Table II have been divided into two groups, one which may be called developed, and one which we may call underdeveloped. These two groups of countries are delineated in Table III. The basis upon which this delineation was made was the per capita Gross National Product of each country. Any country having a per capita Gross National Product of over $\$ 500$ was classified as a developed country, while any country having a per capita GNP of less than $\$ 500$ was put into the underdeveloped category. While this is a fairly arbitrary cutting-point, I would suggest that it does differentiate the total group of 70 countries into two groups having much different standards of living and technological development. While the average per capita GNP of the 30 developed countries Is nearly four times greater than that of the 37 underdeveloped countries, it must be admitted that there are some countries counted as developed which do not have per capita GNP's of $\$ 500$ or more. In fact, there are five such countries--Algeria, Tunisia, Iran, Costa Rica, and Chile. These countries were counted as developed for the following reason: "technological" data was available for them. It should be remembered that data on the technological variables was avaflable for only 30 out of the total of 70 countries. If these five countries had not been included in the developed group, only 25 countries would have composed the group. Considering this, I felt that some compromise had to be struck between precision of classifi- 
TWO GROUPS OF COUNTRIES AND THEIR AVERAGE PER CAPITA GROSS NATIONAL PRODUCTS

\section{Underdeveloped Countries--Average Per Capita} Gross National Product, $\$ 367$

Morocco

Egypt

Ghana

Liberia

Sierra Leone

Mauritius

Angola

Gabon

South Africa

Cyprus

Jordon

Turkey

India

Pakistan

Indonisia

Malaysia

Thailand

Hong Kong
Korea (Republic of)

E1 Salvador

Guatamala

Honduras

Nicaragua

Panama

Barbados

Dominican Republic

Jamaica

Tobago

Columbia

Guyana

Peru

Surinam

Venezuala

Paraguay

Bulgarla

Malta

F111

30 Developed Countries--Average Per Capita

Gross National Product, \$1285

\section{Algeria}

Tunisia

Israel

Iran

Japan

Canada

United States

Costa Rica

Mexico

Ecuador

Argentia

Chile

Denmark

Finland

Ireland
Norway

Sweden

United Kingdom

Austria

Belgium

France

Germany (Federal

Czechoslovakia

Republic)

Hungary

Greece

Italy

Portugal

Spain

Yugoslavia

Australia 
cation and the most extensive utilization of the technological data available. Since the technological variables are considered to be of the greatest importance to the study of urbanization, it was felt that including these five extra countries in the developed category would increase this study's ability to use technological varlables in the analysis.

The fact that we now have three groups of countries--the 30 developed, the 37 underdeveloped, and the combined group of 70 (three countries, LIbya, Kuwalt, and Iceland, were not classified as either developed or underdeveloped; consequently, they appear in the analysis only when the combined group is considered)--means that our analysis can be directed at two very different groups of countries, and at both groups combined. In terms of our factor analyses, it means that we can now do a factor analysis of the organizational variables in the total of 70 countries, a factor analysis of these variables in the 37 underdeveloped countries, and two factor analyses in the 30 developed countries: one of the organizational variables, and one of the technologlcal variables.

It should not be forgotten that the reason for doing these factor analyses is to determine the "best" Indicators of these two components of the ecological complex so that they might be utilized in regression analysis. With this goal in mind, let us turn to the specific factor analyses in these three groups of countries.

\section{Countries}

The technique of factor analysis ylelds a "factor matrix". The number of columns in the matrix can be interpreted as the number of 
"...substantively meaningful independent (uncorrelated) patterns of relationship among the variables" (Rummel, 1967: 463). For the organizational variables for the 70 countries, each of these ten variables will have a score, or "loading" on each of these patterns. The loadings measure the extent to which the variable is involved in the particular pattern; that 1s, if a variable has a loading of .95 on a pattern, we could say that the relationship between this variable and the other variables in the pattern is very strong. If one squares the loading and multiplies by 100 , one will obtain the percent varlation that a variable has in common with the particular pattern.

These facts enable us to look at the factor matrix of the ten organizational variables in these 70 countries and choose the variable with the highest loading on each pattern; this varlable can be thought of as representative of the other vartables on the pattern, and the best indicator of them. Since the factor matrix we are inspecting is yielded by one orthogonal rotation, it will be the case that the majority of these organizational variables will be highly loaded on one pattern, but not nearly as highly loaded on the remaining patterns (indeed, it is just this characteristic of an orthogonally rotated factor matrix which makes it most suftable for our purpose). In all cases, the variable chosen to represent the pattern was one which had the highest loading on the pattern, but which was not loaded highly at all on the remaining patterns.

The orthogonally rotated factor matrix of these ten organizational variables in these 70 countries is exhibited in Appendix A (for convenfence, all the factor analyses of the organizational and technological variables in the three groups of countries may be found 
In the Appendix rather than in the text). It can be seen that three patterns have emerged. Let us begin with the first pattern. The organizational variable having the highest loading on this pattern is the percent of the economically active in agriculture. Although there are five other variables which have loadings of .70 or above on this factor, the percent of the economically active in agriculture has by far the highest loading; 1ts loading of -.9488 tells us that 89.3 percent of the variation in this varlable is in common with the other nine variables in this pattern. This being the case, we can choose the percent of the economically active in agriculture as the best indicator of this pattern of relationship among the ten variables.

The variable with the highest loading on the second pattern is the number of cities of one million or more in a country. It can be seen that this variable has a much higher loading on this pattern than any of the remaining nine. However, the number of cities of one million or more in a country is intimately related to the percent of the total population living in cities of 100,000 or more--the dependent variable. It would appear that the number of cities of one milIIon or more is a partial measure of the percent of the total population in cities of 100,000 or more; that is, the number of cities of one million or more describes a phenomena which is measured also by the percent of the total population in cities of 100,000 or more. Since this second pattern of variables appears to be best represented by the number of cities of one million or more, it would seem reasonable not to utilize this pattern in the regression analysis. If we did utilize this variable in the analysis, we would be faced with a situation in which one of the independent variables is a partial 
measure of the dependent variable. It. would seem best, then, not to use this second pattern.

The highest loading on the third pattern is illustrated by the percent of the economically active in electricity, gas, water and sanitary services. Its loading of .9440 means that $89 \%$ of its variation is in common with the other nine variables in this pattern. It should also be noted that the loading of this variable on the other two patterns is very sma11; this indicates that this variable is not strongly involved In the other two patterns.

The factor analysis of the organizational variables in the total of seventy countries has thus yielded three independent patterns of relationship. Since one of these patterns is best described by a variable which is also a partial measure of the dependent variable, we will have to be content with the best indicators of two, rather than three, patterns. In our regression analysis we can now utilize two independent indicators, or representatives, of the patterns of relationship among these ten organizational variables. If we add the variables representing the characteristics of the population--the annual rate of growth, and the total population--and the environment--the land area--we will have an equation of the following kind for these 70 countries:

Metropolitanism $=$ total population + the annual rate of growth + land area + the percent of the economically active in agriculture + the percent of the economically active in electricity, gas, water, and sanitary services.

\section{The Underdeveloped Countries}

The factor analysis of the ten organizational variables in the 37 underdeveloped countries yields three independent patterns of 
relationsh1p (the orthogonally rotated factor matrix may be found in Appendix B). The three variables which have the highest loadings on these three patterns are the percent of the economically active in construction (-.8369), the percent of the economically active in commerce $(-.8644)$, and the percent economically active in the total population (.9135). This means that each of these variables have $70 \%$, $75 \%$, and $83 \%$ of their variation in common with the particular pattern. Note, also, that although these three variables have the highest loadings on each of the three patterns, they are not loaded highly on the remaining two patterns; that is, each of these three variables have high loadings on only one pattern--the pattern they define, or represent.

These three variables will be thought of as defining the three patterns of relationship which emerged among the ten organizational variables. Thus, for these 37 underdeveloped countries we can add the annual rate of growth, the total population and the land area to these three variables to obtain an equation of the following form: Metropolitanism $=$ total population + the annual rate of growth + land area + percent of the economically active in construction + percent of the economically active in commerce + percent economically active in the total population

We can be assured that the three organizational variables in this equation describe independent dimensions of the relationships among all the organizational variables for these countries. As such, they are, I suggest, the best indicators of all ten of these variables.

\section{The Developed Countries}

It should be remembered that for the 30 developed countries we 
cannot only look at the ten organizational variables, but also at the six technological variables as we11. Thus, for these countries, a factor analysis of the ten organizational varlables and a factor analysis of the six technological variables may be performed. We will look at the factor analysis of the organizational varlables first.

The factor analysis of the ten organizational variables reveals three independent patterns of relationship ( the rotated factor matrix w111 be found in Appendix C). The variables having the highest loadIngs on each of these three patterns are the percent of the economicalIy active in construction $(-.8910)$, the percent of the economically active In electricity, gas, water, and sanitary services (-.8212), and the number of cities with one million or more inhabitants $(-.8175)$. Since the square of these loadings multiplied by 100 ylelds the percent of the varlation of each of the variables which it has in common with the other varlables in the pattern, we can see that these three variables have $79 \%, 67 \%$, and $66 \%$ of their variation in common with the other varlables. Again, we can note that although these three variables have the highest loadings on the three patterns, their loadings are not nearly as high on the remaining two patterns.

As was suggested in the discussion of the factor analysis of the organizational variables for the 70 countries, the number of cities of one million or more inhabitants should not be used in the regression analysis. The fact that it has again emerged as a variable best defining a pattern of relationships among these ten variables in the 30 developed countrles means that we wIll again be forced to ignore this pattern. Therefore, rather than having three Indicators of these organizational variables, we will be forced to utilize only two. If we 
now add the total population, annual rate of growth and the land area to these two representatives of the organizational variables, we have the following:

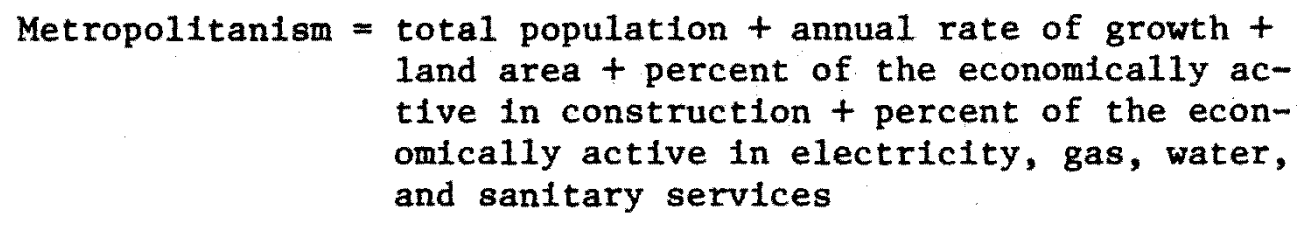

If we now turn to the factor analysis of the six technological variables for these 30 countries, we find that two distinct patterns of relationship among the variables have emerged (the rotated factor matrix w111 be found in Appendix D). The two variables which have the highest loadings on these two patterns are the number of passenger cars in use (.9517), and the production of coal (.7536). These two variables thus have $91 \%$ and $57 \%$ of their variation in common with the other five variables in the patterns. Both of these variables are loaded highly on only one of the factors.

We can think of these two variables, then, as defining these two patterns of relationship between the $\mathbf{s i x}$ technological variables for these 30 countries. They are thus the two "best" variables to utilize as indicators of technology in the regression analysis. If we now add the total population, annual rate of growth and the land area, we have the following equation:

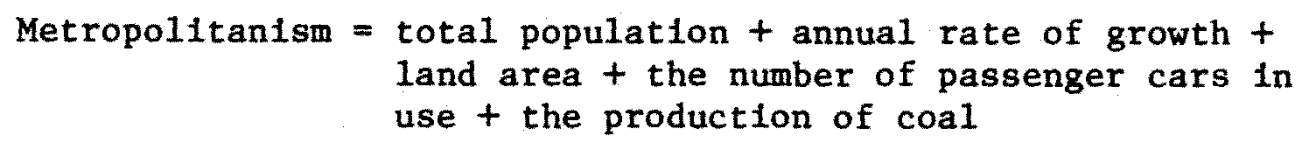
land area + the number of passenger cars in use + the production of coal

The ultimate goal of these factor analyses, of course, is to furnish us with the best indicators of the various components of the ecological complex so that they may be used in regression analysis. We are interested, then, in using the best variables for every 
component of the ecological complex. Since we are able to look at the organizational and technological variables for the 30 developed countrles, we are now able to add the total population, annual rate of growth and the land area to obtain the following equation:

$\begin{aligned} \text { Metropolitanism }= & \text { total population }+ \text { annual rate of growth }+ \\ & \text { land area }+ \text { percent of the economically ac- } \\ & \text { tive in construction }+ \text { percent of the econom- } \\ & \text { ically active in electricity, gas, water, and } \\ & \text { sanitary services + number of passenger cars } \\ & \text { in use }+ \text { the production of coal }\end{aligned}$

This is the only equation which will be composed of at least one representative of each component of the ecological complex. The organizational and technological varlables in this equation describe independent dimensions of the relationships between the organizational variables and between the technological variables. As such, they provide the best Indicators of these groups of varlables for these 30 countries.

\section{CATEGORIES OF PER CAPITA IMPORTS PLUS EXPORTS}

We now have three equations which are composed of the best indicators of the four components of the ecological complex. All the variables in these equations are, of course, what we have called "internal variables"; that 1 , they are characteristics of countries, and possible determinants of metropolitanism. The hypothesis with which we are ultimately concerned, however, is that metropolitanism In these various groups of countries is significantly effected by each country's economic exchanges with other countries. The primary measure of these exchanges are the per capita imports plus exports of the various groups of countries. We have called this sort of international interaction an "external variable". 
To each of the equations that have so far been presented, then, it w11l be necessary to add the per capita 1mports plus exports for each country. Only in this way, can our hypothesis be tested.

The per capita Imports plus exports for each country are actually derived from ten categories, or types, of imports and exports. That 1s, the per capita 1mports plus exports is a gross measure, composed of Imports and exports of ten spectflc kinds. I suggest that in the regression analysis it would be profitable to "break-up" the per capita Imports plus exports into the varlous types of Imports plus exports and utflize these. I am not suggesting that the total per capita Imports plus exports be 1gnored; rather, I am suggesting that after the total per capita Imports plus exports are utilized in the regression analysis the various component categorles of this total measure should then be used as well.

Again we are faced with the problem of determining which of the possible vartables would be best to use in regression analysis. Just as we had ten organizational variables and six technological varfables from wh1ch to choose, we now have ten types of per capita imports plus exports from which to choose. What is called for, it geems to me, is a factor analysis of the varfous categories of per captta imports plus exports. What is more, we could perform a factor analysis of the various categories for the total of 70 countries, for the 37 underdeveloped countries, and for the 30 developed countries. This would yield us, I suggest, the "best" categories of economic exchange for the three groups of countries.

Before we turn to the factor analysis in the three groups of countries, it should be explafned that nine, rather than ten, categorles of 
per capita imports plus exports were used in the factor analyses. One category--goods not classified by kind--seemed to be a "catch-all" category and, in terms of its content, was quite nebulous. Therefore, it was not included in the factor analyses of the categories. The nine categories, and their specific contents, which were included in the factor analyses are exhibited in Appendix E.

We can begin with the import-export categories for the 70 countries. The factor analysis reveals that there are three distinct patterns of relationship among these nine categories of per capita imports plus exports (the rotated factor matrix may be found in Appendix F). The categories having the highest loadings on these three patterns are the per capita imports plus exports of animal, vegetable o11, and fats $(-.8080)$, the per capita imports plus exports of food and live animals (.6886), and the per capita imports plus exports of basic manufactures (-.6995). Thus, these three categories of per capita imports plus exports have $65 \%, 47 \%$, and $49 \%$ of their variation in common with the other eight categories in the three patterns. None of these three categories have high loadings on any of the other patterns.

Just as we did with the organizational and technological variables, we may think of these three categories as being the "best" representatives of the particular pattern in which their highest loading occurs. In the regression analysis, then, these three categories will be utilized as the best indicators of the various types of per capita imports plus exports for each of the 70 countries. If we now add these three categories to the population, environment, and organization variables previously discussed, we get an equation of the following form: 
Metropolitanism = percent of the economically active in agriculture + percent of the economically active in electricity, gas, water, and sanitary services + per capita imports plus exports of food and live animals + per capita imports plus exports of animal, vegetable oil, fats + per capita imports plus exports of basic manufactures

It should be remembered that before this equation would be utilized, the total per capita imports plus exports would be put into the equation with the two organizational variables. After this was done, however, the three categories of per capita imports plus exports would replace this gross measure. In conjunction with the two organizational variables, the three categories would assure one that independent dimensions of the relationships between these nine categories were being utilized in the regression analysis.

The factor analysis of these nine categories in the 37 underdeveloped countries ylelds four patterns of relationship (the rotated factor analysis may be found in Appendix G). The four categories which have the highest loadings on these patterns are the per capita imports plus exports of beverages and tobacco $(.8346)$, the per capita imports plus exports of crude materials except fuels $(-.8731)$, the per capita imports plus exports of mineral fuels $(-.7905)$, and the per capita imports plus exports of basic manufactures $(-.8367)$. These four categories have $70 \%, 76 \%, 62 \%$, and $70 \%$ of their varlation in common with the other nine variables in the patterns. We also find that none of these four categories have significantly high loadings on any pattern besides the one on which it has its highest loading.

In the regression analysis, we can use these four categories of per capita imports plus exports as representatives of the four patterns of relationships which emerged between these nine categories for these 
37 underdeveloped countries. If we add these four categortes to the population, environment, and organization variables described previously, the following equation is obtained.

$\begin{aligned} \text { Metropolitanism }= & \text { percent economically active in the total pop- } \\ & \text { ulation }+ \text { percent of the economically active } \\ & \text { in construction }+ \text { percent of the economically } \\ & \text { active in commerce }+ \text { per capita imports plus } \\ & \text { exports of beverages and tobacco }+ \text { per capita } \\ & \text { imports plus exports of crude materials except } \\ & \text { fuels }+ \text { per capita imports plus exports of } \\ & \text { mineral fuels }+ \text { per capita imports plus ex- } \\ & \text { ports of basic manufactures }\end{aligned}$

Before this equation is used, the total per capita imports plus exports would be placed in the equation. The substitution of these four categories would provide one with a means for a more concise investigation of the effects of these independent dimensions of external economic exchange on metropolitanism.

Finally, we can look at the factor analysis of these nine categorles in the 30 developed countries. This factor analysis delineates four distinct patterns of relationship among these nine categories (the rotated factor matrix is provided in Appendix H). The four categorfes which have the highest loadings on each of the patterns are, the per capita imports plus exports of beverages and tobacco $(-.8371)$, the per capita imports plus exports of mineral fuels $(-.8310)$, the per capita imports plus exports of miscellaneous manufactured goods $(-.7489)$, and the per capita imports plus exports of basic manufactures $(-.8362)$. Put another way, these four categorles have $70 \%, 69 \%, 56 \%$, and $70 \%$ of their varlation in common with the other nine categories in each pattern. In this case once again, although these four categories have the highest loadings on each of the four patterns, they are not highly loaded on any of the other three patterns. 


\title{
CHAPTER VI
}

\begin{abstract}
AN EMPIRICAL TEST OF THE PROPOSED RELATIONSHIP BETWEEN CONTEXTUAL FACTORS AND METROPOLITANISM
\end{abstract}

\section{INTRODUCTION}

We are now ready to empirically address the proposition that International variation in metropolitanism is significantly affected by the contextual characteristics of a world-wide system of countries. If the volume of economic exchange any country has with other countries is an acceptable measure of its involvement in this system of countries, it is necessary to determine the extent to which this involvement influences the level of metropolitanism in the country under consideration.

Multiple regression analysis provides an excellent means for the investigation of the proposed relationship. Multiple regression is a statistical technique in which "... we attempt to predict a single dependent variable from any number of independent variables". (Blalock, 1972:429). Given the many factors which have been suggested to account for the existence of cities, it is clear that we must have some means to assess the relative effects of many variables on metropolitanism. Since multiple regression enables us to "control" any number of independent variables while obtaining a measure of the direct effect of one of the independent variables on the dependent 
These four categories will be used in the regression analysis as the best Indicators of the four patterns of relationship which emerged between all nine of the categorles. When these four categorles are added to the population, environment, organization, and technology variables, the equation for these developed countries takes this form:

$\begin{aligned} \text { Metropolitanism }= & \text { percent of the economically active in construc- } \\ & \text { tion }+ \text { percent of the economically active in } \\ & \text { electricity, gas, water, and sanitary services } \\ & + \text { the number of passenger cars in use t the } \\ & \text { production of coal }+ \text { per capita imports plus } \\ & \text { exports of beverages and tobacco }+ \text { per capita } \\ & \text { imports plus exports of mineral fuels + per } \\ & \text { capita Imports plus exports of basic manufac- } \\ & \text { tures + per capita imports plus exports of } \\ & \text { miscellaneous manufactures }\end{aligned}$

The total Imports plus exports will be used in the analysis before these four categories are substituted.

The factor analyses discussed in this chapter were undertaken in order that an empirical basis might be obtained for the inclusion of some variables, and not others, in the regression analysis. For this reason, little attention was given to the more general meanings these factor analyses may have. There can be little doubt that the many factor analyses describe important regularities among the variables utilized In this study; it is true that these regularities deserve more specific attention than given them here. Yet, given the purpose for which they were undertaken, this was clearly impossible. In any event, the factor analyses have provided us with a method for determining which of the many variables will be more intensively scrutinized in regression analysis. It is with this analysis that this study will conclude. We can now turn to that analysis. 
variable $e^{1}$, it will be possible to determine the direct effect of a country's volume of economic exchange with other countries on its level of metropolitanism with the internal variables held constant. Further, we will be able to compare this direct effect of the volume of economic exchange on metropolitanism with the effect of each of the internal variables when the volume of economic exchange is controlled. Another Important property of regression analysis for our purposes is that it yields a multiple correlation coefficient. We are primarily interested in how well the independent variables in the regression equation explain the varlance observed in the dependent variable. The square of the multiple correlation coefficient tells us how much of the variance in the dependent variable (In our case, metropolitanism) has been explained by the various independent variables (the internal variables, external variable, and both acting together). As a result, it will be possible to find out how much of the international variation in metropolitanism can be accounted for by the internal variables, how much by the external variables, and how much with both groups of varlables taken together.

Before we go any further, 1t would be wise to take into account the following words of caution. This study can only address a total of 70 of the world's countries. This total constitutes not quite half of the total number of countries existing in the world. As was observed in the preceeding chapter, these 70 countries may be broken

$1^{1}$ For a concise discussion of the statistical means by which control is exercised in regresston analysis, see Blalock, pp. 430-31. 
down into two groups: a group of 37 underdeveloped countries, and a group of 30 developed countries (it will be remembered that three countries were not included in the developed or underdeveloped group because they did not seem to belong in elther group). It would be incorrect, however, to view these two groups of countries as being composed of very similar members; in other words, those countries called "underdeveloped" do not compose a homogeneous group of countries. Rather, the countries in this group not only have different levels of metropolitanism, but also different internal characteristics (as we have measured them) and even different economic systems. Exactly the same thing is true for the developed countries. These countries are anything but homogeneous; Indeed, if one looks at the standard deviation of metropolitanism in these two groups of countries, it would be found that while the standard deviation was $11.89 \%$ in the underdeveloped countries, it was $14.31 \%$ in the developed ones. This indicates that in terms of their levels of metropolitanism, the developed countries are more heterogeneous than the underdeveloped ones. That 1s, while the developed countries are similar in terms of their higher Gross National Products, the levels of population concentration in these countries vary significantly. Thus, generalizations concernIng the factors which are associated with metropolitanism in these countries must not be understood as implying any sort of direct causal relationship; rather, the most that can be said, considering the diversity of the object of explanation, is that this or that factor is related elther positively or negatively to metropolitanism.

Although there is less diversity in levels of metropolitanism among the underdeveloped countries, the same limitations are relevant 
to generalizations about the relationships between the internal and contextual factors and metropolitanism in this group of countries. After al1, the object of this study is international variation in metropolitanism. This being the case, we will inevitably be forced to remaln at a falrly high level of abstraction in any conclusions which are reached. It is in this sense, and with this object in mind, that generalizations about the two groups of countries must be interpreted.

One final word of caution might be added before we turn our attention to the substantive analysis. As noted above, the object of this study is international variation in metropolitanism; thus, the majority of our attention will be directed toward the explication of the relationship between the various internal and contextual varfables and metropolitanism. It must be recognized, however, that the Internal and contextual variables are also a function of the degree and extent of metropolitanism in any particular country. Clearly, then, the internal and contextual factors cannot be viewed as causIng metropolitanism in any stralghtforward, clear-cut manner. Any relationships found between the internal and contextual factors and metropolitanism must be interpreted as Indications that some type of relationship exists between the particular variable and metropolitan1sm. Since the primary object of explanation is metropolitanism, by far the greatest amount of attention will be given to what any discovered relationship tells us about metropolitanfsm; but, insofar as no cause and effect relationship can be Implied, at least some attention wi11 be given to the Implications of the relationships for the manner in which the internal and contextual variables are influenced 
by metropolitanism.

\section{INTERNATIONAL VARIATION IN METROPOLITANISM}

The purpose of this section is two-fold. First of all, we shall look at the amount of variance in metropolitanism which can be explained by the internal variables, and by the internal and external varlables in the developed and underdeveloped countrles, and in both groups together. Secondly, it will be found that a statistical adjustment is necessary so that comparisons can be made between the three equations composed of the internal and contextual variables in each group of countries; only after this adjustment is made may we determine how much more (if any) variation in metropolitanism is explained with the addition of contextual variables to the regression equation.

It should be remembered that the square of the multiple correlation coefficient provides us with a measure of the percentage of variation in the dependent variable explained by all the independent variables in the equation. The square of the multiple correlation coefficient is often denoted as $R^{2}$. Let us begin by observing the amount of variation in metropolitanism that can be explained by the Internal variables in the total of 70 countries. Equation number 1 In Table IV lists the various internal characteristics of these 70 countries and provides their $R^{2}$ value. The value of $R^{2}$ is .243; this suggests that the four internal characteristics in this equation, taken together, explain just over $24 \%$ of the variation in metropolitanism in these 70 countries. The significance of the $R^{2}$ value should not be underestimated. Even though over three-fourths 
NINE REGRESSION EQUATIONS IN THREE GROUPS OF COUNTRIES, THE VARIABLES COMPOSING THE EQUATIONS, AND THE AMOUNT OF VARIANCE IN METROPOLITANISM EXPLAINED BY THE VARIABLES

\section{COUNTRIES}

1. $\mathrm{R}^{2}=.243$

Metropolitanism $=$ Total Population + Annual Rate of Growth + Land Area + Percent of the Economically Active in Agriculture + Percent of the Economically Active In Electricity, Gas, Water, and Sanitary Services

2. $\mathrm{R}^{2}=.290$

Metropolitanism $=$ Total Population + Annual Rate of Growth + Land Area + Percent of the Economically Active in Agriculture + Percent of the Economically Active in Electricity, Gas, Water, and Sanitary Services + Per Capita Imports Plus Exports

3. $\mathrm{R}^{2}=.357$

Metropolitanism = Total Population + Annual Rate of Growth + Land Area + Percent of the Economically Active in Agriculture + Percent of the Economically Active in Electricity, Gas, Water, and Sanitary Services + Per Capita Imports Plus Exports of Food and Live Animals + Per Capita Imports Plus Exports of Animal, Vegetable 011, Fats + Per Capita Imports Plus Exports of Basic Manufactures

\section{UNDERDEVELOPED COUNTRIES}

4. $\mathrm{R}^{2}=.422$

Metropolitanism $=$ Total Population + Annual Rate of Growth + Land Area + Percent Economically Active in the Total Population + Percent of the Economically Active In Construction + Percent of the Economically Active in Commerce

5. $\mathrm{R}^{2}=.433$

Metropolitanism = Total Population + Annual Rate of Growth + Land Area + Percent Economically Active in the Total Population + Percent of the Economically Active in Construction + Percent of the Economically Active in Commerce + Per Capita Imports Plus Exports 
TABLE IV

(continued)

\section{UNDERDEVELOPED COUNTRIES}

(continued)

6. $\mathrm{R}^{2}=.48$

Metropolitanism = Total Population + Annual Rate of Growth + Land Area + Percent Economically Active in the Total Population + Percent of the Economically Active in Construction + Percent of the Economically Active in Commerce + Per Capita Imports Plus Exports of Beverages and Tobacco + Per Capita Imports Plus Exports of Crude Materials Except Fuels + Per Capita Imports Plus Exports of Mineral Fuels + Per Capita Imports Plus Exports of Basic Manufactures

\section{DEVELOPED COUNTRIES}

7. $\mathrm{R}^{2}=.203$

Metropolitanism = Total Population + Annual Rate of Growth + Land Area + Percent of the Economically Active In Construction + Percent of the Economically Active in Electricity, Gas, Water, and Sanitary Services + Production of Coal + Number of Passenger Cars in Use

8. $\mathrm{R}^{2}=.203$

Metropolitanism $=$ Total Population + Annual Rate of Growth + Land Area + Percent of the Economically Active in Construction + Percent of the Economically Active in Electricity, Gas, Water, and Sanitary Services + Production of Coal + Number of Passenger Cars in Use + Per Capita Imports Plus Exports

9. $\mathrm{R}^{2}=.431$

Metropolitanism = Total Population + Annual Rate of Growth + Land Area + Percent of the Economically Actlve in Construction + Percent of the Economically Active in Electricity, Gas, Water, and Sanitary Services + Production of Coal + Number of Passenger Cars in Use + Per Capita Imports Plus Exports of Beverages and Tobacco + Per Capita Imports Plus Exports of Mineral Fuels + Per Capita Imports Plus Exports of Basic Manufactures + Per Capita Imports Plus Exports of Miscellaneous Manufactures 
of the variation in metropolitanism cannot be accounted for by these Internal characteristics of the 70 countries, it must be remembered that only flve internal indicators were ut111zed; with knowledge of only five of the characteristics of these 70 countries, we can account for nearly one-fourth of the variation in metropolitanism.

If one now looks at equation number 2 in Table IV, it can be seen that the total per capita imports plus exports have been added to the flve previously mentioned internal characteristics. With this contextual varlable added, the $\mathrm{R}^{2}$ is .290 ; that $1 \mathrm{~s}$, with knowledge of flve of the Internal characteristics of these 70 countries and their total volume of economic exchange with other countries, we can explain $29 \%$ of the variation in metropolitanism. If we now exclude the total per captta 1mports plus exports from the equation, and instead substitute three categories, or types, of per capita imports plus exports (see equation number 3 in Table IV), we are now able to explain nearly $36 \%$ of the variation in metropolitanism. That is, when specific kinds of imports and exports are consldered, In conjunction with the internal characteristics of the countries, we can account for well over onethird of the variation in metropolitanism.

One could repeat this type of examination for the group of underdeveloped countries and for the developed ones. Looking at Table IV in its entirety, however, two observations might be made. First of all, $48 \%$ of the variation in metropolitanism in the underdeveloped countries can be accounted for when the internal variables and the categories of external economic exchange are considered as independent variables. It would seem that metropolitanism in these 37 countries is influenced signfficantly by not only the internal characterlstics of the countries 
themselves, but also by the involvement of these countries in an international system of economic interdependence. As was suggested in Chapter III, population agglomerations in third world countries may very well depend for at least some of their support on goods and materials acquired outside the national borders. The fact that the Internal characteristics of these countries and their involvement in external relationships can explain a significant proportion of international variation In metropolitanism tends, I suggest, to support the hypothesis presented in Chapter III. At the very least, it provides us wth absolutely no reason to refect the proposed hypothesis.

The second observation that may be made concerning Table IV is directed at the 30 developed countries. Equation number 7 is of particular interest. In this equation, only the indicators for the four components of the ecological complex have been included. These six indicators can explain, however, only $20 \%$ of the variation in metropolitanism in these 30 countries. If the truly voluminous literature on the development and mantenance of cities in the Industrialized countries is an accurate summation of the varlous forces involved in city growth, it would seem that the internal characteristics of these countries would explain more of the international variation in metropolitanism than they do. I am not suggesting that the majority of the literature reviewed in Chapter II is simply incorrect; rather, I am suggesting that it is surprising, given the importance attributed to the internal characteristics of the various countries, that these characteristics can only explain a fairly small amount of variation in metropolitanism. It is clear that metropolitanism in these developed countries is a complex phenomena. St111, the fact that the internal 
variables considered in equation 7 can only account for $20 \%$ of the variance in metropolitanism may lead one to wonder just how important the internal characteristics of these countries are to the population concentrations contained within them. On the other hand, the rather small proportion of the varlation explained by these indicators may suggest that the various indicators utilized are not valid ones and therefore do not measure what they purport to. However, I would argue that the various indicators used are the most valld ones avallable, espectally when one considers the problems associated with the availability of this type of data (as discussed in Chapter IV). I certainly think that it would be a mistake to argue that the various indicators used are totally invalid; thus, the many Indicators used in this study wi11 be considered to have an adequate degree of validity.

One need not look at Table IV in any great detail to note an extremely interesting thing: the multiple correlation coefficients, in all three groups of countries, are smallest when only the internal characteristics of the countries are considered; when the contextual variable is added, the multiple correlation coeffictent increases (except in the 30 developed countries where it remains exactly the same), and, when specific categories of per capita imports plus exports are added, the $\mathrm{R}^{2}$ goes up even further. That is, no matter which group of countries is considered, the addition of the contextual, or external variables enables one to explain a greater amount of international variation in metropolitanism. It is clear that this observation lends a great deal of support to the hypothesis that a country's involvement in a world-wide system of intersocietal interdependence has a significant effect on 1ts level of metropolitanism. 
While it is very tempting to draw this conclusion from Table IV, 1t would be incorrect to do so. In order to see why this 1s so, look at the three equations for the developed countries. Equation number 7 contains seven Independent varlables. On the other hand, equation number 8 includes eight Independent variables; In this equation, one external variable has been added to the seven internal ones. Further, in equation number 9, four external variables have been added to the seven internal variables. The point is, while equation number 9 "explains" nearly $23 \%$ more of the variance in metropolitanism it also ut1lized four more independent variables to do it. A valid question is, is the increased ability of equation 9 to explain varlation in metropolitanism a result of the explanatory power of the four added contextual variables, or is it simply because four more variables have been added to the equation? That is, based on only 30 countries, will consideration of ten Independent variables invariably yleld a multiple correlation coefficient which is larger than the one ylelded by only six independent varlables, regardless of the degree to which these four additional varlables are related to the dependent variable?

It can be seen that this same question is valid when one considers the three equations in the total of 70 countries (equations 1-3) and the equations in the 37 underdeveloped countries (equations 4-6). Just as In the developed countries, as more variables are added, the amount of variation explained increases. This study is concerned, of necessity, with a fairly sma11 sample of countries, so the addition of independent variables to the regression equations will critically influence the $R^{2}$ values obtained. Indeed, Kerlinger $(1973: 618)$ has suggested that any time regression analysis is used on a sample which is less than two 
hundred, a "shrinkage formula" must be used in order to correctly interpret the multiple correlation coefficient. This "shrinkage formula" takes the following form:

$$
R_{C}^{2}=1-\left(1-R^{2}\right)\left(\frac{N-1}{N-n}\right)
$$

where $R_{c}^{2}=$ shrunken or corrected $R^{2} ; N=$ size of sample; and $n=$ total number of variables in the analysis.

Before the corrected $R^{2}$ values for equations 1-9 are presented, a very important point must be made. The $\mathrm{R}^{2}$ values in Table IV are not invalid. That is, they accurately represent the amount of variation explained by the various internal and contextual indicators which are included in the equations. The problem arises when, for instance, one attempts to compare equations 1 and 3 . There is no way of knowing how much the $11 \%$ increase in variation explained is the result of a strong relationship between the added contextual variables and metropolitanism, or how much is the result of the simple fact that three more variables have been added to the equation. Or, to take another example, equation number 3 explains $7 \%$ more variation in metropolitanism than equation number 2. Equation number 3 substitutes three categories of contextual variables for the total per capita imports plus exports; it thus uses two more Independent variables than equation number 2 . While it would be very interesting to theoretically account for the fact that three categories of contextual indicators can explain more variation in metropolitanism than the "gross" measure of external exchange, one would have no way of knowing if, and to what extent, the simple addition of two variables to the equation would effect the $R^{2}$ value obtained. As long as one does not wish to make comparisons between the various equations, however, the $R^{2}$ values in Table IV are perfectly valld. 
The problem with which we are concerned, on the other hand, demands that we do make comparisons between these various equations. Since the ultimate goal of this study is to determine the extent to which the consideration of contextual indicators helps us to explain variation in metropolitanism, the $R^{2}$ values of equations having only Internal variables in them must be compared with the $\mathrm{R}^{2}$ values of the equations with the contextual indicators added. Table V Iists the corrected $R^{2}$ values for equations $1-9$.

Inspection of Table $\mathrm{V}$ provides a somewhat different picture of the relationship between metropolitanism and the various internai and external factors. In the total of 70 countries, the least amount of variation In metropolitanism is accounted for when only the internal characteristics of the countries are considered. When the total per capita imports plus exports are added to these internal variables, it can be seen that an additional $4 \%$ of the variation can be explained. If, on the other hand, we substitute three categories, or types, of per capita imports plus exports for the total per capita imports plus exports, and add them to the internal variables, we find that we can explain $9 \%$ more of the variation in metropolitanism than if only the Internal variables are considered, and $5 \%$ more of the variation than we could if only the gross indicator of external economic exchange is used .

What does this tell us in theoretical terms? It indicates that In a fairly large group of heterogeneous countries attention to each country's involvement in economic relations with other countries enables one to account for a larger portion of variation in metropolitanism than would be possible if these external relations were ignored. 
TABLE V

CORRECTED $\mathrm{R}^{2}$ VALUES FOR NINE REGRESSION EQUATIONS

IN THREE GROUPS OF COUNTRIES ${ }^{a}$

\section{COUNTRIES}

1. $\mathrm{R}^{2}=.18$ Metropolitanism $=$ Three Components of the Ecological Complex

2. $\mathrm{R}^{2}=.22$ Metropolitanism $=$ Three Components of the Ecological Complex + Contextual Variable

3. $\mathrm{R}^{2}=.27$ Metropolitanism = Three Components of the Ecological Complex + Three Categories of Contextual Variables

\section{UNDERDEVELOPED COUNTRIES}

4. $\mathrm{R}^{2}=.31$ Metropolitanism $=$ Three Components of the Ecological Complex

5. $R^{2}=.30$ Metropolitanism $=$ Three Components of the Ecological Complex + Contextual Variable

6. $\mathrm{R}^{2}=.28$ Metropolitanism = Three Components of the Ecological Complex + Four Categorles of Contextual Varlables

\section{DEVELOPED COUNTRIES}

7. $\mathrm{R}^{2}=0$ Metropolitanism = Four Components of the Ecological Complex

8. $\mathrm{R}^{2}=0$ Metropolitanism $=$ Four Components of the Ecological Complex + Contextual Variable

9. $R^{2}=.08$ Metropolitanism $=$ Four Components of the Ecological Complex + Four Categories of Contextual Variables

a--For the specific component of the Ecological Complex and Categories of Contextual Variables included in any particular equation, refer to Table IV. 
Independently of factors Internal to the country (its population, environment, organization, and technology), the country's involvement in international trade has at least some influence on metropolitanism. Further, while consideration of all types of exchange "lumped" together enables us to explain more varlation than if only factors internal to the country are considered, consideration of only some types, or categories, of exchanges enables us to explain even more variation. Thus, in these 70 countries the use of only three types of external economic exchange enables one to explain more variation in metropolitanism than if all ten types are considered together. The importation and exportation of food and live animals, animal, vegetable o11, fats, and basic manufactures can then be suggested to be those particular types of economic exchange which are most strongly related to metropolitanism in these 70 countries. The implication is, as far as metropolitanism is concerned, that some kinds of contextual relationships are more important to the ability of populations to concentrate themselves than others. When one considers these particular kinds of contextual indicators, one's ability to account for international variation in metropolitanism increases. This finding lends support to the hypothesis advanced in Chapter III. Let us now turn our attention to the $R^{2}$ values for the 37 underdeveloped countries, as exhibited in Table V. One finds that the greatest amount of variation in metropolitanism can be explained when only the internal variables are considered. In fact, $1 \%$ less variation may be explained in metropolitanism when the total per capita imports plus exports are added to the equation, and $3 \%$ less variation is explained when specific categories of per caplta imports plus exports are considered. This is exactly the opposite of what was found when the total 
of 70 countries were the object of analysis.

How may this finding be interpreted? First, it seems to indicate that the addition of contextual variables does not "buy" one any variation. That is, the consideration of contextual factors does not enable one to increase his explanatory power; indeed, it tends to decrease it. Even though the $R^{2}$ values for these equations have been "corrected" to take Into account the addition of Independent variables, these variables do not explain enough additional variation in metropolitanism to increase the $R^{2}$ value; it appears that they explain so little additional variation in metropolitanism that their inclusion has actually "depressed" the total amount of variance explained. In essence, they do not "buy" enough additional variation to justify their inclusion in the equation. Since the addition of more independent variables cannot mathematically reduce the percentage of variance explained, the corrected $\mathrm{R}^{2}$, which is an approximation, or conservative estimate, cautions us that the ratio of number of variables to number of cases is too high here to warrant any meaningful conclusions, If this general result were obtained with a larger number of cases (1.e., a larger number of countries), it would indeed be theoretically interesting.

It was argued in Chapter III that the cities of the third world depend for their support on extra-societal economic exchange; that is, the very high growth rates of these countries, and the large clties within them, make it necessary that these cities become integrated into an International system of Interdependence. If this were so, we would expect that the addition of the contextual varlables would significantly Increase the amount of varlation in metropolitanism that could be explained. Recognizing that little validity can be attached to the 
corrected $\mathrm{R}^{2}$ value in this case, the hypothesis advanced in Chapter III does not appear to be confirmed for the group of underdeveloped countries.

If we look, finally, at the group of 30 developed countries, we notice that the $R^{2}$ values for two of the three equations are zero, and the value for the third equation is very nearly so. In other words, the "corrected" square of the multiple correlation coefficient tells us that none of the variation in metropolitanism in this group of countries is explained by the various internal characteristics of the countries, or by the addition of the total per capita imports plus exports of each country; if we add the various types of per capita imports plus exports of each country to the internal characteristics, we find that we can explain some very small part of the variation in metropolitanism. Now, strictly speaking, from Table IV we saw that the internal and contextual variables do in fact explain a certain amount of the variation in metropolitanism in this group of countries. But, in order to make comparisons between the three equations it was necessary to "correct" the $\mathrm{R}^{2}$ value. What the values for this group tell us then, is that 30 countries constitute too small a "sample" from which to assess the effects of seven to eleven independent variables on a dependent variable. In other words, the ratio of variables to cases is too high with the result that the corrected $\mathrm{R}^{2}$ 11terally shrinks away to nothing. We are left, unfortunately, in the position of being unable to determine whether or not the addition of contextual variables enables us to explain a greater amount of the international variation in metropolitanism in these 30 developed countries.

Consideration of Table $\mathrm{V}$ appears to lead to the conclusion that 
the addition of contextual variables to the internal ones does not necessarily enable one to explain more of the varfation in metropolitanism. However, Table V may be seen to support the proposed hypothesis in the following way. If one were to develop a theory which purported to explain international variation in metropolitanism only within a group of underdeveloped or developed countries, it may not be necessary to consider the external relations each country in the group has with other countries. That is, a theory of variation in urbanization within a group of countries which are fairly homogeneous with respect to their gross national products need not be sensitive to the external trade relations of each country in the group. Within the developed or underdeveloped group of countries, such sensitivity to external trade relations does not enhance one's ability to explain variation in metropolitanism. On the other hand, if the developed and underdeveloped countries are combined into one large group of countries and one were to elaborate a theory of variation in metropolitanism for this diverse group, then a country's external trade relations with other countries is a significant factor which must be included in the theory. In other words, when country's which are diverse in terms of their gross national products are considered as a group, a comprehensive theory of variation in metropolitanism should include each country's involvement in international trade relations. The fact that in the combined group of 70 countries the corrected $R^{2}$ increased with the inclusion of the contextual variable or variables indicates that when developed and underdeveloped countries are considered as a group the variation in metropolitanism within this diverse group is better explained when each country's volume of economic exchange with other countries is included. Insofar as the focus of this 
study has been on the world as a whole (although the problem of missing data has greatly restricted this focus), it is suggested that, interpreted in this way, Table $V$ tends to enhance the applicability of the hypothesis advanced in Chapter III to a wide range of the world's countries.

Thus, while the "uncorrected" multiple correlation coefficients reveal that the inclusion of the contextual varlables always increases the proportion of variation in metropolitanism which we can explain, the "corrected" multiple correlation coefficients lead us to a more ambivalent interpretation. Indeed, the interpretation provided of these multiple correlation coefficients might be viewed as resulting from the statistical method utilized rather than from theoretically meaningful differences in international variation in metropolitanism; that is, the corrected $\mathrm{R}^{2}$ values might be viewed as "artifacts" of the statistical methods used. While the author does not personally subscribe to this view, it is only fair to point out that such a view may not be totally invalid. If the reader is suspicious of the validity of the correction procedure, he is welcome to disregard it, and the results it yields, and to interpret the uncorrected multiple correlation coefficients. Such an interpretation very strongly supports the hypothesis that consideration of international trade increases one's ability to explain international variation in metropolitanism in developed, underdeveloped, or in a combined group of countries. Those who choose to interpret the uncorrected multiple correlation coefficients have, at least, been warned of the dangers of such interpretation.

Let us, for a moment, refer back to Table IV. This table enabled us to determine how much of the total variance in metropolitanism we can 
explain by the utilization of the various components of the ecological complex and the contextual variables. Although the various equations In Table IV cannot be directly compared to one another without the application of a "correction" procedure, they do suggest the proportion of total variance in metropolitanism accounted for by the groups of internal and contextual variables. For example, equation 3 accounts for nearly $36 \%$ of the total variation in metropolftanism among the total of 70 countries; thus, this equation cannot explain over $64 \%$ of the total variation. Now, this particular equation is composed of two population variables, an environment variable, two organization variables, and three categories of contextual variables. An important question is, what is the independent contribution of the population, environment, organization, and contextual variables to the total variation in metropolitanism in this group of 70 countries? That is, of the total variation in metropolitanism which exists in these 70 countries, what part can be attributed to the various components of the ecological complex and the contextual variables?

Table VI provides this information. 2 Inspection of Table VI indicates that for the combined group of 70 countries, the largest independent contribution to the total variance in metropolitanism is made by the organizational component of the ecological complex. We can also note that the population component makes a negative independent contribution

2 The values in Table VI were derived by taking the zero-order correlation of any particular variable with metropolitanism, and multiplying this by the standardized regression coefficient of the particular variable. When two or more variables existed to define any component of the ecological complex, the resulting products of the above described operation for each variable were summed. 


\section{TABLE VI}

INDEPENDENT CONTRIBUTIONS* OF FOUR COMPONENTS OF THE ECOLOGICAL COMPLEX, AND THE CONTEXTUAL VARIABLE

AND CATEGORIES OF CONTEXTUAL VARIABLES, TO TOTAL VARIANCE

IN METROPOLITANISM, IN THREE GROUPS OF COUNTRTES ${ }^{a}$

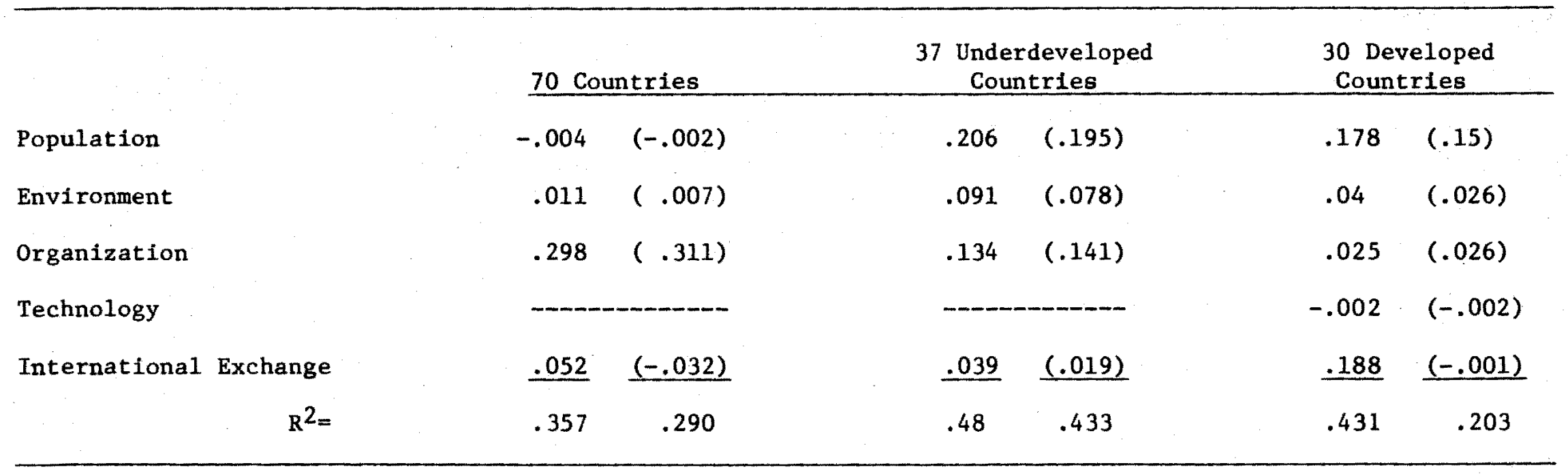

*-Values in the table are proportions.

a--The values in parentheses denote the independent contribution of the Population, Environment, Organization, and Technology components and the total per capita imports plus exports to the total variance in metropolitanism when the total per capita imports plus exports, rather than the various categories of per capita imports plus exports, are considered in the equation. In order to determine which specific variables represent the four components of the ecological complex and the categories of international exchange in the equations for the three groups of countries, refer to Table IV. 
to the total variance, regardless of whether the various categories of economic exchange or the total economic exchange are considered in the equation; that is, the characteristics of the populations in these 70 countries tend to depress, or suppress, the multiple correlation coefficient. Further, it can be noted that the independent contribution of the total per capita imports plus exports also is negative. On the other hand, the largest independent contribution to total variance in metropolitanism is made by the population component in the 37 underdeveloped countries, while the organization component makes much less of an independent contribution than 1 toes in the total of 70 countries. In the 30 developed countries, the largest independent contribution is made by the various categories of international exchange, followed closely by the population component of the ecological complex.

What significance may be attached to these findings? The fact that nearly $30 \%$ of the total variance in metropolitanism in the 70 countries can be attributed to the organizational component suggests that the distribution of the labor force in these countries is significantly related to metropolitanism. If one observes the particular indicators which define the organizational component of the ecological complex for these 70 countries, it will be noted that the percent of the economically active in agriculture is one such indicator. The percent of the economically active in agriculture is clearly inversely related to the proportion of the total population in cities of 100,000 or more. However, it is not the obverse of our measure of metropolitanism; it is concelvable that a country could have a small percentage of its labor force in agriculture and a very small proportion of its population in large cities. Still, the inverse relation between the percent in 
agriculture and metropolitanism is strong enough that the percent in agriculture must not be conceived as a cause of metropolitanism. It is argued, however, that the percent in agriculture is highly related to metropolitanism; Indeed, the large Independent contribution of the organization component to variance in metropolitanism is accounted for primarily by the percent in agriculture. Thus, insofar as this study is oriented toward examining those factors which w111 help us to explain international variation in metropolitanism, the percent of the labor force in agriculture is a significant factor which must be taken Into account. As long as one does not view this significant relation in causal terms, its Importance will not be misunderstood.

The most important finding for these 70 countries, taken as a group, is that the distribution of the labor force makes the largest independent contribution to the total variance in metropolitanism. It can be seen that the independent contribution of the organization component is much larger than the independent contribution of international exchange; this is so whether or not the various categories of international exchange or the total measure of International exchange are in the equations. This implies that the division of labor in this group of countries is more highly related to metropolitanism than is the involvement in an international system of exchange. Since this group of countries is composed of the underdeveloped and developed countries, this Indicates that for an economically heterogeneous group of countries, the distribution of the labor force in varlous activities is more importantly related to metropolitanism than is the trade with other countries. However, as we saw in Table V, the addition of the contextual variables enabled us to explain more of the variance in metropoli- 
tanism in these 70 countries. While this previous finding appears to contradict the finding now under discussion, it actually does not.

Table $V$ told us that the addition of the indicators of economic exchange helps us account for more variance in metropolitanism than we could if we did not consider these indicators; once we have explained all the variance we can in this manner, we now find that the group of indicators which makes the greatest independent contribution to this total variance are the organizational ones, and not the contextual ones. Thus, in order to explain the greatest amount of variance in metropolitanism in these 70 countries one must consider the economic exchange of each country with other countries. However, the contextual indicators do not make the largest contribution to this total amount of variance which we have explained. As long as one is aware of the different type of question which is being asked in each case, the apparent contradiction vanishes.

One further comment may be made concerning these 70 countries. Table VI 11lustrates that the independent contribution of the population component makes a negative Independent contribution to the total variance in metropolitanism. The population indicators in the equations have functioned to depress the total amount of varlance accounted for in metropolitanism. Independently of the other components of the ecological complex and the indicators of international exchange, the indicators of the population component in these 70 countries do not make a positive contribution to our ability to explain metropolitanism. However, when viewed as operating in conjunction with the other indicators in the equation, their addition to the equation cannot depress the magnitude of the multiple correlation; that is, when the population indi- 
cators operate in conjunction with the other indicators in the equation they will elther operate to Increase the amount of variance explained or will have no effect on 1t. Their independent contribution, however, is negative.

The magnitude of the independent contribution of the population component is, it can be noted, very sma11. This suggests that the characteristics of the populations in this group of 70 countries are only minimally related to metropolitanism. In fact, the magnitudes of this component are so small that one might reasonably argue that the size of the population and its rate of growth have no significant relationship at all with metropolitanism. The fact that the independent contribution of this component is negative further indicates that its relationship with metropolitanism enables us to explain 11ttle of the international variation in metropolitanism in this group of countries.

If we now turn our attention to the 37 underdeveloped countries it can be seen that the population component makes the largest independent contribution to total variation in metropolitanism. While the population indicators made only a very small independent contribution when the underdeveloped and developed countries were considered together, the characteristics of the population are much more highly related to metropolitanism when only the underdeveloped countries are considered. Further, while the organization component made the largest independent contribution in the total of 70 countries, its independent contribution is much less in the underdeveloped countries. Just as in the total of 70 countries, however, the independent contribution of international exchange is very small in the underdeveloped countries.

It will be remembered that in both Chapters II and III it was 
observed that the high levels of population growth and the large sizes of the populations in the underdeveloped countries account for much of the growth and persistence of large cities in these countries. Table VI substantiates this view by illustrating that independently of the other characteristics of the country the size of the population and its rate of growth are strongly related to metropolitanism. It should further be remembered that much of the 1iterature reviewed in Chapter II suggests that many of the underdeveloped countries are "over-urbanized": that levels of population concentration exist in these countries which cannot be accounted for simply in terms of labor force characteristics and activities which, in the West, have been associated with large population concentrations. The fact that the independent contribution of the population component to total variance in metropolitanism is larger than the independent contribution of the organization component lends, I would argue, at least some support to the notion that in this group of underdeveloped countries the characteristics of the population are more important influences on metropolitanism than the degree, or type, of division of labor. The over-urbanization thesis, then, does seem applicable to this group of underdeveloped countries.

The situation is different in the 30 developed countries. In this group the organization component makes only a small independent contribution to total variance in metropolitanism. As compared to the independent contribution of the organization component in the underdeveloped and the combined group of countries, the independent contribution of this component in the developed countries is very small. The 1iterature reviewed in Chapter II indicates that the characteristics of the labor forces in the developed countries have traditionally been assoclated with 
the development and persistence of large cities. Our findings for this group of developed countries, on the other hand, tell us that the relationship between various types of specialized activity and metropolitanism is very small. One might conjecture that while the characteristics of the labor forces of the developed countries were significantly related to the growth of large cities as these countries were developing, now that these countries are, for the most part, developed, the relationship between the characteristics of the labor forces and metropolitanism is neither as direct nor important as it might have been in the past. It might also be that the population concentrations which now exist in these developed countries are so diversified that any particular indicator of specialized activity will not, statistically at least, be highly related to them. In any event, the organization component of the ecological complex makes only a very small contribution to the total variance in metropolitanism in this group of countries.

On the other hand, the largest independent contribution to total variance in metropolitanism is made by the various categories of international exchange. This suggests that metropolitanism in these countries is strongly related to each country's involvement in trade relations with other countries; indeed, this relationship is stronger than that between metropolitanism and any of the "internal" characteristics of the country itself. However, the relationship between metropolitanism and the total volume of economic exchange is nearly non-existent. The total amount of international trade is, apparently, much too broad an indicator of involvement in the international system; that is, it does not allow for the specification of important relationships between various types of international trade and metropolitanism. By lumping 
all types together the differential effects of the various types no doubt "cancel-out" one another. When these particular types are considered separately, the relationships between them and metropolitanism are allowed to emerge.

The independent contribution of the population component is nearly as large as the independent contribution of the categories of international exchange. Apparent1y, metropolitanism in these developed countries must be understood in relation to the size and growth of the national populations. However, differences in the characteristics of the population are not as important as the differential involvement of these countries in an international system of economic exchange.

Given the fact that most theorles of the emergence and persistence of cities consistently argue that such things as the division of labor, technological development, distribution of resources, and demographic characteristics of the population are the most significant factors in the process (as we saw in Chapter II), the finding that the economic interactions with other countries make the largest contribution to variance in metropolitanism in the developed countries is somewhat surprising. Further, it is astonishing to note that in these 30 countries the technological component makes no contribution to the total variance in metropolitanism. In fact, the independent contribution of the technology component is negative, indicating that it is of 1ittle help in enabling us to explain international variation in metropolitanism in these developed countries.

How might one account for the fact that the various categories of international exchange make the largest independent contribution to the total variance in metropolitanism? The 30 countries which make up this 
group have far higher standards of living, as measured by their per capita gross national products, than the 37 underdeveloped countries and the combined group of 70 countries. A high standard of living generally means that the population has access to a great diversity of material goods. When these populations reside in large cities we could say that these agglomerations demand that many diverse products be acquired from many sources. The fact, then, that the various categories of per capita imports plus exports make a large contribution to the total variance in metropolitanism leads us to the view that the cities in these countries rely on economic exchange with other countries to maintain the standards of living of their populations. These sources of needed materials are even more important to the existence of large cities in these countries than the characteristics of the population itself, its division of labor, or its technology. This finding lends support to the hypothesis advanced in Chapter III.

\section{INDEPENDENT EFFECTS OF INTERNAL INDICATORS ON METROPOLITANISM}

We now have some idea of how well the internal factors, the external factors, and both types of factors acting together, can account for international variation in metropolitanism. Further, Table VI has provided us with a general idea of the manner in which the various components of the ecological complex and the contextual variables contribute, independently of one another, to the total variance in metropolitanism; this table, then, has given us a conceptual clue as to what the components of the ecological complex and the contextual categories, as groups of specific indicators, can tell us about variance in metropolitanism. 
The question we have been addressing in the preceeding section is this: how strong is the degree of association between the various internal and contextual indicators and metropolitanism? That is, are the various internal and contextual indicators associated with metropolitanism and, if so, how strong is this association? In this section, on the other hand, we are going to address a different question: what is the direction and magnitude of the effect of each of the specific indicators which make up the various components of the ecological complex? The type of analysis which will be pursued in this section seeks to assess the manner and extent to which particular indicators exert an influence on metropolitanism regardless of the amount of total variance which is explained by all of these indicators acting together. Thus, even though in the preceeding section we discovered that the addition of the contextual variables in the underdeveloped countries did not enable us to explain any additional variance in metropolitanism, a comparison of the relative effects of each variable involved in those equations is still of interest. This is so primarily because the analysis of the direction and magnitude of the effect of one variable upon another is a fundamentally different question than the strength of association between one or more variables and another. For example, it is quite possible that one or more variables could be added to a regression equation and not enable us to explain any additional variance in the dependent variable; however, the variable or variables which are added may still have some effect on the dependent variable. It is for this reason that the type of analysis presented in this section may yield us much important information.

In this section, then, we will concentrate on: the manner in which 
the specific empirical indicators of the components of the ecological complex Influence metropolitanism. Th1s w111 be done when only Ind1cators of the components of the ecological complex are considered in the equation, and when the contextual indicators are added.

The utflization of regression analysis enables one to obtain a measure of the effect of each of the independent variables on the dependent varlable, while the remalning independent varlables in the equation are held constant. Thus, one obtalns a measure of this type for each of the independent varlables in the equation. This measure is often called a "partial slope". Blalock (1972: 452) tells us that these partial slopes

...can be interpreted as the hypothetical change that would occur In the dependent variable if one of the Independent varlables were to change by one unit and If the other independent varlables were to remain constant. This can therefore be interpreted as a measure of the direct effect of the independent variable on the dependent variable; If the partial slope is zero, this would Imply no direct effect.

Since the units of change in the dependent varlable given by the partial slopes vary according to the units in which the various independent var1ables have been measured, It is necessary to "standardize" these partial slopes so that they are comparable from one independent varlable to the next. ${ }^{3}$ When these partial slopes have been standardized, they are often called "beta welghts", and represent the change in standard deviation units of the dependent variable 1 f the independent variable under consideration were to change by one standard deviation unft. Thus, a beta

3 the standardization of the partial slopes amounts to dividing the standard deviation of the independent varlable under consideration by the standard deviation of the dependent varlable and multiplying the result by the unstandardized regression coefficient. 
weight of . 50 would tell us that for every change of one standard deviation unit in our independent variable we can expect a change of one-half of one standard deviation unit in the dependent variable if the other independent variables are held constant.

A word of caution must be inserted at this point. Although this section is directed toward the analysis of the independent effects of the various internal and contextual indicators on metropolitanism, it should be clearly understood that no causal interpretations of these effects are suggested. As close attention to the preceeding paragraph reveals, the type of effect we will be observing is one which expresses the "form" of the relationship between two variables; the beta weights tell us what rate of change in the dependent variable is associated with a given rate of change in the independent variable. Quite often, the form of the relationship expressed by the beta weights are interpreted as the extent to which the independent variable causes change to occur in the dependent variable. However, one need not view the rates of change revealed by the beta weights in such a deterministic fashion. All one really need do is observe that the dependent variable is likely to change in value if the independent variable were to change by a certain quantity. Clearly, the problem at hand is much more complex than a simple cause and effect relationship would imply; metropolitanism is certain to effect the characteristics of the population, its activities, its environment, its technology, and its ability to engage in international trade. Yet, since the object of this study is to explain, or account for international variation in metropolitanism, our greatest attention will be upon the manner in which the internal and contextual characteristics effect metropolitanism. It should constantly be remembered, 
however, that the observed effect of any factor upon metropolitanism is certainly influenced by the effect of metropolitanism on the particular factor.

Table vII 1llustrates the independent effect of each of the Indicators of the components of the ecological complex when only they are considered, and when the contextual variables are added. It thus gives us an 1dea of the extent to which the internal characteristics of each country influence the level of metropolitanism, both by themselves and when the contextual variables are held constant.

\section{The Combined Group of 70 Countries}

We might begin by looking at the independent effects of the various empirical indicators of the ecological complex on metropolitanism in the combined group of 70 countries. One of the first things that strikes one is that four out of the five indicators seem to have little effect on metropolitanism; with the exception of one of the organization indicators, the percent of the economically active in agriculture, the indicators of the components of the ecological complex in these 70 countries have only a minimal influence on metropolitanism. It is even more interesting to note that this is true whether or not the contextual variables are held constant; even when the effects of a country's involvement in an international system of economic exchange are controlled so as not to distort any relationship between these four internal variables and metropolitanism, it can be seen that only a very slight relationship exists between these factors and metropolitanism.

More specifically, it can be seen that two characteristics of the populations of these countries, their size and their annual rates of 
TABLE VII

INDEPENDENT EFFECTS OF INDICATORS OF THE COMPONENTS OF THE ECOLOGICAL COMPLEX ON METROPOLITANISM WHEN THE INDICATORS OF THE COMPONENTS ARE CONSIDERED ALONE, AND WHEN CONTEXTUAL VARIABLES ARE ADDED, IN THREE GROUPS OF COUNTRIES ${ }^{\mathrm{a}}$

70 COUNTRIES

1. Metropolitanism = Population + Environment + Organization

Total Population--

Annual Rate of Growth--

Land Area--

Percent of the Economically Active in Agriculture--

Percent of the Economically Active in Electricity,

Gas, Water, and Sanitary Services--

2. Metropolitanism $=$ Population + Environment + Organization + Contextual Variable

Total Population--

.016

Annual Rate of Growth--

.036

Land Area--

.072

Percent of the Economically Active in Agriculture--

$-.659$

Percent of the Economically Active in Electricity,

$-.061$

Gas, Water, and Sanitary Services--

$$
-.061
$$

3. Metropolitanism $=$ Population + Environment + Organization + Categories of Contextual Variables

Total Population--

Annual Rate of Growth--

Land Area--

Percent of the Economically Active in Agriculture--

Percent of the Economically Active in Electricity, Gas, Water, and Sanitary Services--

\section{UNDERDEVELOPED COUNTRIES}

4. Metropolitanism $=$ Population + Environment + Organization

Total Population--

Annual Rate of Growth--

Land Area--

Percent Economically Active in the Total Population-- .011

Percent of the Economically Active in Construction-- $\quad .104$

Percent of the Economically Active in Commerce-- 
TABLE VII

(continued)

37 UNDERDEVELOPED COUNTRIES

BETA WEIGHT

(continued)

5. Metropolitanism $=$ Population + Environment + Organization

+ Contextual Variable

Total Population--

Annual Rate of Growth--

Land Area--

Percent Economically Active in the Total Population--

Percent of the Economically Active in Commerce-- 405

6. Metropolitanism = Population + Environment + Organization + Categories of Contextual Variables

Total Population--

Annual Rate of Growth--

Land Area--

Percent Economically Active in the Total Population--

Percent of the Economically Active in Construction--

Percent of the Economically Active in Commerce--

30 DEVELOPED COUNTRIES

7. Metropolitanism $=$ Population + Environment + Organization + Technology

Total Population--

Annual Rate of Growth--

$-.196$

Land Area--

.267

Percent of the Economically Active in Construction--

.046

Percent of the Economically Active in Electricity,

Gas, Water, and Sanitary Services--

$-.146$

Production of Coa1--

$-.705$

Number of Passenger Cars In Use--

.000

8. Metropolitanism- $=$ Population + Environment + Organ $1-$ zation + Technology + Contextual Variable

Tota1 Population--

Annual Rate of Growth--

Percent of the Economically Active in Construction-- 
TABLE VII

(continued)

\section{DEVELOPED COUNTRIES \\ (continued)}

BETA WEIGHT

Percent of the Economically Active In Electricity,

Gas, Water, and Sanitary Services--

Production of Coal--

$-.705$

Number of Passenger Cars in Use--

9. Metropolitanism = Population + Environment + Organization + Technology + Categories of Contextual Variables

Tota1 Population--

Annual Rate of Growth--

Land Area--

Percent of the Economically Active in Construction--

Percent of the Economically Active in Electricity,

Gas, Water, and Sanitary Services--

Production of Coal--

$-.796$

Number of Passenger Cars in Use--

.000

a--For the specific Categories of Contextual Variable included in any particular equation, refer to Table IV.

growth, have thelr largest effects on metropolitanism when only the remaining components of the ecological complex are controlled, and the contextual indicators are not considered at all. When the international economic exchanges of these countries are controlled, these two characteristics of the populations have an even smaller effect on metropolitanism. Th1s suggests that in this diverse group of 70 countries, economic exchanges with other countries are one way in which the effects of population size and growth become less important to the level of metropolitanism attained. That is, a country's economic trade with other countries is a factor which depresses the influence of the characteristics of the population on metropolitanism. 
The positive relationship which exists between these characteristics of the population and metropolitanism would seem to suggest that in these 70 countries large population agglomerations are associated with, or related to, the growth of the populations and their total size. It would seem that large cities, at least to some extent, encourage population growth in these 70 countries. Table VII tells us, however, that if these countries could no longer trade with other countries (when contextual variables are controlled), the extent of metropolitanism would not influence population growth and population size as positively.

The effect of a country's land area on metropolitanism can also be observed to decrease when the contextual variables are controlled. A1though the relationship between land area and metropolitanism, as illustrated by the beta weight, is very sma11, this signifies that the environment of these countries is less of an influence on metropolitanism when economic exchange with other countries is not allowed to operate. As we saw in Chapter. II, the city and its environment, or hinterland, are intimately interdependent. This intimate interdependence may be illustrated by the fact that the influence of land area on metropolitanism remains relatively constant; that is, regardless of whether only the other internal factors are controlled, or whether the contextual factors are also controlled, the influence of land area on metropolitanism is very much the same. The fact that the magnitude of this influence is surprisingly small may suggest that our indicator of the environment, total land area, is not the most accurate measure of a country's environment. While this may be possible, about all that can be said is that it was the best indicator available to us. 
The relationship between one organizational characteristic of the countries, the percent of the economically active in electricity, gas, water, and sanitary services, and metropolitanism is, however, very different. First of a11, we can note that this organlzational characteristic of a country is related to metropolitanism in a negative way; that is, as more of the labor force in these countrles are engaged in these sorts of activities, we could expect that the level of metropolitanism would decrease. Insofar as electrical services and other utflity-oriented services measured by this variable are generally of the greatest Importance in large cities, the negative influence of this vartable is surprising. What is most significant, however, is that this negative relationship becomes greater when the contextual factors are statistically controlled. This tells us that when a country's economic exchanges with other countries are taken into account as an influence on metropolitanism, this type of organizational characteristic of these countries is related to metropolitanism in a negative fashion.

On closer inspection, the negative relationship between this variable and metropolitanism may not be as surprising as it first appears. If we think of this varlable as measuring the proportion of the labor force in utility-related occupations, then what we are being told is that as more individuals are employed in these occupations high levels of population concentration will decline. It would not be unreasonable to suggest that utilities allow, or encourage, a certain degree of decentralization of the population. Electrical services, for example, make it possible for individuals to reside in areas that previously may have been considered to be too 1solated. Likewise, the increase of sanItary services may make it feasible for man to inhabit places which had 
formerly been considered too "primitive".

I am certainly not arguing that an increase in labor force involvement in utility-related occupations causes decentralization; rather, I am simply stating that an increase in this type of organized activity is likely to be related to an increase in population decentralization. That this sort of relationship becomes stronger when the contextual variables are controlled indicates that decentralization may occur more rapidly when International trade is taken into account.

Without a doubt, the most significant relationship which emerges in these 70 countries is that between another organizational characteristic, the percent of the economically active in agriculture, and metropolitanism. As has been noted previously, the percent in agriculture is strong1y inversely related to metropolitanism; because of this, it must not be thought that the percent of the economically active in agricultural causes an increase or decrease in metropolitanism in any deterministic fashion. However, it is clear that these two characteristics of any society are strongly related. This being the case, it is important that we look at the form which this relationship takes, and its implications for population agglomeration in these 70 countries.

Table VII reveals that a negative relationship exists between the percent of the economically active in agriculture and metropolitanism. It should not surprise us that as the percent of the labor force in agriculture increases, the proportion of the total population living in cities of 100,000 or more decreases. What is more important, however, 1s that when the contextual variables are controlled this inverse relationship becomes much stronger. This might be explained in the following way. City populations must be supported by their "hinterlands". Quite 
often these hinterlands are agricultural areas. As was argued in Chapter III, however, it is often the case that these agricultural hinterlands are incapable of completely supporting city populations. When this happens, the country may be forced to engage in international economic exchange in order to support their cities. In effect, the hinterlands of these cities become the agricultural areas of other societies. Now, when this external economic exchange is statistically controlled, we find that the proportion of the labor force engaged in agricultural activities has a greater negative effect on the proportion of the total population living in big cities. If external economic exchange is one way in which city populations are supported, this is exactly what we would expect to happen. That is, if the effects of international economic exchange on metropolitanism could somehow be set aside, the effect of that portion of the labor force which supplies city populations with the materials they need to survive would almost certainly be seen to be very strong. Another way of saying the same thing is that if suddenly $a^{*}$ country could no longer trade with other countries, the number of people within that country producing agricultural materials would more closely influence the number of individuals who could live in large cities.

\section{The Underdeveloped Countries}

A cursory inspection of Table VII will reveal that there are six internal indicators which have been used in the regression equations in the 37 underdeveloped countries: two population indicators, one environment indicator, and three organization indicators. It can also be seen that, with two exceptions, the magnitude of the relationship between these indicators and metropolitanism increases when the categories of contextual variables are controlled in these equations. 
The two exceptions to this generalization define the population component of the ecological complex--the total size of the population and its annual rate of growth. Let us consider the annual rate of growth first. We might remind ourselves that one of the most important characteristics of the underdeveloped countries is their very high rates of growth. Indeed, if the reader will compare Appendix I with Appendix $\mathrm{K}$, it will be noted that the annual rates of growth of the 37 underdeveloped countries, are, in general, much higher than the annual rates of growth of the 30 developed countries. As we might expect, then, a very strong relationship exists between the annual rates of growth of these countries and metropolitanism. When the division of labor, the environment, and the size of the populations of these countries are controlled, the relationship between population growth and metropolitanism is strongest; if we now add the contextual indicators to those factors being statistically controlled, we find that the growth of the populations in these countries is related to metropolitanism less strongly. This observed weaker relationship suggests that while the growth of the population has a strong effect on metropolitanism, its effect is intimately intertwined with the effects of other factors as we11. That is, while the growth of the population in underdeveloped countries encourages rising levels of population concentration, it does so in concert with other factors which describe the country's economic interactions with other countries. When these contextual factors are controlled, the relationship between population growth and metropolitanism becomes less intense.

The above comments should not be understood to imply that the annual growth of population in these countries causes metropolitanism. It is quite possible that the existence of large cities in these countrles 
is a factor which contributes to the high growth rates observed. It could be plausably argued that a sort of interactive effect exists between the annual rate of growth and metropolitanism: that a high degree of metropolitanism will promote a high rate of growth. If this is in fact the case, I would argue that the most significant comment which might be made, for our purposes at least, is that the intensity of this interactive effect is influenced by the international trade in which each country engages. As we saw above, when the contextual factors are controlled, the relationship between the annual rate of growth and metropolitanism becomes weaker. Even if, then, high levels of metropolitanism encourage high rates of population growth, international trade is a factor which influences the extent to which this will take place.

It can be seen that the absolute size of the populations of these countries is more strongly related to metropolitanism than the growth of these populations. However, while the growth of these populations is positively related to metropolitanism, the absolute size of these populations is negatively related to metropolitanism. What is more, the negative influence of population size does not decrease when the various categories of contextual variables are controlled along with the indicators of the components of the ecological complex. How might this finding be interpreted?

Once again, let us look at Appendix I. It can be seen that those countries having comparatively small populations also have comparatively small annual rates of growth. For example, Gabon, Barbados, Liberia, Mauritius, Malta, and Cyprus all have relatively small populations and relatively small annual rates of growth. Exceptlons to this generalization are Guyana, Surinam, and Fiji. The point is, that in general larger 
populations grow faster than smaller ones.

Now, if this general observation is valid, what does it tell us about the manner in which the population size of an underdeveloped country is related to its level of metropolitanism? We have already seen that the growth of the populations in these countries helps to "feed" the growth of large cities. If we note in Appendix I that the vast majority of our underdeveloped countries have large populations and large annual rates of growth, I would suggest that in these countries a point is reached at which population growth results in populations so large that their concentration in cities is discouraged. That is, the fact that large populations grow very quickly leads us to argue that while this growth may Independently be associated with increases in metropolitanism, the Independent effect of the total population size on metropolitanism is negative. If our "sample" of underdeveloped countries were composed of countries with small total populations and small rates of growth (such as those 11sted above), it is quite possible that both the annual rates of growth of these populations and their absolute sizes would be positively assocfated with metropolitanism. I would argue that in this type of country the relatively small population may grow at a rapid rate in such a way that the growth of large clties is encouraged. However, since our "sample" is composed predominantly of countries which have high population growth rates and large total populations, the negative relationship between total population size and metropolitanism indicates that prolonged high rates of growth may ultimately result in populations so large that they become unfavorable to the continued growth of large cities. 
If we look at the beta weights for the total population when the contextual factors are controlled, it is clear that trade relations with other countries do not act as forces which modify the above described relationship to any great extent. It was argued in Chapter III that international trade was one way in which large, growing population agglomerations in the underdeveloped countries are supported. However, it can be seen that when the various types of international trade are controlled, the relationship between total population size and metropolitanism remains fairly constant; further, if the total volume of international trade is held constant, rather than the various types which compose it, the negative relationship between these two indicators slightly decreases in magnitude. These findings, then, are not consistent with the postulated relationship.

Yet, if they are interpreted in light of the suggested relationship between the annual rates of growth of the populations, their total sizes, and metropolitanism, these findings are less contradictory toward the hypothesis advanced in Chapter III. A glance at Table VII will illustrate that the relationship between the annual rates of growth of the population and metropolitanism becomes less positive when the contextual indicators are controlled. In other words, when various types of international trade are held constant, the annual rate of growth is not as positively associated with metropolitanism as it is when these indicators are not controlled. This signifies that trade relations with other countries are a means by which large cities can be supported when thelr populations are growing; if ; hypothetically, a country did not trade with other countries the growth of its population would not be associated as strongly with high levels of metropolitanism. This much is consistent 
with the hypothesis of Chapter III. However, I have argued that sustained high rates of growth of large populations w11l result in populations so large that they discourage concentration. If such a point is reached, Table VII tells us that external trade with other countries will not serve to make these large populations more congenial to largescale concentration. In other words, at some point the populations of these countries become so large that their size is "dysfunctional" to metropolitanism. Once this point is reached, external relations will not provide enough support so that these large populations will encourage concentration.

Quite obviously, the data available for this study provide one with no means of determining the exact point at which the size of the population of an underdeveloped country begins to discourage metropol1tanism; nor is it certaln that such a point will ever be empirically discovered. It is certainly true that the underdeveloped countries, considered as a group, are characterized by both large populations and high levels of metropolitanism. The method of analysis undertaken here is aimed toward uncovering the dynamics associated with the process of metropolitanism and its increase. For this reason, although the above described finding may appear contradictory to what we know about the extent of population concentration in underdeveloped countries, it is relevant insofar as our interest is in those factors and processes associated with increases or decreases in metropolitanism.

The remaining indicators of the environment and organization components all have their strongest relationship with metropolitanism when the contextual factors are held constant. What does this tell us? 
First of all, it is clear that the volume of economic exchange of these countries is related, at least to some extent, with metropolitanism. However, there are three additional observations which can be made concerning the specific internal variables included in the equations.

We might first look at the environment indicator--the land area of the country. Let us concelve of the total land area of each country as being an index of the resources avallable to the populations of each country. It must be admitted that total land area is not a totally accurate indicator of resource avallability; however, in terms of the data avallable for this study, it is the best indicator of the environment and the resources it provides.

It was previously noted that an intimate reciprocity exists between large cities and the "hinterlands" surrounding them. If we think of these hinterlands as being important to the existence of cities primarily because they provide those resources necessary for concentration to take place and increase, and, if we think of the total land area of the country as being an index of these resources, then we would expect the total land area of a country to be closely related to metropolitan1sm. A glance at Appendix I (1n which the total land area for the 37 underdeveloped countries is found) and Appendix J (in which metropolitanism for the 37 underdeveloped countries is listed), however, will 11lustrate that no clear relationship exists between the total land area of each country and its level of metropolitanism (In fact, the zero-order correlation between total land area and metropolitanism is $.17)$.

Multiple regression analysis, on the other hand, illustrates that the total land area of each country has a relatively strong influence 
on metropolitanism. The beta weights in Table VII tell us that when the characteristics of the population and its division of labor are held constant, the total land area has a stronger Independent effect on metropolitanism than any other internal characteristic of this group of countries; further, even when the contextual indicators are controlled along with the internal characteristics, the total land area has the strongest independent effect on metropolitanism of any of the other variables considered. Thus, if one were asked to choose the single most important influence on the existence of large cities in these countries, the index of resource availability--total land area--would be the correct choice. It should also be observed that the relationship between resource availability and metropolitanism is positive, indicating that as more resources are avaflable to the populations an increase in metropolitanism can be expected.

Table VII reveals that when the various types of international trade are controlled, the relationship between total land area and metropolitanism becomes more intense. The fact that this is not the case when only the total volume of international trade is controlled indicates that the four types of trade which are controlled are related to metropolitanism in such a way that they tend to "mediate" the direct effect of avallable resources on metropolitanism. That is, the four types of trade which are statistically controlled function to make the relationship between available resources and metropolitanism less direct; when they are controlled, the intensity of the relationship increases. As we have seen, the underdeveloped countries have large and growing populations. This being the case, the resources available to the population are, in general, "spread" more thinly among the population 
than they are in the developed countries. This is to say that the ratio of population to resources is much higher in the underdeveloped countries than it is in the developed ones. The literature on cities tells us that the existence of large cities is critically dependent on a large amount and diversity of resources (objects of consumption, as Gibbs and Martin call them). It follows that the type and extent of resources within a country's borders are, of course, importantly influenced by the level of technology within the particular country. Further, the manner In which these resources are used is also relative to the level and type of technology within the country. Unfortunately, technological indicators were not available for these underdeveloped countries; thus, technological variables were not controlled in order to obtain the above described relationship (The reader is warned to interpret this relationship in the light of this unfortunate shortcoming). One way in which these underdeveloped countries may cope with this high ratio between population and resources, and the implications it has for metropolitanism, is to supplement their resource bases by engaging in international trade. If these countries do engage in these sorts of activities for this reason, then when these activities are not allowed (statistically, of course) to help support city populations, we might expect that the limitations imposed by the environment, in terms of available resources, would increase in their significance for metropolitanism. When international economic exchange in controlled, the environment of any population becomes a more important influence on the ability of the population to concentrate itself in large cities.

We may now turn our attention to the first of the three organization indicators--the percent economically active in the total population. 
We are immediately impressed by the fact that this characteristic of the manner in which a population organizes its activities is only minimally related to metropolitanism. This finding tends to lend at least some empirical support to the over-urbanization thesis, insofar as it suggests that large population agglomerations exist in the underdeveloped countries in the absence of the high proportions of the total population economically active in the West. Further, a glance at Table VII tells us that although this organization indicator has almost no effect at all on metropolitanism when only the population and environment indicators are controlled, it also has very little effect when the contextual variables are held constant. It is true that it does have a greater effect on metropolitanism when the contextual variables are controlled; still, the effect is so small that it must be concluded that in these countries the proportion of the population economically active has little influence on whether or not metropolitanism occurs. It should be noted that the comparatively low proportions of the total populations economically active in the underdeveloped countries is critically influenced by the very young age compositions of these populations and by the frequent exclusion of women from the labor forces of these countries. Thus, while It is generally true that in the underdeveloped countries unemployment is higher than in the developed countries, it is important to understand that the lower proportions of the total populations economically active in these countries is influenced by factors other than the lack of employment available to the populations.

Since cities are generally conceived to be places in which largescale economic activities take place, the above finding is certainly surprising. If cities are a collective adaptation to the various 
circumstances in which a population finds itself, cities themselves can be viewed as an organizational means by which a population attempts to ensure its survival. In the West, the origin and persistence of cities is recognized to have taken place in just this way (as suggested by the 1iterature reviewed in Chapter II). The finding that the proportion of the total population economically active is only very minimally related to metropolitanism in these countries should sensitize us to the likelihood that the cities of the underdeveloped world have arisen and persist for very different reasons than the cities of the developed world.

The percent of the economically active in construction is our second organization indicator. Table VII illustrates that the percent of the economically active in construction is positively associated with metropolitanism. Construction activities are generally associated with cities and their surrounding areas; this is not to say that construction in non-metropolitan areas is not as important as construction in or around cities. Rather, it is to say that in the West construction has generally increased as cities grew. We now find that, indeed, this positive association between metropolitanism and the proportion of the total population economically active in construction is present in the underdeveloped countries as well.

It is not implied, of course, that the proportion of the economically active in construction causes metropolitanism; it is only suggested that this organizational characteristic of the population is positively assoclated with metropolitanism. Table VII tells us that while the percent in construction is positively associated with metropolitanism, this association is not terribly strong. Thus, in any event, no direct, intense relationship is observed. 
For our purposes the most important consideration is that as the international economic exchange of these countries is controlled, the relationship between the percent in construction and metropolitanism increases in intensity. The relationship, in other words, becomes more direct when the contextual variables are held constant. International economic exchange acts as a means by which the relationship between the percent in construction and metropolitanism is modified; if the effects of international trade are held constant, the percent in construction is more strongly positively related to metropolitanism. This suggests that whatever forces are operating in the underdeveloped countries to create and perpetuate this relationship, they operate more strongly when contextual factors are statistically controlled.

The final organization indicator is the percent of the economically active in commerce. It can be seen that this indicator is positively associated with metropolitanism, and that this positive association becomes stronger when the contextual indicators are controlled.

Commercial activities have always been highly associated with cities. Many a city in the now industrialized west first arose in conjunction with the increase in the number of individuals engaging in commercial endeavors. It is certainly not suggested that an increase in commercial activities caused cities to arise and grow, any more than it is suggested that the existence and growth of cities caused an increase in commercial activites. There can be no doubt that an intimate reciprocity existed between the proportion engaging in commercial activities and the existence and proliferation of cities.

The beta weight for the percent of the economically active in commerce illustrated in Table VII must, then, be conceived as signifying the 
close relationship between those engaging in commercial activites and metropolitanism even in these underdeveloped countries. The fact that this relationship comes to be even more intense when contextual factors are controlled tells us that this highly specialized activity influences (and is influenced by) metropolitanism even more closely when international exchange is controlled.

We can argue, then, that regardless of the particular indicator of the three components of the ecological complex under consideration, the statistical control of international economic exchange influences the relationship between these variables and metropolitanism. In theoretical terms, we might say that in these 37 underdeveloped countries, while the population, environment, and organization certainly are related to metropolitanism, this relationship varies according to the international economic exchange of the particular country. The implication, of course, is that this international economic exchange is related, at least to some extent, to the level of metropolitanism in these countries.

\section{The Developed Countries}

Table VII provides data for the 30 developed countries on the seven indicators for the four components of the ecological complex--two for the population component, one for the environment component, two for the organization component, and two for the technology component. It is only in these developed countries, of course, that we will be able to assess the effects of the technology indicators on metropolitanism. Even with these indicators added, however, it can still be seen that for five out of the seven indicators a stronger relationship with metropolitanism is evidenced when the contextual variables are controlled. Since 
this is the first opportunity we have had to look at the effects of the technology indicators on metropolitanism, let us turn our attention to these two variables first.

The production of coal in these countries has the greatest effect on metropolitanism of any of the indicators of any of the components. If the reader will inspect Appendix D it will be seen that while the production of coal has the highest loading on the second factor (.7536), and thus defines it, the per capita Gross National Product also has a very high loading on this factor $(.7109)$. As a result, I suggest that we consider this factor to be a "wealth" factor; for example, we can consider the production of coal as signifying natural resource wealth and technology associated with it, and we can further consider the per capita Gross National Product as representing productive wealth and the sophisticated technologies associated with it.

Table VII 11lustrates that the production of coal is very strongly negatively related to metropolitanism. What is more, this negative relationship becomes even stronger when the contextual variables are held constant. If the production of coal can be interpreted as representing a measure of wealth and the technology associated with it, we are told, in effect, that if differential international exchange is controlled along with the other internal factors, as wealth increases the level of metropolitanism very strongly decreases. Insofar as wealth of productive and natural resources is an accurate indicator of the technology component of the ecological complex, the inference is that technology in these developed countries has a negative independent influence on large population concentrations, and that this negative influence becomes greater when international trade is controlled. 
Perhaps one's initial impression of this finding is that it is contradictory of much of our thinking about the relationship between technology and cities. However, upon more careful inspection this finding becomes less surprising. It is plausable to argue that the very wealthy nations which are represented in the 30 countries here considered are able to afford the costs associated with overcoming friction; that is, the wealth at the disposal of these countries enables their populations to decentralize themselves and to be better equipped to cope with the inevitable costs associated with increased distance. Thus, it is likely that decentralization of population is occurring in these countries and that metropolitanism is either increasing more slowly than previously, or may be slightly declining. If this is in fact the case, the wealth of these countries is a force which served to de-concentrate populations. In this 1ight, the negative relationship between production of coal and metropolitanism is not surprising.

This finding may be interpreted in another manner. If we view the production of coal as an indicator of technology, the negative relationship between production of coal and metropolitanism may suggest that many of these 30 developed countries are coming to depend more on oil, hydroelectric power, and nuclear power for the fuels needed to sustain their high levels of technology. If we view technology as a force which is critical to the existence and proliferation of cities, the discovered relationship tells us that "coal-power" has come to be less important as a force which concentrates population. Conceived in this way, these developed countries have adopted alternative sources of the materials needed for technology, and thus the production of coal is no longer positively associated with metropolitanism. Those countries which do produce 
large amounts of coal for technological use could then be considered as countries which are relatively backward or least modernized; and, since the majority of our 30 developed countries are anything but backward, in terms of technology, the production of coal is not positively related to metropolitanism.

Regardless of which of the alternative interpretations provided above is the most valid, it is clear, from Table VII, that the relationship between the production of coal and metropolitanism becomes more Intense when the contextual indicators are controlled. Our interpretation of this finding will depend on which of the alternative interpretations provided above is adopted. Let us consider both of these interpretations and their implications for this last empirical finding.

If we consider the production of coal as an indicator of wealth (along with the per capita Gross National Product, as suggested above), the large negative relationship between this indicator and metropolitanism when contextual factors are controlled may lead one to the following conclusion. In Chapter III we argued that integration into an international system of exchange is a force which will encourage population agglomeration. If this is so, and if the wealth of these countries, as it is reflected in their technologies, is a force toward de-centralization of the population, then we would expect that when this international exchange is controlled the relationship between this measure of technology and metropolitanism will increase in magnitude. In other words, Insofar as production of coal can be conceived as a force which enables a population to become dispersed, when the concentrating tendencies of international trade are controlled, it is plausable to argue that the 
relationship between the production of coal and metropolitanism will become more intense.

On the other hand, if the production of coal is no longer as critical to the existence of technology in these countries, and has been transcended in importance by alternative sources of needed power, the increase in magnitude of the negative relationship between production of coal and metropolitanism can be understood in the following way. Cities depend on various technologies for their existence. Since technology must generally be powered by materials of some sort, and since few countries have all of these materials within their borders, it will generally be the case that a country must import (that is, trade for) the materials it needs. If this trade for these materials is held constant, the inability of coal production to support metropolitanism becomes even greater. Thus, for example, if the importation of oil is held constant when oil has superceded coal as a primary source of power for technology, the negative relationship between the production of coal and metropolitanism would be expected to be quite large. This negative relationship would certainly be much larger than it would be when international trade in these types of commodities are not held constant.

The second indicator of the technological component is the number of passenger cars in use. Table VII reveals that this indicator and metropolitanism are not related at all. Even though the population, environment, organization, and contextual indicators have been controlled in the various equations, no relationship is found between the number of passenger cars in use and metropolitanism. The countries in this group vary tremendously in the number of passenger cars in use; yet, there could be discerned no relationship between this indicator and 
metropolitanism. Thus, we must conclude that the number of passenger cars in use and metropolitanism are not related in any meaningful way. Insofar as the number of passenger cars in use is a valid measure of technology, our analysis illustrates that metropolitanism in these countries occurs independently of this particular indicator of technology.

The reader should be warned, however, that the absence of any empirical relationship between the number of passenger cars in use and metropolitanism does not necessarily imply that no such relationship exists. Regression analysis only provides one with a measure of the relationship between a number of independent variables and a dependent variable. The observed relationship (or lack of one) is of course influenced by the particular variables included in, and excluded from, the equations. Thus, the absence of a linear relationship between the number of passenger cars in use and metropolitanism may be at least a partial result of the fact that many variables were not included in the regression analysis; that is, the fact that many possibly relevant variables were not statistically controlled in the analysis, and thus may confound any relationship between the number of passenger cars in use and metropolitanism, could result in the lack of a linear relationship between these two variables. It could also be that such things as the policy against private ownership of automobiles in many communist countries, and the relatively few passenger cars in use, "balanced" the large number of passenger cars in use in non-communist countries and resulted in the lack of a relationship between the number of passenger cars in use and metropolitanism.

We can now turn our attention to the population component of the ecological complex and its two indicators--the total population size and 
its annual rate of growth. At the outset it is important to note that no causal effect of these two indicators upon metropolitanism is suggested. Rather, our concern will be with the direction and strength of the relationship between the indicators and metropolitanism. It is quite possible, then, that the empirical values which these population indicators have are a consequence of metropolitanism, and not the other way around. St1ll, since our focus of attention is metropolitanism and the factors which contribute to its existence and persistence, we will concentrate on what these population indicators can tell us about metropolitanism in these 30 developed countries.

The total population size of these developed countries can be seen to be very strongly positively related to metropolitanism. It will be remembered that in the underdeveloped countries the population size and metropolitanism were negatively related. Therefore, the type of relationship between population size and metropolitanism is very different in the two groups of countries. If we now look at the second indicator of the population component, the annual rate of growth, 1t will be noticed that in these developed countries the relationship between this indicator and metropolitanism is negative, whereas in the underdeveloped countries it was positive. Taken together, the two indicators of the population are related to metropolitanism in one way in the underdeveloped countries and in quite another in the developed countries.

While we argued that in the underdeveloped countries the growth of the population was one factor which "fed" urban growth, it was also observed that high rates of such growth may ultimately lead to a population so large that it actually discourages agglomeration in large cities. Clearly, this does not occur in the developed countries. In these 
countries the absolute size of the population does not depress metropolitanism; at the same time, any increment in the growth of these populations is associated with a decrease in metropolitanism. We might confecture that given the higher standards of living and availability of objects of consumption in the developed countries, and their lower rates of growth, the cities in these countries are not adversely effected by the total size of the population. It might even be that rising levels of metropolitanism encourage greater population size. The fact that when the contextual variables are controlled the positive relationship increases, tells us that even if these countries could not trade with other countries, the sizes of their populations would not be detrimental to large cities. Population size per se, then, is positively associated with metropolitanism in these countries.

What clearly is not positively assoclated with population agglomeration are the annual rates of population growth in these countries. We thus might envision a large (or smal1) population in one of these countries; as long as this population's size remained constant (the population did not grow), it would tend to encourage population agglomeration. However, if and when this population grew, the added numbers of people would be associated with a decrease in agglomeration. If we further envision a situation in which these countries could not trade with other countries, we can note that the addition of Individuals to the population would even more strongly be associated with a decline in metropolitanism. Insofar as these populations do trade with other populations, it can be suggested that such trade is one way in which the inverse relationship between population growth and metropolitanism is modified so that it is less intense. 
The relationship between the environment indicator--land area--and metropolitanism in these 30 developed countries is similar to the observed relationslip between these two variables in the 37 underdeveloped countries. Just as in the underdeveloped countries, the relationship between land area and metropolitanism is positive and increases when the contextual indicators are controlled. Thus, the various resources available to a country's population, as they are measured by its land area, are positively associated with metropolitanism; further, when international trade is controlled, it can be seen that the resources available to the population become even more critical to the level of agglomeration which is achieved.

An important difference between the underdeveloped countries and the developed ones is illustrated by the greater intensity of the relationship between land area and metropolitanism in the underdeveloped countries. As has been previously suggested, the ratio of population to resources is far higher in the underdeveloped countries than it is in the developed ones. We would expect that the resources provided by the environment would be utilized very intensely by the populations in these underdeveloped countries; so much so that many of these resources become pitifully scarce. If cities are modes of organization which both depend on a variety of resources for their existence, and serve to modify the resource base of the area in which they exist, the intense relationship between land area and metropolitanism in the underdeveloped countries illustrates the interdependence between the national environment and the level of concentration achieved. Further, the fact that when the contextual indicators are controlled this relationship increases in magnitude tells us that international trade is one way in which needed resources 
are acquired by populations in these countries. In the underdeveloped countries, it is generally the case that various sorts of raw materials are exported: rubber, lumber, oil, etc.; on the other hand, these countries generally import various types of food products and manufactured (consumer) goods. In effect, then, raw materials are exchanged for processed sustenance materials. If these countries could not engage in this type of exchange, they would be forced to utilize, as best they could, those raw materials within their borders. This would mean that the type and extent of these raw materials would critically influence the extent to which the population could be supported; it is no overstatement to suggest that without international trade of the sort outlined above, the populations of underdeveloped countries could not be supported at their current levels. Without this type of international trade (raw materials traded for food and manufactured goods) it is also safe to say that population agglomerations would depend very intimately on the extent of raw materials found within the country. The food and manufactured products needed for the support of these cities would have to be created from the raw materials found within the environment of the country. In essence, the resources within the environments of these countries would become even more critical to the population's ability to concentrate itself.

The relationship just outlined certainly holds true for the deve1oped countries as well. However, as the beta weights for land area 11lustrate, the relationship is not as intense in the developed countries. This less intense relationship may be interpreted in the following way. The developed countries have, in general, higher levels of technological development. The comparatively sophisticated technologies of the 
developed countries enables their populations to modify the resources the environment provides; in other words, the diverse technologies at the disposal of the populations of the developed countries makes them much more able to utilize the available resources efficiently than can the populations of the underdeveloped countries. This, in effect, means that while a close interdependence exists between cities and their environments in the developed countries, these cities, as modes of organization, are not as constrained by a given level of resources as are cities in the underdeveloped countries. We could say, then, that an increase or decrease in resources in the underdeveloped countries is likely to be more closely related to an accompanying increase or decrease in metropolitanism than would be the case in the developed countries. Because of the higher levels of technology in the developed countries, a greater degree of autonomy exists between the resources provided by the environment and metropolitanism.

Just as in the underdeveloped countries, the relationship between land area and metropolitanism becomes more intense when the contextual variables are controlled. In reference to the underdeveloped countries we argued that the stronger relationship between land area and metropolitanism which emerged when the contextual indicators were controlled told us that an important way in which these countries "supplemented" their resource bases was through international trade. We can now argue that much the same phenomenon occurs in the developed countries. In fact, given the higher standards of living in these countries, and the wide diversity of products which their populations demand, it should not be difficult to see that international trade is very important to these countries. Insofar as concentrated populations need and demand a large 
number of diverse materials, we can suggest that international trade w111 be highly related to the existence and proliferation of large cities. In fact, it would not be overstating the matter to argue that if nations could no longer trade with other nations the large cities within them would find their continued existence extremely uncertain. We may now turn our attention to the two indicators of the organization component of the ecological complex for these 30 developed countries. The first of these is the percent of the economically active in construction. Table VII tells us that there is almost no relationship between this type of organized activity and metropolitanism in these countries; this is so regardless of whether only the remaining indicators of the components of the ecological complex are controlled, or whether the contextual variables are also controlled. The observed relationship is so sma11, in fact, that it suggests that in these 30 countries metropolitanism and construction activities occur almost independently of one another.

It will be recalled that in reference to the relationship between the production of coal and metropolitanism it was argued that perhaps the wealth of these developed countries was a factor which contributed to the decentralization of the population. If this is so, then we may now argue that the almost total lack of relationship between the percent in construction and metropolitanism can also be understood in this 1ight. That is, if, in fact, the populations of these countries find it possible to disperse themselves over the landscape, it would be necessary that an increasing proportion of those involved in construction activities now engage in these activities in places other than large cities. If individuals live in places other than large cities, 
and if more and more of the population find it possible to move away from the congested cities, then an increasing proportion of construction activities will be undertaken in these areas. This might account for the lack of any significant relationship between percent in construction and metropolitanism. Although the sma11 relationship which does exist is positive, its magnitude is so small that it indicates that in these countries the percent in construction certain1y does not act as a force which significantly increases metropolitanism; while it doesn't discourage metropolitanism, it doesn't encourage it to any meaningful degree. It can also be noted that the statistical control of the contextual indicators does not modify the observed relationship (or lack of one) to any great extent, indicating that international economic exchange has little influence on whatever relationship exists.

The second indicator of the organization component is the percent of the economically active in electricity, gas; water, and sanitary services. As can be seen from Table VII, the beta weight for this indicator is negative.

The type of organized activity that this indicator represents is generally associated with the delivery of energy and services to populations. We could think of this indicator, in general terms, as a service indicator. Insofar as this is valid, we can say that countries having large proportions of their economically active in these activities are also likely to be those with a fairly high level of metropolitanism. Historically, it has been the case that not only have urbanized populations depended on services of this type but the fact that urbanized populations existed encouraged a proliferation of activities of this sort. Therefore, in the developed countries at least, a close 
reciprocity has arisen between concentrated populations and organized activity of this type.

Given this as so, it is perhaps surprising that the relationship which has been found is negative. It is possible that a reason for this is the decentralization of population which has been suggested above. If these developed countries have been experiencing at least some decentralization of population, it is likely that the services represented by this indicator have been extended to this dispersed population. This being the case, it is ilkely that a greater proportion of the economically active performing these activities have come to orient themselves to areas which are not within the confines of large cities.

It can also be seen that when the contextual indicators are controlled the relationship between the percent of the economically active in electricity, gas, water, and sanitary services and metropolitanism increases in intensity. The more intensely negative relationship between this indicator and metropolitanism when international trade is controlled signifies that the relationship between these two characteristics of the developed countries is inhibited by the differential involvement in external trade relationships. Even with this international trade controlled, however, it can be seen that the relationship between this indicator and metropolitanism is not terribly strong.

INDEPENDENT EFFECTS OF CONTEXTUAL INDICATORS ON METROPOLITANISM

As we saw in Chapter $V$, the total per capita imports plus exports is actually composed of ten specific categories, or types, of per capita imports plus exports; we also saw that since the tenth category was a 
general "catch-all" category, it could be dropped from the analysis, leaving us with nine categories.

The general perspective of this study is that both the various components of the ecological complex and the contextual variables are related to metropolitanism, and that in order to most effectively account for international variation in metropolitanism it is necessary to consider a country's economic exchanges with other countries. Thus, it has never been suggested that contextual indicators alone can significantly explain international variation in metropolitanism. The regression analysis, however, has yielded a measure of the relationship between the various categories of per capita imports plus exports and metropolitanism, with not only the remaining categories but with the various components of the ecological complex held constant. The relationships between the various categories of economic exchange and metropolitanism are illustrated in Table VIII.

The various relationships revealed in Table VIII will not be discussed in depth; as were the relationships between the various internal factors and metropolitanism. This lack of attention may be justified on the following grounds: the various categories of economic exchange revealed in Table VIII were derived by summing the total imports of the particular commodity with the total exports of the particular commodity. This procedure yielded a measure of the total volume of exchange in this particular commodity. This measure, therefore, does not enable one to determine the extent to which a particular country imported a particular commodity or the extent to which it exported a particular commodity; it only enables us to determine the extent to which it imported and exported the particular commodity. Now, if one's 
TABLE VIII

INDEPENDENT EFFECTS OF CATEGORIES OF PER CAPITA IMPORTS PLUS EXPORTS, WITH THE COMPONENTS OF. THE ECOLOGICAL COMPLEX AND THE REMAINING CATEGORIES CONTROLLED, IN THREE GROUPS OF COUNTRIES ${ }^{\mathrm{a}}$

\section{COUNTRIES}

BETA WEIGHT
Metropolitanism = Population + Environment + Organization + Three Categories of Contextual Variables

Per Capita Imports P1us Exports of Food and Live Animals-- -.392 Per Capita Imports Plus Exports of Animal, Vegetable 0il, Fats-Per Capita Imports Plus Exports of Basic Manufactures--

37 UNDERDEVELOPED COUNTRIES
Metropolitanism $=$ Population + Environment + Organization + Four Categories of Contextual Variables

Per Capita Imports Plus Exports of Beverages and Tobacco-- -.17

Per Capita Imports Plus Exports of Crude Materials Except Fuels--

Per Capita Imports Plus Exports of Mineral Fuels--

Per Capita Imports Plus Exports of Basic Manufactures--

$-.105$

\section{DEVELOPED COUNTRIES}

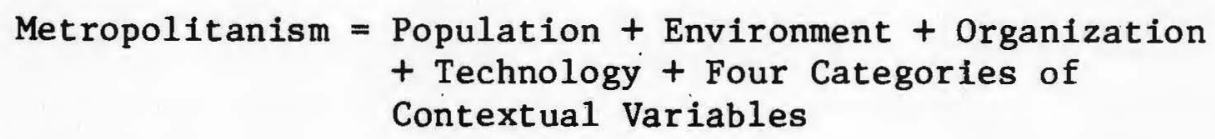

Per Capita Imports Plus Exports of Beverages and Tobacco-- -.591

Per Capita Imports Plus Exports of Mineral Fuels-- -.505

Per Capita Imports Plus Exports of Basic Manufactures--

Per Capita Imports Plus Exports of Miscellaneous

$\begin{array}{ll}\text { Manufactures-- } & 1.00\end{array}$

a--For the specific indicators of the Components of the Ecological Complex included in any particular equation, refer to Table IV. 
object were to assess the effect of international trade in a particular commodity on metropolitanism, it would be important to separate the effects of imports of a particular item on metropolitanism from the effects of exports of a particular item on metropolitanism. In this way, one could be certain that any observed relationships were a reflection of either the importation of various commodities or the exportation of various commodities. Since our measure of economic exchange is a summation of these two very different types of activities, we have no way of knowing whether the observed relationship reflects intense importation of a particular good, intense exportation of a particular good, or a combination of the two.

Table VIII, then, provides Information regarding the extent to which the total imports and exports influence metropolitanism in the three groups of countries. As a glance at the table will illustrate, the relationship between the imports and exports of various commoditles and metropolitanism is, in many cases, quite strong. As we have argued above, the interpretation of these relationships is very difficult since imports and exports were combined. In any event, the general perspective of this study does not demand that we pay a great deal of attention to the independent effect of various types of economic exchange on metropolitanism; it has only been argued that economic exchange with other countries must be considered, in addition to factors internal to the particular country, if we are to most fully explain international variation in metropolitanism. The statistical analysis employed in this final chapter has, I would suggest, 111ustrated the utility of this perspective. 


\section{CONCLUDING REMARKS}

The purpose of this final chapter was to determine, utilizine regression analysis, if involvement in an international system of economic exchange is related to metropolitanism. Toward this end, we first looked at the amount of international variation, in the three groups of countries, in metropolitanism that could be accounted for by the varfous indicators of the components of the ecological complex alone, and then with the various contextual indicators added. It was found that with the addition of the "gross" contextual variable, the total per capita imports plus exports, and then with the substitution of the various categories of contextual variables, more international variation in metropolitanism could be explained in the total of 70 countries. When we divided this group of 70 countries into two subgroups--a group of 37 underdeveloped countries, and a group of 30 deve1oped countries--our findings were somewhat different. Operating under the limitations of a relatively small sample size relative to the models employed (that 1s, while our sample of countries was small, a large number of "Independent variables" were used in the analysis), a statistical correction procedure was employed so as not to "Inflate" the $\mathrm{R}^{2}$ value. In the 37 underdeveloped countries, we noted that more international variation in metropolitanism could be explained when only the various components of the ecological complex were considered. It was then found that in the group of 30 developed countries we were unable to explain any variation in metropolitanism at all. Since this group is highly diverse in terms of metropolitanism, and since only a sma1l number of countries were avallable for analyols, the corrected 
correlation coefficients literally shrank away to nothing.

If one views this correction procedure as being a necessary and valid device for conservatively estimating the multiple correlation coefficient, then the above findings can be interpreted in the following way. If one were to attempt to formulate a theory of metropolitanism for the widest possible range of the world's countries it would be necessary to include a country's economic involvements with other countries in that theory. That is, while a theory concerning metropolitanism in either the developed or underdeveloped countries apparently need not consider the "context" of each country, a theory of metropolitanism for both the developed and underdeveloped countries, in order to more fully account for metropolitanism, must take into account the country's economic exchanges with other countries.

It should be remembered that before the correction procedure was applied, in the group of 70 countries, the 37 underdeveloped countries, and the 30 developed countries, the addition of the contextual variables always enabled us to explain more variance in metropolitanism. Thus, if the reader is suspicious of the validity of the correction procedure, the uncorrected multiple correlation coefficients indicate that in every case, consideration of the contextual variables is necessary in order to explain the greatest amount of variation in metropolitanism. The reader, however, must be aware of the dangers of such interpretation, as they were outlined in the text.

We next turned to a different type of analysis. Whereas we had previously been concerned with the strength of association between the various indicators of the components of the ecological complex and the contextual indicators and metropolitanism, we now concerned ourselves 
with the direction and magnitude of the effect of each of the internal indicators on metropolitanism; we were, then, in this section, concerned with the direct, independent relationship between the various indicators and metropolitanism, and not with the extent to which all, taken together, were associated with metropolitanism.

The relationships between the various internal indicators and metropolitanism were first observed when only the indicators of the various components were included in the equations, and then when the contextual variables were controlled. In all three groups of countries the independent relationship of each indicator of the particular component always changed when the contextual variables were statistically controlled. In many cases, the change was substantial. Whether the relationship between the particular indicator and metropolitanism increased or decreased depended on which indicator and which component was under consideration. Perhaps one of the most interesting findings was that in the developed countries a certain amount of "decentralization" of the population is taking place, and that it is the superior. technology of these countries that is intimately related to this decentralization. It was also, and most importantly, found that international trade was one way in which this decentralization was encouraged. Looking at this aspect of the regression analysis, it is suggested that it has been demonstrated that a country's "context" is indeed related to the extent of population agglomeration.

I would like to conclude by suggesting that the type of analysis undertaken in this study should serve to sensitize the reader to the critical interdependence of the many countries of the world. Problems which have heretofore been discussed in the context of the politically 
autonomous nation-state are increasingly recognized to be problems which pay no heed to political boundaries; for example, we often hear of the "world" hunger problem and of "world" overpopulation. The survival of organized populations on this planet may ultimately depend on the ability of these populations to make the most efficient use of the resources scattered over, and beneath, the surface of the entire planet.

This study began with the observation that more and more of the world's people are now living in large cities. We have seen that these population agglomerations are significantly influenced by national involvement in an international system of economic exchange; thus, the ability of these agglomerations to persist is importantly influenced by the acquisition and sale of economic products. It is in this sense that I believe this study should be conceived as a baseline: a "benchmark" which tells us that in the year 1971 the integration of 70 of the world's countries into a system of economic exchange was significantly related to the proportion of a country's population concentrated in large cities. The analysis may be conceived as providing a base from which to determine the extent to which integration into such an international system may come to be either more or less related to metropolitanism.

As we noted above, there appears to be increasing sensitivity to the fact that many of the problems faced by organized populations are world-wide in scope. It can be expected, then, that organized population concentrations will become even more highly related to international trade in the future. As populations grow, as less arable land becomes available, and as these populations become more concentrated, what they require to sustain themselves is 11kely to be acquired from 
ever more distant locations. Insofar as nation-states continue to exist at this point in the future, economic exchange between them will come to have a critical influence on the large cities they contain. 
Abu-Lughod, Janet, "Urban-Rural Differences As a Function of the Demographic Transition", in Charles Tilly, Ed., An Urban World.

Boston: Little, Brown and Company, 1973. pp. 68-86.

Ackerman, Edward A., "Population and Natural Resources", in Philip M. Hauser, Ed., The Study of Population. Chicago: University of Chicago Press, 1959. pp. 621-648.

Baggaley, Andrew R., Intermediate Correlational Methods. New York: John Wiley and Sons, Inc., 1964.

Berry, Brian J. L., "Research Frontiers in Urban Geography", in Philip M. Hauser and Leo F. Schnore, Eds., The Study of Urbanization. New York: John Wiley and Sons, Inc., 1965. pp. 403-430.

St. Martin's Press, 1973.

Blalock, Herbert M. Jr., Social Statistics. New York: McGraw-Hill, 1972.

Clark, Cal and Susan Welch, "National Conditions as a Base Mark for Supranational Integration: The Case of Trade Patterns", Comparative Political Studies, Vol. 8, No. 3, October, 1975. pp. 345-359.

Coale, Ansley J., "Population and Economic Development", in PhIlip M. Hauser, Ed., The Population Dilemma. Englewood Cliffs, New Jersey: Prentice-Hall, Inc., 1969. pp. 59-84.

Cook, Robert, "The World's Great Cities: Evolution or Devolution?", Population Bulletin, Vol. 16, September, 1960. pp. 109-131.

Davis, Kingsley, "The Origin and Growth of Urbanization in the World", The American Journal of Sociology, Vol. 60, March, 1955. pp. 429437.

New York: Sclentific American, Inc., 1968. pp. 3-24.

World Urbanization 1950-1970, Volume I. Berkeley: Institute of International Studies, Population Monograph Series, No. 4, 1969.

World Urbanization 1950-1970, Volume II. Berkeley: Institute of International Studies, Population Monograph Series, No. 9,1972 . 
Duncan, Otis Dudley, "Human Ecology and Population Studies", In Philip M. Hauser, Ed., The Study of Population. Chicago: University of Ch1cago Press, 1959. pp. 678-716.

Duncan, Ot1s Dudley, W. Richard Scott, Stanley Lleberson, Beverley Duncan, and Hal H. Winsborough, Metropolis and Region. Baltimore: Johns Hopkins Press. 1960.

Ecologica1 Perspectives in the Study of Soclal Organtzation", The Amer1can Journal of Soclology, Vo1. 60, No. 2, September, 1959. pp. 132-153.

Fisher, Joseph L. and Neal Potter, "Natural Resource Adequacy for the United States and the World", in PhIllp M. Hauser, Ed., The Population Dilemma. Englewood Cliffs, New Jersey: Prentíce-Hall, Inc., 1969. pp. 106-138.

German1, Gino, "Urbantzation, Social Change, and the Great Transformation", in Gino Germani, Ed., Modernization, Urbanlzation, and the Urban Crisis. Boston: Little, Brown and Company, 1973. pp. 3-58.

Gibbs, Jack P. and Walter T. Martin, "Urbanization and Natural Resources: A Study In Organizational Ecology", American Soctological Review, Vo1. 23, No. 3, June, 1958. pp. 266-277.

Data in the International Study of Urbanization", American Sociological Review, Vo1. 23, October, 1958. pp. 505-514.

--_-_- and Walter T. Martin, "Urbanization, Technology, and the Division of Labor: International Patterns", American Sociological Review, Vo1. 27, October, 1962. pp. 667-677.

Hauser, PhIlip M., "Urbanlzation: An Overview", in Philip M. Hauser and Leo F. Schnore, Eds., The Study of Urbanization. New York: John Wiley and Sons, Inc., 1965. pp. 1-47.

The Populd Population Growth", In Philip M. Hauser, Ed., The Population Dilemma. Englewood Cliffs, New Jersey: PrenticeHa11, Inc., 1969. p. 12-33.

Hawley, Amos H., Human Ecology: A Theory of Community Structure. New York: Ronald Press Company. 1950.

International Labour office, Yearbook of Labour Statistics 1971. Geneva, 1972.

Isard, Walter, Introduction to Reglonal Sclence. Englewood Cliffs, New Jersey: PrentIce-Ha11, Inc., 1974. 
Katzenstein, Peter J.; "International Interdependence: Some Long-Term Trends and Recent Changes", International Organization, Vol. 29, No. 4, Autumn 1975. pp. 1021-1034.

Kerlinger, Fred N., Foundations of Behavioral Research. New York: Holt, Rinehart and Winston, Inc. 1973.

Keyfitz, Nathan, "Political-Economic Aspects of Urbanization in South and Southeast Asia", in Philip M. Hauser and Leo F. Schnore, Eds., The Study of Urbanization. New York: John Wiley and Sons, Inc., 1965. Pp. 265-309.

Lampard, Eric E., "The History of Cities in the Economically Advanced Areas", Economic Development and Cultural Change, Vol. 3, No. 2, January, 1955. pp. 81-136.

and L. F. Schnore, Eds., The Study of Urbanization. New York: John Wiley and Sons, Inc., 1965. pp. 519-554.

Lorimer, Frank, "Issues of Population Policy", in Philip M. Hauser, Ed., The Population Dilemma. Englewood Cliffs, New Jersey: PrenticeHal1, Inc., 1969. pp. 168-206.

Martin, Walter T., "Urbanization and National Power to Requisition External Resources", Pacific Soclological Review, Vol. 5, No. 2, Fal1, 1962. pp. 93-97.

Marx, Kar1, Cap1tal. London: Lawrence and Wishart. 1970.

Matras, Judah, Populations and Socleties. Englewood Cliffs, New Jersey: Prent1ce-Hall, Inc. 1973.

Myrdal, Gunnar, "The Transfer of Technology to Underdeveloped Countries", Sclentific American, Vo1. 231, No. 3, September, 1974. pp. 173182.

Ogburn, William F. and Francis R. Allen, "Technological Development and Per Capita Income", The American Journal of Soclology, Vo1. 65, No. 2, September, 1959. pp. 127-131.

Plzzorno, Alessandro, "Three Types of Urban Soclal Structure and the Development of Industrial Soclety", In Gino Germant, Ed., Modernization, Urbanization, and the Urban Crisis. Boston: Little, Brown and Company, 1973. . pp. 121-138.

Rand-McNalley World Atlas 1971. New York, 1972.

Rummel, R. J., "Understanding Factor Analysis", Journal of Conflict Resolution, Vo1. 11, No. 4, December, 1967. pp. 444-480. 
Sjoberg, Gideon, "Theory and Research in Urban Sociology", in P. M. Hauser and L. F. Schnore, Eds., The Study of Urbanization. New York: John Wiley and Sons, Inc. 1965.

Cross-Cultural Analysis", in P. M. Hauser and L. F. Schnore, Eds., The Study of Urbanization. New York: John Wiley and Sons, Inc. 1965. pp. 157-189.

-_-_- "The Origin and Evolution of Citles", In Citles. New York: Scientific American, Inc., 1968. pp. 25-39.

Sovani, N. V., "The Analysis of Over-Urbanization", Economic Development and Cultural Change, Vol. 12, No. 2, January, 1964. pp. 113-122.

Spengler, Joseph, Population Change, Modernization, and Welfare. Englewood Cliffs, New Jersey: Prentice-Ha11, Inc. 1974.

Tisdale, Hope, "The Process of Urbanization", Social Forces, Vo1. 20, March, 1942. pp. 311-316.

Turnham, David and Ingelies Jaeger, The Employment Problem in Less Develaped Countries. Paris: Organization for Economic Co-Operation and Development, 1971.

United Nations, United Nations Demographic Yearbook, 1971. New York, 1972.

United Nations, "Population Division Working Paper \#34, United Nations", in Judah Matras, Populations and Societies. Englewood Cliffs, New Jersey: Prentice-Hall, Inc., 1973. Table located inside front and back covers. 
APPENDIX A

ORTHOGONALLY ROTATED ${ }^{a}$ FACTOR MATRIX*, TEN ORGANIZATIONAL

VARIABLES, FOR 70 COUNTRIES

\begin{tabular}{|c|c|c|c|c|}
\hline & & 1 & 2 & 3 \\
\hline 1. & $\begin{array}{l}\text { Number of cities with populations } \\
\text { over one million }\end{array}$ & -.1123 & $(-.7347)$ & .0355 \\
\hline 2. & $\begin{array}{l}\text { Percent economically active in } \\
\text { the total population }\end{array}$ & .1135 & -.5775 & .1804 \\
\hline 3. & $\begin{array}{l}\text { Percent of the economically } \\
\text { active in agriculture }\end{array}$ & $(-.9488)$ & .1695 & -.0692 \\
\hline 4. & $\begin{array}{l}\text { Percent of the economically } \\
\text { active in manufacturing }\end{array}$ & .7184 & -.5384 & .0361 \\
\hline 5. & $\begin{array}{l}\text { Percent of the economically } \\
\text { active in construction }\end{array}$ & .8281 & .1588 & .0568 \\
\hline 6. & $\begin{array}{l}\text { Percent of the economically } \\
\text { active in commerce }\end{array}$ & .7259 & -.3961 & -.1323 \\
\hline 7. & $\begin{array}{l}\text { Percent of the economicaily } \\
\text { active in electricity, gas, } \\
\text { water, and sanitary services }\end{array}$ & -.0105 & -.0918 & $(.9440)$ \\
\hline 8. & $\begin{array}{l}\text { Percent of the economically } \\
\text { active in transport, storage, } \\
\text { and communication }\end{array}$ & .8510 & -.2071 & -.2511 \\
\hline 9. & $\begin{array}{l}\text { Percent of the economically } \\
\text { active in services }\end{array}$ & .7580 & .1470 & .4496 \\
\hline 10. & $\begin{array}{l}\text { Percent of the total population } \\
\text { in cities of one million and over }\end{array}$ & .2151 & -.6153 & -.1932 \\
\hline
\end{tabular}

a Varimax rotation.

* The highest loadings on each of the three factors are shown in parentheses. 
APPENDIX B

ORTHOGONALLY ROTATED ${ }^{a}$ FACTOR MATRIX*, TEN ORGANIZATIONAL

VARIABLES, FOR 37 UNDERDEVELOPED COUNTRIES

\section{- \\ 1. Number of cities with populations} over one million

2. Percent economically active in the total population

3. Percent of the economically active in agriculture

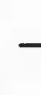
1 2 3

4. Percent of the economically active in manufacturing

\begin{tabular}{|c|c|c|}
\hline .5398 & .0605 & -.3851 \\
\hline .1397 & -.0586 & $(.9135)$ \\
\hline .6551 & -.6569 & .1627 \\
\hline-.2616 & .8498 & .1627 \\
\hline$(-.8369)$ & .2494 & -.0280 \\
\hline-.0583 & $(.8644)$ & -.1601 \\
\hline-.7440 & -.0463 & -.0998 \\
\hline-.4974 & .7176 & -.0843 \\
\hline-.6684 & .3298 & -.3868 \\
\hline .3730 & .6917 & -.1480 \\
\hline
\end{tabular}

5. Percent of the economically active in construction

6. Percent of the economically active in commerce

7. Percent of the economically active in electricity, gas, water, and sanitary services

8. Percent of the economically active in transport, storage; and communication

9. Percent of the economically active in services

10. Percent of the total population in cities of one milion and over

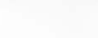

$+2$

2

3


APPENDIX C

ORTHOGONALLY ROTATED ${ }^{a}$ FACTOR MATRIX ${ }^{*}$, TEN ORGANIZATIONAL

VARIABLES, FOR 30 DEVELOPED COUNTRIES

\begin{tabular}{|c|c|c|c|c|}
\hline & & 1 & 2 & 3 \\
\hline 1. & $\begin{array}{l}\text { Number of cities with populations } \\
\text { over one million }\end{array}$ & -.0717 & -.0484 & $(.8175)$ \\
\hline 2. & $\begin{array}{l}\text { Percent economically active in } \\
\text { the total population }\end{array}$ & .5181 & -.3663 & .4828 \\
\hline 3. & $\begin{array}{l}\text { Percent of the economically active } \\
\text { in agriculture }\end{array}$ & .7587 & .2177 & -.2803 \\
\hline 4. & $\begin{array}{l}\text { Percent of the economically active } \\
\text { in manufacturing }\end{array}$ & .6289 & -.1556 & .6081 \\
\hline 5. & $\begin{array}{l}\text { Percent of the economically active } \\
\text { in construction }\end{array}$ & $(-.8910)$ & .0830 & -.0445 \\
\hline 6. & $\begin{array}{l}\text { Percent of the economically active } \\
\text { in commerce }\end{array}$ & .7491 & -.0835 & .1677 \\
\hline 7. & $\begin{array}{l}\text { Percent of the economically active } \\
\text { in electricity, gas, water, and } \\
\text { sanitary services }\end{array}$ & -.4170 & $(-.8212)$ & .0683 \\
\hline 8. & $\begin{array}{l}\text { Percent of the economically active } \\
\text { in transport, storage, and communi- } \\
\text { cation }\end{array}$ & .8649 & .2255 & .0790 \\
\hline 9. & $\begin{array}{l}\text { Percent of the economically active } \\
\text { in services }\end{array}$ & .4112 & -.8090 & -.1588 \\
\hline 10. & $\begin{array}{l}\text { Percent of the total population in } \\
\text { cities of one million and over }\end{array}$ & .1793 & .1968 & $.5771^{\circ}$ \\
\hline
\end{tabular}

a Varimax rotation.

* The highest loadings on each of the three factors are shown in parentheses. 


\section{APPENDIX D}

ORTHOGONALLY ROTATED ${ }^{a}$ FACTOR MATRIX*, SIX TECHNOLOGICAL VARIABLES, FOR 30 DEVELOPED COUNTRIES

\begin{tabular}{lcc}
\hline & 1 & 2 \\
\cline { 2 - 3 } 1. Production of coal & -.1427 & $(.7536)$ \\
2. Consumption of coal & -.3052 & .2404 \\
3. Railroads: Net-ton kilometers & -.3029 & .4250 \\
4. Number of passenger cars in use & $(.9517)$ & -.0747 \\
5. Number of commercial vehicles & .9246 & .0784 \\
6. Per capita gross national product & .2243 & .7109 \\
\hline
\end{tabular}

a

Varimax rotation.

* The highest loadings on each of the two factors are shown in parentheses. 
APPENDIX E

EXAMPLES OF THE CONTENTS OF NINE CATEGORIES OF

PER CAPITA IMPORTS PLUS EXPORTS

1. Per Capita Imports Plus Exports of Food and Live Animals

Meat and Meat Preparations

Dairy Products and Eggs

Fish and Preparations

Cereals and Preparations

Fruit and Vegetables

Sugar and Honey

Coffee, Tea, Cocoa, Splces

Miscellaneous Food Preparations

2. Per Capita Imports Plus Exports of Beverages and Tobacco

Tobacco and Manufactures

Alcoholic Beverages

3. Per Capita Imports Plus Exports of Crude Materials Except Fuels

Oil Seeds, Nuts, Kernels

Wood Lumber and Cork

Textile Fibers

Crude Fertilizer

Crude Animal, Vegetable Matter

4. Per Capita Imports Plus Exports of Mineral Fuels

Petroleum and Products

Gasoline

Kerosene

Lubricating oils

5. Per Capita Imports Plus Exports of Animal, Vegetable 011, Fat

Fixed Vegetable 011, Fat

Fixed Vegetable 011 , Soft

Groundnut, Peanut 0 il 


\section{APPENDIX E}

(continued)

6. Per Capita Imports Plus Exports of Chemicals

Chemical Elements, Compounds

Dyes, Tanning, Color Products

Medicinal Products

Perfume, Cleaning Products

Fertilizers, Manufactured

Plastic Materials

Pesticides

7. Per Capita Imports Plus Exports of Baslc Manufactures

Rubber Manufactures

Wood, Cork Manufactures

Paper, Paperboard Manufactures

Textile Yarn, Fabrics

Nonmetal Mineral Manufactures

Iron and Steel

Non-Ferrous Metals

Metal Manufactures

8. Per Capita Imports Plus Exports of Machines and Transport Equipment

Machinery, Non-Electric

Electrical Machinery

Transport Equipment (cars, alrplanes, trucks, etc.)

9. Per Capita Imports Plus Exports of Miscellaneous Manufactures

Plumbing, Heating, Lighting Equipment

Furniture

Clothing

Footwear

Instruments, Watches, Clocks

Sound Recorders, Producers

Printed Matter 
ORTHOGONALLY ROTATED ${ }^{a}$ FACTOR MATRIX*, NINE CATEGORIES OF PER CAPITA IMPORTS PLUS EXPORTS, FOR 70 COUNTRIES

\begin{tabular}{|c|c|c|c|c|}
\hline & & 1 & 2 & 3 \\
\hline 1. & $\begin{array}{l}\text { Per Capita imports plus exports } \\
\text { of food and live animals }\end{array}$ & .1770 & $(.6886)$ & -.2987 \\
\hline 2. & $\begin{array}{l}\text { Per Capita imports plus exports } \\
\text { of Beverages and Tobacco }\end{array}$ & .7147 & .2504 & -.1555 \\
\hline 3. & $\begin{array}{l}\text { Per Capita imports plus exports } \\
\text { of crude materials except fuels }\end{array}$ & .1087 & .1608 & -.6362 \\
\hline 4. & $\begin{array}{l}\text { Per Capita imports plus exports } \\
\text { of mineral fuels }\end{array}$ & .5853 & -.1891 & .1629 \\
\hline 5. & $\begin{array}{l}\text { Per Caplta imports plus exports } \\
\text { of animal, vegetable o11, fat }\end{array}$ & $(.8080)$ & .0052 & -.0963 \\
\hline 6. & $\begin{array}{l}\text { Per Capita imports plus exports } \\
\text { of chemicals }\end{array}$ & .3981 & .0759 & -.3552 \\
\hline 7. & $\begin{array}{l}\text { Per Capita imports plus exports } \\
\text { of basic manufactures }\end{array}$ & -.0215 & -.1024 & $(.6995)$ \\
\hline 8. & $\begin{array}{l}\text { Per Capita imports plus exports } \\
\text { of machines and transport } \\
\text { equipment }\end{array}$ & -.0150 & -.5461 & -.4737 \\
\hline 9. & $\begin{array}{l}\text { Per Capita imports plus exports } \\
\text { of miscellaneous manufactures }\end{array}$ & .4961 & -.5781 & -.1260 \\
\hline
\end{tabular}

a Varimax rotation.

* The highest loadings on each of the three factors are shown in parentheses. 
APPENDIX G

ORTHOGONALLY ROTATED ${ }^{a}$ FACTOR MATRIX*, NINE CATEGORIES OF PER CAPITA IMPORTS PLUS EXPORTS, FOR 37 UNDERDEVELOPED COUNTRIES

\section{$\begin{array}{lll}1 & 2 & 3\end{array}$}

1. Per capita imports plus exports of food and live animals

$\begin{array}{llll}-.1059 & -.6383 & -.1003 & -.2380\end{array}$

2. Per capita imports plus exports of beverages and tobacco

$\begin{array}{llll}(.8346) & -.1797 \quad .3237 & -.0352\end{array}$

3. Per capita imports plus exports of crude materials except fuels

4. Per capita imports plus exports of mineral fuels $\begin{array}{llllll}1546 & -.2536 & (-.7905) & .2786\end{array}$

5. Per capita imports plus exports of animal, vegetable oil, fat

$.0672 \quad(-.8731) \quad .0848 \quad-.0198$

6. Per capita imports plus exports of chemicals

$.7424 \quad .1258 \quad-.2711 \quad-.2919$

$.2150 \quad-.3577 \quad-.3007 \quad-.5203$

7. Per capita imports plus exports of basic manu$\begin{array}{lllll}\text { factures } & .0832 & -.1522 & .0943 & (-.8367)\end{array}$

8. Per capita imports plus exports of machines and $\begin{array}{llllll}\text { transport equipment } & .0453 & .2098 & -.7273 & -.3857\end{array}$

9. Per capita imports plus exports of miscellaneous manufactures

$\begin{array}{llll}.7785 & .0592 \quad-.2743 \quad .0104\end{array}$

\footnotetext{
a Varimax rotation.

* The highest loadings on each of the four factors are shown in parentheses.
} 
APPENDIX H

ORTHOGONALIY ROTATED ${ }^{a}$ FACTOR MATRIX ${ }^{*}$, NINE CATEGORIES OF PER CAPITA IMPORTS PLUS EXPORTS, FOR 30 DEVELOPED COUNTRIES 1. Per capita imports plus
exports of food and live animals

$-.4104 \quad .7620$

.1096

.3336

2. Per capita imports plus exports of beverages and tobacco

$$
(-.8371) \quad-.0250 \quad .1324 \quad-.2273
$$

3. Per capita imports plus exports of crude materials except fuels

$$
-.3301 \quad-.0092 \quad-.5783 \quad-.2314
$$

4. Per capita imports plus exports of mineral fuels $\quad-.2559 \quad(-.8310) \quad .0552 \quad .1083$

5. Per capita imports plus exports of animal, vegatable ofl, fat

$\begin{array}{llll}-.7508 & .0000 & -.1445 & .1040\end{array}$

6. Per capita imports plus exports of chemicals.

$$
-.3920 \quad-.1730 \quad-.0728
$$

7. Per capita imports plus exports of basic manufactures

$$
-.1974 \quad-.1494 \quad-.1077 \quad(-.8362)
$$

8. Per capita imports plus exports of machines and $\begin{array}{lllll}\text { transport equipment } & .1008 & .1703 & -.6448 & -.0505\end{array}$

9. Per capita Imports plus exports of miscellaneous manufactures

a Varimax rotation.

* The highest loadings on each of the four factors are shown in parentheses. 
APPENDIX I

SELECTED CHARACTERISTICS OF 37 UNDERDEVELOPED COUNTRIES

\begin{tabular}{|c|c|c|c|c|c|}
\hline Country & $\begin{array}{c}\text { Total } \\
\text { Population } \\
\end{array}$ & $\begin{array}{l}\text { Total } \\
\text { Land Area }\end{array}$ & $\begin{array}{l}\text { Annual Rate } \\
\text { of Growth }\end{array}$ & $\begin{array}{l}\text { Percent of Population } \\
\text { under } 15 \text { Years of Age }\end{array}$ & $\begin{array}{l}\text { Percent } \\
\text { Economically Active } \\
\text { in Total Population }\end{array}$ \\
\hline Morocco & 163 & 173 & 33 & 46 & 26 \\
\hline Egypt & 349 & 386 & 28 & 43 & 26 \\
\hline Ghana & 93 & 92 & 30 & 45 & 41 \\
\hline Liberia & 12 & 43 & 19 & 37 & 41 \\
\hline Sierra Leone & 27 & 28 & 23 & 41 & 43 \\
\hline Mauritius & 9 & 1 & 19 & 41 & 28 \\
\hline Angola & 58 & 481 & 21 & 42 & 29 \\
\hline Gabon & 5 & 102 & 9 & 36 & 51 \\
\hline South Africa & 206 & 472 & 24 & 40 & 36 \\
\hline Cyprus & 6 & 4 & 9 & 35 & 42 \\
\hline Jordan & 24 & 35 & 33 & 46 & 23 \\
\hline Turkey & 365 & 296 & 27 & 44 & 44 \\
\hline India & 5695 & 1262 & 26 & 41 & 33 \\
\hline Pakistan & 1416 & 366 & 33 & 45 & 31 \\
\hline
\end{tabular}


APPENDIX I

(continued)

\begin{tabular}{|c|c|c|c|c|c|}
\hline Country & $\begin{array}{c}\text { Total } \\
\text { Population }\end{array}$ & $\begin{array}{c}\text { Total } \\
\text { Land Area }\end{array}$ & $\begin{array}{l}\text { Annual Ratce } \\
\text { of Growth }\end{array}$ & $\begin{array}{l}\text { Percent of Population } \\
\text { under } 15 \text { Years of Age }\end{array}$ & $\begin{array}{l}\quad \text { Percent } \\
\text { Economically Active } \\
\text { In Total Population }\end{array}$ \\
\hline Indonesia & 1249 & 736 & 29 & 42 & 34 \\
\hline Malaysia & 111 & 128 & 28 & 44 & 39 \\
\hline Thailand & 374 & 200 & 33 & 43 & 48 \\
\hline Hong Kong & 43 & 1 & 25 & 40 & 42 \\
\hline Korea (Rep. of) & 329 & 30 & 25 & 42 & 33 \\
\hline El Salvador & 36 & 8 & 34 & 45 & 37 \\
\hline Guatamala & 53 & 42 & 29 & 46 & 31 \\
\hline Honduras & 28 & 43 & 34 & 51 & 30 \\
\hline Nicaragua & 21 & 54 & 30 & 48 & 27 \\
\hline Panama & 15 & 29 & 33 & 43 & 34 \\
\hline Barbados & 3 & 1 & 8 & 38 & 35 \\
\hline Dominican Republic & 44 & 19 & 34 & 47 & 33 \\
\hline Jamaica & 20 & 4 & 21 & 41 & 41 \\
\hline Tobago & 11 & 2 & 18 & 43 & 35 \\
\hline Columbia & 221 & 445 & 34 & 47 & 29 \\
\hline
\end{tabular}


APPENDIX I

(continued)

\begin{tabular}{|c|c|c|c|c|c|}
\hline Country & $\begin{array}{c}\text { Total } \\
\text { Population }\end{array}$ & $\begin{array}{c}\text { Tota1 } \\
\text { Land Area } \\
\end{array}$ & $\begin{array}{l}\text { Annual Rate } \\
\text { of Growth }\end{array}$ & $\begin{array}{l}\text { Percent of Population } \\
\text { under } 15 \text { Years of Age }\end{array}$ & $\begin{array}{l}\quad \text { Percent } \\
\text { Economically Active } \\
\text { In Total Population }\end{array}$ \\
\hline Guyana & 8 & 83 & 29 & 46 & 27 \\
\hline Peru & 140 & 496 & 31 & 45 & 31 \\
\hline Surinam & 4 & 55 & 32 & 46 & 27 \\
\hline Venezuela & 111 & 352 & 34 & 46 & 30 \\
\hline Paraguay & 25 & 157 & 34 & 45 & 32 \\
\hline Bulgaria & 86 & 43 & 7 & 24 & 52 \\
\hline Malta & 3 & 1 & 8 & 32 & 34 \\
\hline$F \mathbf{j} \mathbf{1}$ & 5 & 7 & 27 & 45 & 26 \\
\hline
\end{tabular}
a - in hundreds of thousands
b - in thousands of square miles.
c - per thousand 
APPENDIX J

SELECTED CHARACTERISTICS OF 37 UNDERDEVELOPED COUNTRIES

\begin{tabular}{|c|c|c|c|c|c|}
\hline Country & $\begin{array}{l}\text { Percent of } \\
\text { Economically } \\
\text { Active in } \\
\text { Agriculture } \\
\end{array}$ & $\begin{array}{l}\text { Percent of Econom- } \\
\text { ically Active in } \\
\text { Electricity, Gas, } \\
\text { and Sanitary Services }\end{array}$ & $\begin{array}{l}\text { Percent of } \\
\text { Economically } \\
\text { Active in } \\
\text { Construction } \\
\end{array}$ & $\begin{array}{l}\text { Percent of } \\
\text { Economically } \\
\text { Active in } \\
\text { Commerce } \\
\end{array}$ & $\begin{array}{l}\text { Percent of } \\
\text { Total Population } \\
\text { in Cities of } \\
100,000 \text { and over }\end{array}$ \\
\hline Morocco & 51 & 1 & 5 & 7 & 21 \\
\hline Egypt & 53 & .6 & 3 & 7 & 29 \\
\hline Ghana & 58 & .5 & 3 & 14 & 8 \\
\hline Liberia & 81 & .1 & 3 & 3 & 0 \\
\hline Sierra Leone & 75 & .2 & 2 & 6 & 6 \\
\hline Mauritius & 38 & 1 & 11 & 10 & 0 \\
\hline Angola & 69 & .1 & 4 & 5 & 8 \\
\hline Gabon & 84 & 4 & 2 & 4 & 0 \\
\hline South Africa & 30 & .7 & 5 & 9 & 23 \\
\hline Cyprus & 35 & .6 & 10 & 10 & 19 \\
\hline Jordan & 35 & .4 & 10 & 8 & 33 \\
\hline Turkey & 67 & .1 & 3 & 6 & 19 \\
\hline India & 72 & .3 & 1 & 6 & 9 \\
\hline
\end{tabular}




\section{APPENDIX J}

(continued)

\begin{tabular}{|c|c|c|c|c|c|}
\hline Country & $\begin{array}{l}\text { Percent of } \\
\text { Economically } \\
\text { Active in } \\
\text { Agriculture } \\
\end{array}$ & $\begin{array}{l}\text { Percent of Econom- } \\
\text { ically Active in } \\
\text { Electricity, Gas, } \\
\text { and Sanitary Services }\end{array}$ & $\begin{array}{l}\text { Percent of } \\
\text { Economically } \\
\text { Active in } \\
\text { Construction }\end{array}$ & $\begin{array}{l}\text { Percent of } \\
\text { Economically } \\
\text { Active in } \\
\text { Comerce } \\
\end{array}$ & $\begin{array}{l}\text { Percent of } \\
\text { Total Population } \\
\text { in Cities of } \\
100,000 \text { and over }\end{array}$ \\
\hline Pakistan & 58 & .2 & 4 & 10 & 8 \\
\hline Indonesia & 62 & .1 & 2 & 11 & 10 \\
\hline Malaysia & 49 & .9 & 3 & 10 & 11 \\
\hline Thailand & 81 & .1 & .9 & 4 & 6 \\
\hline Hong Kong & 4 & .5 & 5 & 18 & 23 \\
\hline Korea (Rep. of) & 48 & .4 & 4 & 15 & 36 \\
\hline E1 Salvador & 47 & .3 & 2 & 7 & 9 \\
\hline Guatamala & 65 & .1 & 3 & 6 & 13 \\
\hline Honduras & 67 & .1 & 2 & 5 & 11 \\
\hline Nicaragua & 46 & .6 & 4 & 10 & 19 \\
\hline Panama & 39 & .8 & 6 & 9 & 23 \\
\hline Barbados & 16 & 12 & 13 & 4 & 0 \\
\hline Dominican Republic & 31 & .1 & 2 & 5 & 18 \\
\hline Jamaica & 36 & .5 & 8 & 9 & 5 \\
\hline
\end{tabular}


APPENDIX J

(continued)

\begin{tabular}{|c|c|c|c|c|c|}
\hline Country & $\begin{array}{l}\text { Percent of } \\
\text { Economically } \\
\text { Active in } \\
\text { Agriculture } \\
\end{array}$ & $\begin{array}{l}\text { Percent of Econom- } \\
\text { ically Active in } \\
\text { Electricity, Gas, } \\
\text { and Sanitary Services }\end{array}$ & $\begin{array}{l}\text { Percent of } \\
\text { Economically } \\
\text { Active in } \\
\text { Construction } \\
\end{array}$ & $\begin{array}{l}\text { Percent of } \\
\text { Economically } \\
\text { Active in } \\
\text { Commerce } \\
\end{array}$ & $\begin{array}{l}\text { Percent of } \\
\text { Total Population } \\
\text { in Cities of } \\
100,000 \text { and over }\end{array}$ \\
\hline Tobago & 21 & 3 & 10 & 13 & 0 \\
\hline Columbia & 47 & .3 & 4 & 9 & 37 \\
\hline Guyana & 30 & 1 & 5 & 12 & 12 \\
\hline Peru & 47 & .3 & 4 & 9 & 30 \\
\hline Surinam & 25 & 1 & 3 & 11 & 27 \\
\hline Venezuala & 20 & 1 & 7 & 19 & 44 \\
\hline Paraguay & 55 & .2 & 3 & 7 & 16 \\
\hline Bulgaria & 44 & .4 & 7 & 5 & 20 \\
\hline Malta & 6 & .9 & 8 & 13 & 0 \\
\hline$F i j i$ & 54 & .7 & 6 & 7 & 0 \\
\hline
\end{tabular}




\section{APPENDIX K}

SELECTED CHARACTERISTICS OF 30 DEVELOPED COUNTRIES

\begin{tabular}{|c|c|c|c|c|c|}
\hline Country & $\begin{array}{c}\text { Total } \\
\text { Populationa } \\
\end{array}$ & $\begin{array}{c}\text { Total } \\
\text { Land Areab }\end{array}$ & $\begin{array}{l}\text { Annual Rate } \\
\text { of Growthc }\end{array}$ & $\begin{array}{l}\text { Percent of Population } \\
\text { under } 15 \text { Years of Age }\end{array}$ & $\begin{array}{l}\text { Percent } \\
\text { Economically Active } \\
\text { in Total Population }\end{array}$ \\
\hline Algerla & 145 & 920 & 33 & 47 & 22 \\
\hline Tunisia & 53 & 58 & 31 & 44 & 24 \\
\hline Isreal & 24 & 8 & 24 & 33 & 34 \\
\hline Iran & 292 & 636 & 30 & 46 & 30 \\
\hline Japan & 1047 & 143 & 11 & 25 & 51 \\
\hline Canada & 218 & 3851 & 17 & 33 & 36 \\
\hline United States & 2071 & 3615 & 11 & 30 & 41 \\
\hline Costa Rica & 19 & 20 & 38 & 48 & 30 \\
\hline Mexico & 525 & 758 & 34 & 46 & 27 \\
\hline Ecuador & 63 & 116 & 34 & 48 & 31 \\
\hline Argentina & 247 & 1080 & 15 & 29 & 38 \\
\hline Chile & 100 & 286 & 23 & 40 & 30 \\
\hline Denmark & 50 & 17 & 5 & 24 & 48 \\
\hline Finland & 47 & 130 & 4 & 27 & 46 \\
\hline
\end{tabular}


APPENDIX K
(continued)

\begin{tabular}{lccccc} 
Country & $\begin{array}{c}\text { Total } \\
\text { Population }\end{array}$ & $\begin{array}{c}\text { Total } \\
\text { Land Area }\end{array}$ & $\begin{array}{c}\text { Annual Rate } \\
\text { of Growthc }\end{array}$ & $\begin{array}{c}\text { Percent of Population } \\
\text { under }\end{array}$ 15 Years of Age & $\begin{array}{c}\text { Percent } \\
\text { Economically Active } \\
\text { in Total Population }\end{array}$ \\
\hline Ireland & 30 & 27 & 7 & 31 & 37 \\
Norway & 39 & 125 & 9 & 25 & 40 \\
Sweden & 81 & 174 & 5 & 21 & 42 \\
United Kingdom & 563 & 94 & 5 & 23 & 46 \\
Austria & 75 & 32 & 4 & 24 & 41 \\
Belgium & 97 & 12 & 4 & 24 & 41 \\
France & 515 & 213 & 7 & 25 & 42 \\
Germany (Fed. Rp.) & 589 & 96 & 4 & 23 & 44 \\
Czeckoslovakia & 148 & 49 & 5 & 25 & 49 \\
Hungary & 103 & 36 & 4 & 23 & 48 \\
Greece & 90 & 51 & 8 & 25 & 38 \\
Italy & 541 & 116 & 8 & 24 & 35 \\
Portugal & 96 & 36 & 70 & 29 & 39 \\
Spain & 336 & 195 & & 27 & 35
\end{tabular}




\begin{tabular}{|c|c|c|c|c|c|}
\hline Country & $\begin{array}{c}\text { Total } \\
\text { Population } \\
\end{array}$ & $\begin{array}{c}\text { Total } \\
\text { Land Area } \\
\end{array}$ & $\begin{array}{l}\text { APPENDIX K } \\
\text { (continued) }\end{array}$ & $\begin{array}{l}\text { Percent of Population } \\
\text { under } 15 \text { Years of Age }\end{array}$ & $\begin{array}{l}\text { Percent } \\
\text { Economically Active } \\
\text { In Total Population }\end{array}$ \\
\hline Yugoslavia & 208 & 99 & 10 & 30 & 43 \\
\hline Australia & 128 & 2968 & 19 & 29 & 42 \\
\hline
\end{tabular}

a--in hundreds of thousands

b--in thousands of square miles

c--per thousand 


\section{APPENDIX L}

SELECTED CHARACTERISTICS OF 30 DEVELOPED COUNTRIES

\begin{tabular}{|c|c|c|c|c|c|}
\hline Country & $\begin{array}{l}\text { Percent of } \\
\text { Economica11y } \\
\text { Active in } \\
\text { Agriculture }\end{array}$ & $\begin{array}{l}\text { Percent of Econom- } \\
\text { ically Active in } \\
\text { Electricity, Gas } \\
\text { and Sanitary Services }\end{array}$ & $\begin{array}{l}\text { Percent of } \\
\text { Economically } \\
\text { Active in } \\
\text { Construction }\end{array}$ & $\begin{array}{l}\text { Percent of } \\
\text { Economically } \\
\text { Active in } \\
\text { Commerce }\end{array}$ & $\begin{array}{l}\text { Percent of } \\
\text { Total Population } \\
\text { in Cities of } \\
100,000 \text { and over }\end{array}$ \\
\hline Algeria & 50 & .4 & 5 & 6 & 11 \\
\hline Tunisia & 41 & 2 & 5 & 7 & 8 \\
\hline Isreal & 8 & .8 & 9 & 18 & 38 \\
\hline Iran & 42 & .7 & 7 & 7 & 26 \\
\hline Japan & 19 & 6 & 8 & 24 & 52 \\
\hline Canada & 7 & 1 & 6 & 20 & 24 \\
\hline United States & 4 & 1 & 6 & 25 & 26 \\
\hline Costa Rica & 49 & 1 & 6 & 10 & 10 \\
\hline Mexico & 39 & .4 & 4 & 9 & 27 \\
\hline Ecuador & 57 & .3 & 3 & 7 & 22 \\
\hline Argentina & 18 & 1 & 6 & 12 & 52 \\
\hline Chile & 19 & 8 & 8 & 14 & 36 \\
\hline Denmark & 10 & .6 & 9 & 16 & 23 \\
\hline
\end{tabular}


APPENDIX L

(continued)

\begin{tabular}{|c|c|c|c|c|c|}
\hline Country & $\begin{array}{l}\text { Percent of } \\
\text { Economically } \\
\text { Active in } \\
\text { Agriculture } \\
\end{array}$ & $\begin{array}{l}\text { Percent of Econom- } \\
\text { ically Active in } \\
\text { Electricity, Gas } \\
\text { and Sanitary Services }\end{array}$ & $\begin{array}{l}\text { Percent of } \\
\text { Economically } \\
\text { Active in } \\
\text { Construction } \\
\end{array}$ & $\begin{array}{l}\text { Percent of } \\
\text { Economically } \\
\text { Active in } \\
\text { Commerce }\end{array}$ & $\begin{array}{l}\text { Percentrof } \\
\text { Total Population } \\
\text { in Cities of } \\
100,000 \text { and Over }\end{array}$ \\
\hline Finland & 21 & .9 & 9 & 19 & 16 \\
\hline Ireland & 31 & 1 & 8 & 15 & 23 \\
\hline Norway & 12 & .9 & 9 & 19 & 21 \\
\hline Sweden & 8 & .7 & 9 & 20 & 31 \\
\hline United Kingdom & 3 & 2 & 8 & 16 & 35 \\
\hline Austria & 16 & 1 & 9 & 11 & 72 \\
\hline Belgium & 4 & .8 & 8 & 17 & 22 \\
\hline France & 12 & .8 & 9 & 20 & 18 \\
\hline Germany (Fed. Rp.) & 8 & .8 & 7 & 15 & 34 \\
\hline Czeckoslovakia & 25 & 1 & 8 & 6 & 15 \\
\hline Hungary & 25 & 2 & 7 & 8 & 26 \\
\hline Greece & 40 & .8 & 8 & 13 & 15 \\
\hline Italy & 18 & 1 & 10 & 15 & 28 \\
\hline Portugal & 42 & .4 & 7 & 8 & 11 \\
\hline
\end{tabular}




\section{APPENDIX L}

(continued)

\begin{tabular}{|c|c|c|c|c|c|}
\hline Country & $\begin{array}{l}\text { Percent of } \\
\text { Economically } \\
\text { Active in } \\
\text { Agriculture } \\
\end{array}$ & $\begin{array}{l}\text { Percent of Econom- } \\
\text { ically Active in } \\
\text { Electricity, Gas } \\
\text { and Sanitary Services }\end{array}$ & $\begin{array}{l}\text { Percent of } \\
\text { Economically } \\
\text { Active in } \\
\text { Construction }\end{array}$ & $\begin{array}{l}\text { Percent of } \\
\text { Economically } \\
\text { Active in } \\
\text { Commerce }\end{array}$ & $\begin{array}{l}\text { Percent of } \\
\text { Total Population } \\
\text { in Cities of } \\
100,000 \text { and Over }\end{array}$ \\
\hline Spain & 25 & 10 & .7 & 13 & 37 \\
\hline Yugoslavia & 45 & 6 & 5 & 5 & 12 \\
\hline Australia & 7 & 2 & 8 & 27 & 42 \\
\hline
\end{tabular}


APPENDIX M

SELECTED CHARACTERISTICS OF 30 DEVELOPED COUNTRIES

\begin{tabular}{|c|c|c|c|}
\hline Country & Production of & $\mathrm{Coa}^{\mathrm{a}}$ & $\begin{array}{l}\text { Number of Passenger } \\
\text { Cars in Use }\end{array}$ \\
\hline Algeria & 53 & & 135 \\
\hline Tun1sia & 5 & & 72 \\
\hline Isreal & 8 & & 175 \\
\hline Iran & 316 & & 331 \\
\hline Japan & 49 & & 10,572 \\
\hline Canada & 223 & & 6967 \\
\hline Unfted States & 2029 & & 92,254 \\
\hline Costa Rica & .13 & & 43 \\
\hline Mexico & 59 & & 1338 \\
\hline Ecuador & .31 & & 30 \\
\hline ArgentIna & 38 & & 1669 \\
\hline Ch1le & 9 & & 194 \\
\hline Denmark & 1 & & 1150 \\
\hline Finland & 1 & & 753 \\
\hline Ireland & 3 & & 418 \\
\hline Norway & 9 & & 806 \\
\hline Sweden & 7 & & 2357 \\
\hline Untted Kingdom & 176 & & 12,216 \\
\hline Austria & 10 & & 1325 \\
\hline Belgium & 11 & & 2054 \\
\hline
\end{tabular}


APPENDIX M

(continued)

Country

France

Production of Coala

Germany (Fed. Rp.)

Czeckoslovakia

Hungary

Greece

Italy

Portugal

Spain

Yugoslavia

Australia

54

176

82

23

4

26

1

17

23

75
Number of Passenger Cars in Use $e^{b}$

13,400

14,689

938

295

264

11,299

621

2785

875

4055

a--in millions of metric tons.

b--in thousands of units. 
APPENDIX N

SELECTED CHARACTERISTICS OF 3 COUNTRIES

\section{Characteristics}

Total Population ${ }^{a}$

Total Land Area

Annual Rate of Growth ${ }^{\mathrm{c}}$

Percent of Population under 15 Years of Age

Percent of Economically

Active in Total Population

Percent of Economically

Active in Agriculture

Percent of Economically

Active in Electricity,

Gas, Water, and Sanitary

Services

Percent of Economically

Active in Construction

Percent of Economically

Active in Commerce

Percent of Total Popula-

tion in Cities of 100,000

and over
Libya

19

679

31

44

26

37

2

8

14

10

6

15

13

18

Kuwait

8

6

82

38

32

39

23

.9
a--In hundreds of thousands

b-- In thousands of square miles

c--per thousand 